\title{
Review \\ Electrochemical Sensors Based on Conducting Polymers for the Aqueous Detection of Biologically Relevant Molecules
}

\author{
Álvaro Terán-Alcocer ${ }^{1,+}+\mathbb{C}$, Francisco Bravo-Plascencia ${ }^{1,+}$, Carlos Cevallos-Morillo ${ }^{2}$ and Alex Palma-Cando ${ }^{1, *(\mathbb{C})}$ \\ 1 Grupo de Investigación Aplicada en Materiales y Procesos (GIAMP), School of Chemical Sciences and \\ Engineering, Yachay Tech University, Hda. San José s/n y Proyecto Yachay, 100119 Urcuquí, Ecuador; \\ alvaro.teran@yachaytech.edu.ec (Á.T.-A.); francisco.bravo@yachaytech.edu.ec (F.B.-P.) \\ 2 Facultad de Ciencias Químicas, Universidad Central del Ecuador, Francisco Viteri s/n y Gato Sobral, \\ 170129 Quito, Ecuador; cacevallosm@uce.edu.ec \\ * Correspondence: apalma@yachaytech.edu.ec \\ + These authors contributed equally.
}

Citation: Terán-Alcocer, Á.;

Bravo-Plascencia, F.; Cevallos-Morillo C.; Palma-Cando, A. Electrochemical Sensors Based on Conducting

Polymers for the Aqueous Detection of Biologically Relevant Molecules. Nanomaterials 2021, 11, 252. https:// doi.org/10.3390/nano11010252

Received: 23 December 2020

Accepted: 14 January 2021

Published: 19 January 2021

Publisher's Note: MDPI stays neutral with regard to jurisdictional claims in published maps and institutional affiliations.

Copyright: (c) 2021 by the authors. Licensee MDPI, Basel, Switzerland. This article is an open access article distributed under the terms and conditions of the Creative Commons Attribution (CC BY) license (https:// creativecommons.org/licenses/by/ $4.0 /)$.
Abstract: Electrochemical sensors appear as low-cost, rapid, easy to use, and in situ devices for determination of diverse analytes in a liquid solution. In that context, conducting polymers are much-explored sensor building materials because of their semiconductivity, structural versatility, multiple synthetic pathways, and stability in environmental conditions. In this state-of-the-art review, synthetic processes, morphological characterization, and nanostructure formation are analyzed for relevant literature about electrochemical sensors based on conducting polymers for the determination of molecules that (i) have a fundamental role in the human body function regulation, and (ii) are considered as water emergent pollutants. Special focus is put on the different types of micro- and nanostructures generated for the polymer itself or the combination with different materials in a composite, and how the rough morphology of the conducting polymers based electrochemical sensors affect their limit of detection. Polypyrroles, polyanilines, and polythiophenes appear as the most recurrent conducting polymers for the construction of electrochemical sensors. These conducting polymers are usually built starting from bifunctional precursor monomers resulting in linear and branched polymer structures; however, opportunities for sensitivity enhancement in electrochemical sensors have been recently reported by using conjugated microporous polymers synthesized from multifunctional monomers.

Keywords: electrochemical sensors; conducting polymers; emergent pollutants; neurotransmitters; ascorbic acid; glucose; phenolic compounds; pharmaceuticals; nitroaromatic compounds; hydrogen peroxide

\section{Introduction}

Neurotransmitters are molecules responsible to transmit neurological signals and permit the intercellular communication between neuron cells [1,2]. The body concentration of these molecules affects brain work, mood, pain response, and physical performance [3]. They regulate the process of consciousness, motivation, and memorization [4]. It means that the correct balance of neurotransmitters' concentration in the body is fundamental to maintain human health, and prevent mental disorders and diseases [2]. Uric acid (UA) appears as a particularly important biomarker because it is a final product of purine metabolism and it is easily accumulated in the human body due to its low aqueous solubility, while glucose concentration is an important marker of human health, especially for symptoms associated with diabetes. The elevated concentrations of hydrogen peroxide encountered in biological fluids are generally linked with the incidence of different oxidative stress-related pathologies such as neurological disorders (Parkinson and Alzheimer), cancer, and cardiovascular diseases. Therefore, determination and quantification of the concentration of neurotransmitters, UA, glucose, and hydrogen peroxide in human fluids are critical towards a better and 
fast diagnostic and treatment of different diseases and disorders [5,6]. On the other hand, environmental water pollutants have become an issue of great importance during recent decades [7]. Emerging contaminants are chemicals with potential negative health effects associated with human exposure [8]. These compounds are widely released into aquatic ecosystems from agricultural, paints, textile, plastic, pharmaceutical, petroleum, and other industries [9]. These compounds can be found in aqueous environments dispersing and persisting to a great extent [10]. Among all of these pollutants, phenolic compounds, hydrazine, nitrites, pharmaceutical, and nitroaromatic compounds are especially hazardous, because of their high toxicity, carcinogenicity, and low biodegradability [11]. Skin damage, necrosis, methemoglobinemia, drowsiness, nausea, and many other symptoms have been associated with these pollutants [12-14]. Many contaminants are difficult to remove with conventional wastewater treatment systems, so these facilities are another source of emerging pollutants [15]. Phenols are derived from industrial wastewater [16], used in the production of aromatic compounds such as explosives, fertilizers, paint removers, textile, plastics, and drugs $[17,18]$. Exposures to phenolic compounds damage the lungs, liver, kidneys, and genitourinary tract [19]. Nitrites are found in food and physiological systems [20] producing carcinogenic nitrosamines [21]. As a fertilizer, it can highly impact water sources [22]. Nitroaromatics compounds are the major components of explosives whose residues can accumulate in the environment [23]. Commonly, methods such as gas chromatography, mass spectrometry [24], and high-performance liquid chromatography [25] have been used for biomarkers and emerging pollutants determination, but they are expensive, time-consuming, and require well-skilled operators and pretreated samples [26]. Electrochemical detection has proved to overcome many of the disadvantages of commonly used techniques $[27,28]$. Some electrochemical sensor devices have even reached commercialization and routinely usage [29]. Nevertheless, multiple efforts are oriented to the development of new electrochemical sensors due to their potential and wide application.

Currently, a huge variety of materials has been employed for building electrochemical sensors aiming to improve their properties such as electrical conductivity, surface area, and mechanical- and chemical stability [30]. The building material selection pretends to solve some problems of the electrochemical sensors like electrode fouling and overlapping of the redox potential of the molecules presented as analyte [31]. In that context, intrinsically conducting polymers (CPs) are one of the most relevant and used materials for modification of sensors by their unique physical and chemical properties [32,33] such as adjustable architecture, adaptability, versatility, room stability, and sensitivity to surfer changes in their electrochemical activity with slight changes in its surface [34-36]. The electrochemical sensors have evolved through the employment of novel modifier materials such as conducting polymers and carbon nanomaterials [37,38], because the immobilization transfers the physicochemical properties of the modifier to the electrode surface, showing high surface area, excellent thermal conductivity [39], high conductivity [11], and strong mechanical strength [40-42]. Additionally, different types of nanoparticles can be added to the polymers forming composites [43], allowing for the combination of the properties which can improve the mechanical, optical, and electrical properties of polymer without sacrificing its processability or adding excessive weight [44,45]. CPs such as polypyrroles, polyanilines, and polythiophenes have attracted considerable attention due to their good film-forming property, electrical semiconductivity, high transparency in the visible region, and excellent thermal and environmental stability [46]. Electrode surfaces are usually modified with thin $\mathrm{CP}$ films by a combination of adsorptive attraction and low solubility in the working solution, using pre-formed soluble polymers or electrochemical polymerization.

Over the past five years, several electrochemical sensors based on CPs have been developed by numerous research groups with major contributions in electroanalytical and materials science aiming for the determination of a wide range of analytes. Recently, Wang et al. provided a review on recent reports on electrochemical sensors based on various nanomaterial-doped conducting polymers [47], Ibanez et al. described the most important 
procedures to customize CPs for electroanalytical purposes [48], Park et al. discussed the prospects of scientific and technological challenges for preparing next-generation biosensors focused on CP nanomaterials [49] and Naveen et al. analyzed the applications of conducting polymer composites in electrochemical sensors [50]. Herein, an extensive stateof-the-art review is reported focusing on CPs based electrochemical sensors for detection into liquid solutions of (i) molecules with a function regulation in the human body such as dopamine, epinephrine, serotonin, uric acid, ascorbic acid, glucose, and hydrogen peroxide, and (ii) water emergent pollutants such as phenolic compounds, hydrazine, nitrites, pharmaceuticals, and nitroaromatic compounds. Special focus is put on the formation of nanostructures during the synthesis of the $\mathrm{CPs}$ which usually results in mesoporous and macroporous structures with large surface areas as a recurrent approach for increasing the sensor's sensitivity. Considering the copious and highly dispersed information in the literature, it has become challenging to include all the information reported in scientific journals, therefore we apologize for any work that was not included in this document. This review includes a short section of fundamentals in the electrochemical sensors followed by reports of the last five years, in electrochemical sensors based on conducting polymers. Finally, some important remarks and perspectives are presented for this technique as well as summary tables of the performance for the different electrochemical sensors revised.

\section{Fundamentals of the Electrochemical Sensors}

A chemical sensor is a device composed of a recognition element (receptor) coupled with a physicochemical transducer, which transforms chemical information into analytical signals [51,52]. If the recognition system utilizes a biochemical mechanism, it is categorized as a biosensor [53]. These sensors are classified depending on the property that will be analyzed. Thus, electrical, optical, mass, thermal, and electrochemical sensors have been designed [54]. Compared to others, electrochemical sensors are especially attractive because of their remarkable detectability, relative experimental simplicity, and low cost [55]. Electroanalytical sensors commonly work employing a three electrodes cell arrangement, controlled by a potentiostat [56]. The first one is the working electrode (WE) where chemical energy is converted into electrical energy when a redox reaction takes place. The second one corresponds to the reference electrode (RE) that has a well-known redox pair with defined and stable equilibrium potential; it helps to fix or control the difference of potential applied to the WE. The third one is the counter electrode (CE) where the complementary redox semi reaction occurs. The aqueous electrochemical cell is composed of a solution that includes a large amount of supporting electrolyte to improve the ionic conductivity and reduce the migration component in the mass transfer and one or many analytes [57]. Different perturbation signals give us several electrochemical techniques depending on the parameter measured, e.g., potential, current, time, or charge [56]. There are two commonly used electrochemical devices, voltammetric and amperometric sensors [42].

In the voltammetric sensors, analytes in the solution interact onto the surface of the electrode, where the potential can be controlled, undergoing charge transfer (oxidation or reduction) which produces the current that is measured [58]. The current measured has two components in voltammetric measurements: Faradaic current and charging current known as well as non-faradaic current. The faradaic current originates from electron transfer between the analyte and the electrode surface; it is directly proportional to the concentration of the molecule under study [59]. The charging current is not an analytical signal and it is formed when the double layer at the working electrode is charged or discharged by changes into the potential of the electrode [54]. Linear scan voltammetry (LSV) and cyclic voltammetry (CV) uses a perturbation signal consisting of a ramp of potentials [60]. The applied signal for CV is a triangular waveform, where the scan rate is the slope of the curve [61]. The voltammogram is obtained by plotting the response current signal (i) versus the potential applied [62] where important parameters are measured such as the anodic and cathodic, peak currents, and peak potentials [63]. The peak current 
for a reversible system in pure diffusion is described by the Randles-Ševčík Equation (1) as follows:

$$
i_{p}=\left(2.69 \times 10^{5}\right) n^{3 / 2} A D^{1 / 2} C v^{1 / 2}
$$

where $i_{p}$ is the peak current $(\mathrm{A}), n$ are the electrons exchanged in the reaction, $A$ is the electroactive area $\left(\mathrm{cm}^{2}\right), D$ is diffusion coefficient $\left(\mathrm{cm}^{2} \mathrm{~s}^{-1}\right), C$ is the concentration of the active species $\left(\mathrm{mol} \mathrm{cm}^{-3}\right)$, and $v$ is scan rate $\left(\mathrm{V} \mathrm{s}^{-1}\right)$. The relationship between peak current and concentration of the active species is particularly important in analytical applications and studies of electrode mechanisms. The ratio of peak currents can be significantly influenced by chemical reactions coupled to the electrode process [64]. Different voltammetric techniques, known as pulse techniques, are usually employed to eliminate the charging current and enhance the faradaic current. Differential pulse voltammetry (DPV) and square wave voltammetry (SWV) are quite common techniques for trace analysis [65]. DPV and SWV are techniques where potential pulses are applied upon a staircase waveform ramp potential [66]. After a base potential value is chosen in DPV, the potential increases between pulses with equal increments. The current is immediately measured before the pulse application and at the end of the pulse, then the difference between them is recorded [67]. SWV perturbation signal shows a waveform formed by a series of pulses increasing along a linear baseline where the resulting current is determined by the difference between the current measurement in the forward and backward pulses [68,69]. LSV and CV are commonly used for exploratory purposes, while DPV and SWV are used for quantitative determinations [70,71].

In the amperometric sensors, a constant potential pulse is applied between a reference and a working electrode [72]. If a sufficiently large pulse of potential is applied, the electroactive species interchange electrons, from (reduction) or towards (oxidation) the electrode surface. These electron flows generate the faradaic current $[70,73]$. Amperometric sensors have to ensure two requirements (i) the transport of the electroactive species must be governed by diffusion, and (ii) the electrode surface must remain constant $[74,75]$. These sensors display high sensitivity, a wide detection range, short response time, and selectively between several electroactive species in solution [42]. In a chronoamperometry, the obtained current is related to the bulk concentration of the electroactive species according to the Cottrell Equation (2) as follows:

$$
i=\frac{n F A D^{1 / 2} C}{\pi t}
$$

where $i$ corresponds to the diffusion current (A), $t$ is the electrolysis time (s), $n$ is the number of electrons involved in the reaction, $A$ is the electrode area $\left(\mathrm{cm}^{2}\right), D$ is the diffusion coefficient $\left(\mathrm{cm}^{2} \mathrm{~s}^{-1}\right), F$ is the Faraday constant and $C$ is the concentration of the electroactive species $\left(\mathrm{mol} \mathrm{L}^{-1}\right)[76]$.

\section{Electrochemical Sensors Based on Conducting Polymers}

\subsection{Neurotransmitters}

Biomarkers of the body appeared as a powerful tool to improve the prevention, detection, and treatment of different diseases and degenerative disorders. Neurotransmitters are one of the most important biomarkers because they regulate many functions in cells and tissues. Dopamine (DA) is a molecule that has a fundamental role in cardiovascular, kidney, central nervous, and hormonal system regulation [77]. Abnormal concentrations of DA are related to diseases or disorders such as cancer, Parkinson's, Huntington's, dementia [78], and trending to drug dependence [79]. Serotonin (SER) has a strong influence on mood and sleep regulation [80]. Schizophrenia, depression, and other neuropsychiatric disorders, as well as substance use disorders, have been associated with the imbalance of SER [81]. Another important neurotransmitter is epinephrine (EP) which is known as an alert hormone because it boosts the supply of oxygen and glucose to the brain and muscles in emergency situations. Similar to DA, EP levels in the body are related to Parkinson's 
disease [36] but it also has therapeutic application for asthma, sepsis, severe allergic, cardiac arrest, and anaphylaxis [82].

\subsubsection{Dopamine (DA)}

Selective sensors based on polypyrrole (PPy) have been used for DA detection mainly due to environmental stability, good biocompatibility, and high surface area [83]. Furthermore, polypyrrole is easily synthesized and shows higher conductivity in comparison with other conducting polymers [84]. The amine group (-NH-) on the pyrrole ring enhances the capability of this polymer for biomolecular sensing [85] and provides a non-sensitive character to interferences in the solution [86].

Polypyrrole films doped with anionic sulfonated $\beta$-cyclodextrin (PPy-S $\beta C D)$ were potentiostatically deposited on platinum electrodes [87]. The obtained films showed a structure with ridges and valleys which generate a ladder-like arrangement. LOD of $1 \mu \mathrm{M}$ were chronoamperometrically determined for $\mathrm{DA}$ at $\mathrm{NaCl}$ solutions. Moreover, this modified electrode showed high selectivity for DA due to a strong interaction between cyclodextrin dopant and the protonated DA. A hybrid sensor based on electrochemically reduced graphene oxide and overoxidized electropolymerized polypyrrole (OPPy/ERGO) onto a glassy carbon electrode was made for selective detection of DA [88]. First, reduced graphene was prepared by cyclic voltammetry in a GO/PBS solution at $\mathrm{pH}$ 7.4. Then, PPy was potentiodynamically deposited from a pyrrole solution. SEM analysis showed pristine PPy/ERGO deposits had laminated and spherical structures (attributed to PPy). After overoxidation in a $\mathrm{NaOH}$ solution, a rough, uniform, and compact thin film was obtained with the incorporation of carbonyl groups. LOD was determined by amperometric measurements resulting in a value of $0.2 \mu \mathrm{M}$ with a linear response between $0.4 \mu \mathrm{M}$ and $517 \mu \mathrm{M}$. A negatively charged sensor surface enhanced the adsorption of positively charged DA. A similar approach was taken by Demirkan et al. where palladium nanoparticles supported on polypyrrole/reduced graphene oxide (rGO/Pd@PPy NPs) were developed for ascorbic acid (AA), DA, and UA sensing [89]. TEM images of rGO/Pd@PPy NPs nanocomposites showed spherical Pd nanoparticles distributed into the polymeric film. LOD by DPV for AA, DA, and UA were $4.9 \times 10^{-8} \mathrm{M}, 5.6 \times 10^{-8} \mathrm{M}$, and $4.7 \times 10^{-8} \mathrm{M}$, respectively. This sensor shows electrocatalytic performance, effective electron transfer capability, and better sensitivity because of the synergistic effects of its components. Hybrid composite of molybdenum oxide-based three-dimensional metal-organic frameworks (MOFs) with helical channels combined with polypyrrole $\left(\mathrm{CuTRZMoO}{ }_{4} @ P P y-n\right)$ were tested for DA detection by Zhou et al. [83]. Polypyrrole was employed to boost the conductivity of the preset MOF. Structural analysis reveals a coarse, irregular, and circular fringe nanocomposite surface. A LOD of $80 \mathrm{nM}$ was obtained by DPV and a linear range in a PBS pH 2.5 solution from $1 \mu \mathrm{M}$ up to $100 \mu \mathrm{M}$. ZnO nanotubes supported on molecularly imprinted polymers arrays (MIPs/ZNTs/FTO glass) were used for DA detection [90]. Zn nanorods (ZNRs) were deposited by potentiostatic methods onto fluorine-doped tin oxide (FTO). Then, ZNRs were tuned into Zn nanotubes (ZNT) by chemical etching in alkaline solution at low temperatures. Polypyrrole films were electrodeposited from a solution of the monomer, lithium perchlorate, and DA. Finally, the electrode was potentiodynamic cleaned in PBS to oxidize and eliminate the embedded DA. SEM images showed cylindrical ZNT coated with PPy films. High selectivity for DA was assigned to the molecular printing technique (see Figure 1). 

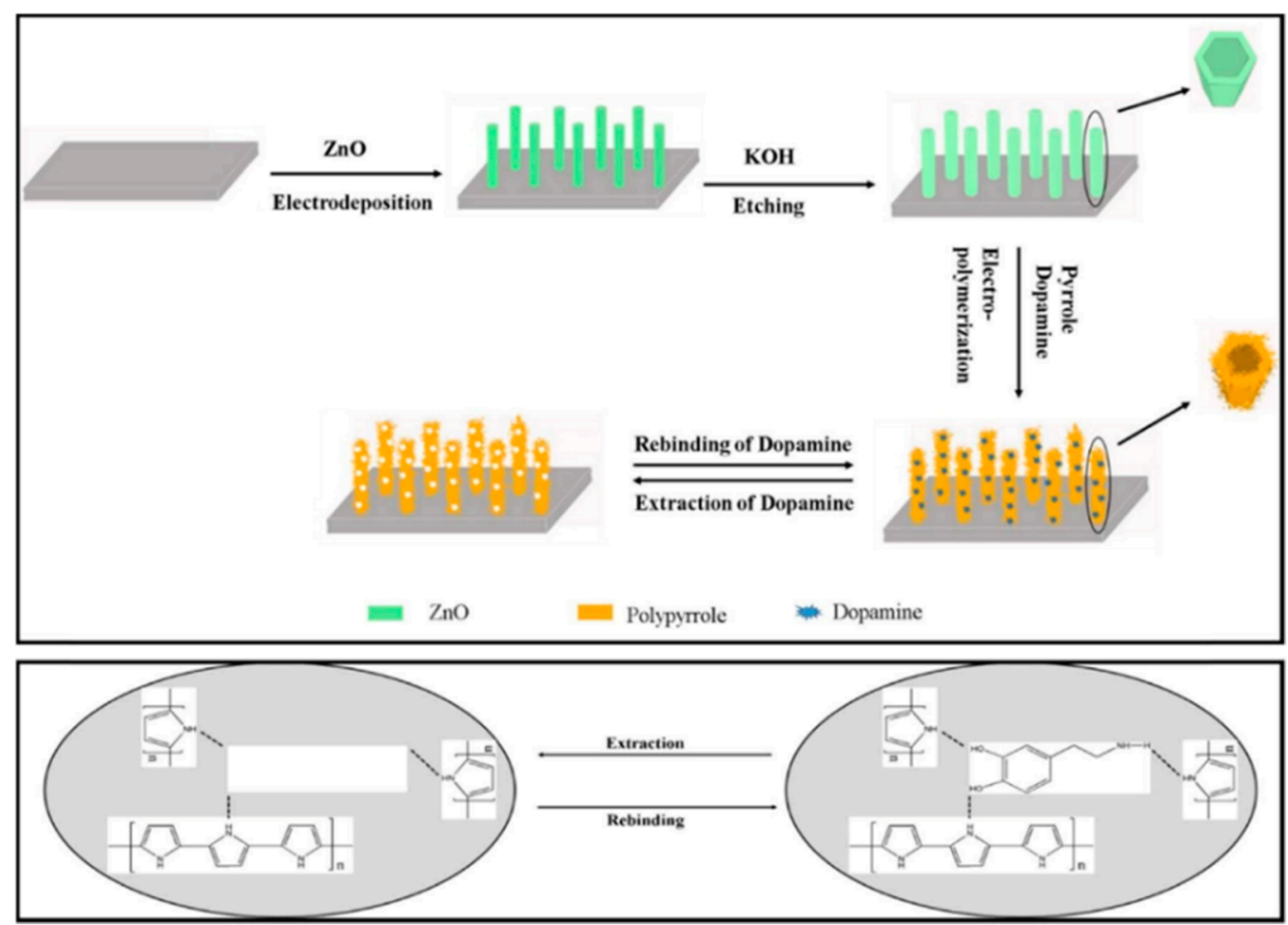

Figure 1. Schematic representation of the molecularly imprinted polymers fabrication process of composite MIPs/ZNTs/FTO glass and its interaction with dopamine. Reproduced with permission from [90]. Copyright 2017 Elsevier B.V.

$\mathrm{PPy} / \mathrm{C \# SiO}$ nanocomposite was synthesized using a mixture of pyrrole and previous manufactured carbon-coated mesoporous $\mathrm{SiO}_{2}$ composite $\left.(\mathrm{C \# SiO})_{2}\right)$ [91]. The deposition of PPy was confirmed using WAXD and FTIR. LOD of $7.6 \times 10^{-7} \mathrm{M}$ was determined by DPV within a linear range of $1 \times 10^{-6}-2 \times 10^{-4} \mathrm{M}$. This electrode showed a small chargetransfer resistance because of the synergetic effect of compounds. Overoxidized polypyrrole/sodium dodecyl sulfate (SDS)-modified multi-walled carbon nanotube (OPPy/SDSCNT) composites were assembled on gold electrodes by potentiostatic techniques [92]. After polypyrrole co-deposited with SDS and MWCNT, electrodes were overoxidized in a $\mathrm{NaOH}$ for generated carboxylic and carbonyl groups in the composite surface. Field emission scanning electron microscopy (FESEM) images showed a rough surface in the pristine deposit due to aggregates of PPy/SDS-CNT which partially disappeared by overoxidation. DA in phosphate buffer solution was detected by DPV showing a linear range from $5 \mathrm{nM}$ to $10 \mathrm{nM}$ and a LOD of $136 \mathrm{pM}$. The high sensibility of this method is attributed to electrostatic interaction between positively charged DA and negatively charged OPPy/SDS-CNT electrode. The nanocomposite of polypyrrole and silver nanoparticles (PPy-Ag) have been also used for DA sensing [93]. Black solid particles of PPy-Ag nanocomposite were synthesized (see Figure 2) and further studied by SEM and TEM. The PPy-Ag showed a rod-like structure with embedded spherical Ag nanoparticles. A detection limit of $50 \mathrm{pM}$ and linear range from $0.05 \mathrm{nM}$ to $3 \mathrm{nM}$ was obtained for DA using LSV in a solution of $\mathrm{PBS}$ at $\mathrm{pH}$ 7. The current signal remained almost the same after five measurements with an interval of 25 min each in $0.05 \mathrm{nM}$ DA. A better electroactive surface that facilitates the tunneling of electrons within the redox couple is responsible for this high sensitivity. Additionally, a biocompatibility assay was performed in mouse fibroblast cells exhibiting low toxicity. 


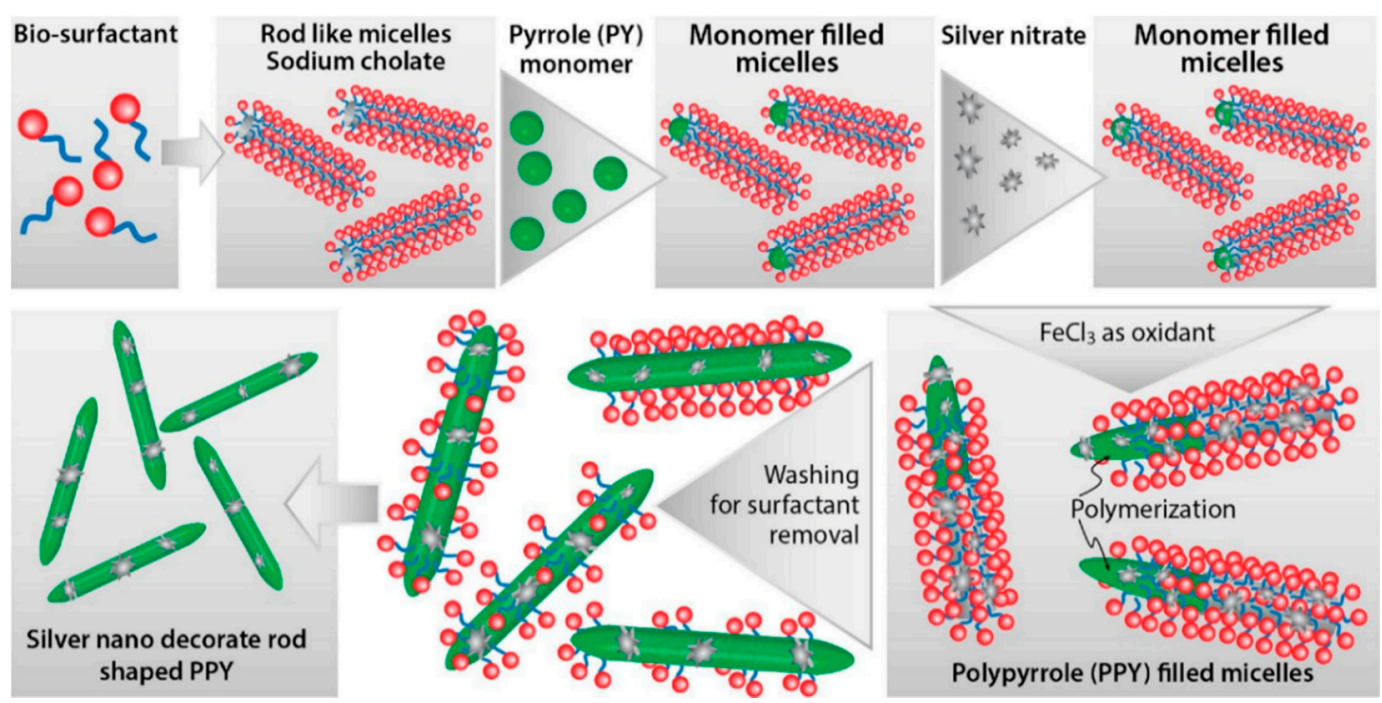

Figure 2. Schematic representation of the fabrication process of composite polypyrrole (PPy)-Ag. Reproduced with permission from [93]. Copyright 2020 Elsevier B.V.

Polyaniline (PANI) appears as one of the most used CP materials for a sensor assembly. PANI presents interesting properties such as stability, flexibility, good electrical, and optical properties [94]. It has - $\mathrm{NH}$ - functional groups in its structure that improve the adsorption of analytes [95]. The low cost, high yield manufacturing process [96] and the possibility to switch between the insulating and conducting phases by acid/base process [97] makes PANI one of the most versatile CPs for application in the sensing field.

Polyaniline-gold nanocomposite (PANI-Au) were fabricated as DA sensors by two different combined acidic and oxidative doping pathways as shown in Figure 3 [98]. Ammonium persulphate (APS) and chloroauric acid $\left(\mathrm{HAuCl}_{4}\right)$ were employed as oxidant agents while p-toluene sulphonic acids (pTSA) and sulfuric acid were used as protonic acid dopants. SEM images showed PANI- $\mathrm{H}_{2} \mathrm{SO}_{4}$ had dense nature while PANI-pTSA had layered morphology with high porosity. Spherical Au nanostructures were deposited over polymeric films. PANI-pTSA@Au sensors gave a LOD of $5.25 \mu \mathrm{M}$ within a linear range of $7-100 \mu \mathrm{M}$. These sensors generated well-defined signals for DA in the presence of inferences.

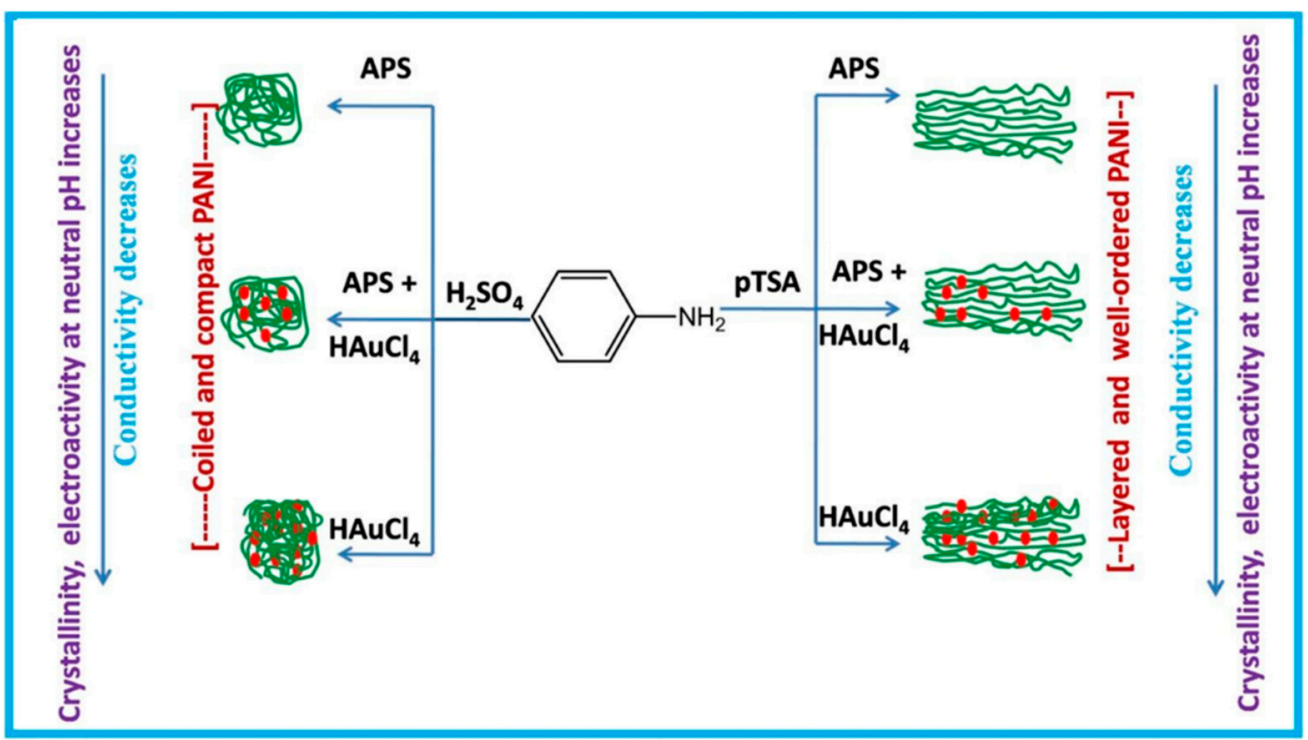

Figure 3. Schematic representation of different synthetic pathways for manufacturing the composite polyaniline-p-toluene sulphonic acids PANI-pTSA. Reproduced with permission from [98]. Copyright 2019 Elsevier B.V. 
Polyaniline deposited over glassy carbon has been also used as support for the electropolymerization of beta-cyclodextrin $(\beta-C D) /$ hydroxyl functionalized multi-walled carbon nanotubes (f-MWCNTs) in PBS solution at pH 7 [99]. Poly- $\beta-C D(f-M W C N T s) / P A N I$ nanocomposite showed a porous granular morphology related to the PANI and poly- $\beta-C D$ microstructures (see Figure 4 ) resulting in high surface areas. LOD of $0.0164 \mu \mathrm{M}$ was determined by DPV. The sensitivity obtained for this electrode was ascribed to the high porosity and high surface area. A sensor based on a derivative of poly (o-methoxyaniline)-gold (POMA-Au) nanocomposites showed a LOD of $62 \mathrm{nM}$ within a linear range from $10 \mu \mathrm{M}$ to $300 \mu \mathrm{M}$ for DA [100]. POMA provided a large surface area while Au nanoparticles high electrical conductivity. Poly (aniline-co-o-anisidine)/graphene oxide nanocomposites coated with Au nanoparticles (AuNPs/PANI-co-PoAN/GO) was also fabricated for DA sensing applications [101]. A copolymer of aniline and o-anisidine was synthesized by adding ammonium persulfate to a solution of hydrochloric acid containing both monomers and GO. Au electrodes were dipped coated into a PANI-co-PoAN/GO solution in chloroform, followed by potentiodynamic deposition of $\mathrm{Au}$ nanoparticles from a $\mathrm{KCl} / \mathrm{HAuCl}_{4}$ solution. LOD for DA using SWV was $33.4 \mathrm{nM}$ within a linear range of 5-100 $\mu \mathrm{M}$. This sensor showed a fast electron transfer and high surface area due to the presence of gold nanoparticles.

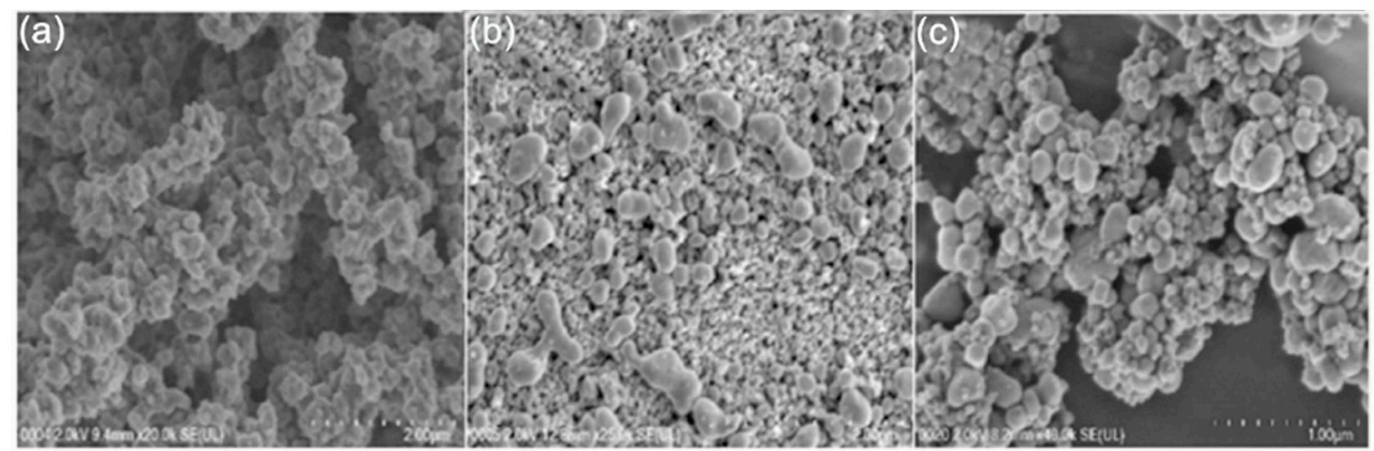

Figure 4. SEM images of (a) PANI, (b) poly- $\beta-C D$, and (c) poly- $\beta-C D$ (f-MWCNTs)/PANI composite. Reproduced with permission from [99]. Copyright 2019 Elsevier B.V.

Poly (N-(Naphthyl) ethylenediamine dihydrochloride) nanofibers onto anodized glassy carbon electrodes (PNEDA/AGCE) were developed as DA electrochemical sensors by Rahman et al. [102]. DPV was employed for DA determination, with concentrations in the range of $0.1-100 \mu \mathrm{M}$ and a LOD of $70 \mathrm{nM}$. DFT calculations showed a strong $\mathrm{H}-$ bonding interaction between the free $-\mathrm{NH}_{2}$ groups of PNEDA and oxidizable -OH groups of DA resulting in a good sensitivity for this sensor. Graphene/poly (o-phenylenediamine) (GP/PoPD) was potentiodynamically deposited onto pencil graphite electrodes (PGE) from lithium perchlorate, o-phenylenediamine and graphene solution [103]. LOD of 0.16 $\mathrm{nM}$ was obtained by SWV within a linear range of $1.0 \mathrm{nM}-150 \mu \mathrm{M}$. This low LOD was ascribed to a high electroactive surface area and fast electron transfer. A highly-selective sensor for DA was developed using poly-4-Amino-6-hydroxy-2-mercaptopyrimidine (PolyAHMP) film over a glassy carbon electrode [104]. A highly rough and porous surface was observed in SEM images of the film resulting in an increased active surface area of the electrode. This sensor showed a LOD of $0.2 \mu \mathrm{M}$ within a linear range from $2.5 \mu \mathrm{M}$ to $25 \mu \mathrm{M}$ employing DPV.

Different polythiophene derivatives have shown potential in the fabrication of electrochemical sensors $[105,106]$ among them poly (3,4-ethylenedioxythiophene (PEDOT) is considered a top choice due to its high electrical conductivity which is in the order of magnitude of silver and copper [107], huge optical transparency at visible light and better room stability than PPy [108]. Furthermore, PEDOT presents extraordinary redox reversibility [109] which provides antifouling properties that expand the using lifetime of the polymer film [108]. PEDOT has also the advantage of easy synthesis [110], and gener- 
ation of deposits with a low tensile module enduring constant mechanical deformation generally related to biological applications [111].

PEDOT-Modified Laser Scribed Graphene (PEDOT-LSG) electrodes were used as an electrochemical sensor for DA [112]. LSG had a regular and smooth flake structure. After PEDOT electropolymerization a 3D porous network structure remains (see Figure 5). A LOD of $0.33 \mu \mathrm{M}$ with a linear range of $1-150 \mu \mathrm{M}$ was obtained by DPV in PBS solution at $\mathrm{pH}$ 7. The sensitivity of this sensor was related to the rapid electron transport properties of porous graphene combined with the electrocatalytic activity of PEDOT deposit.

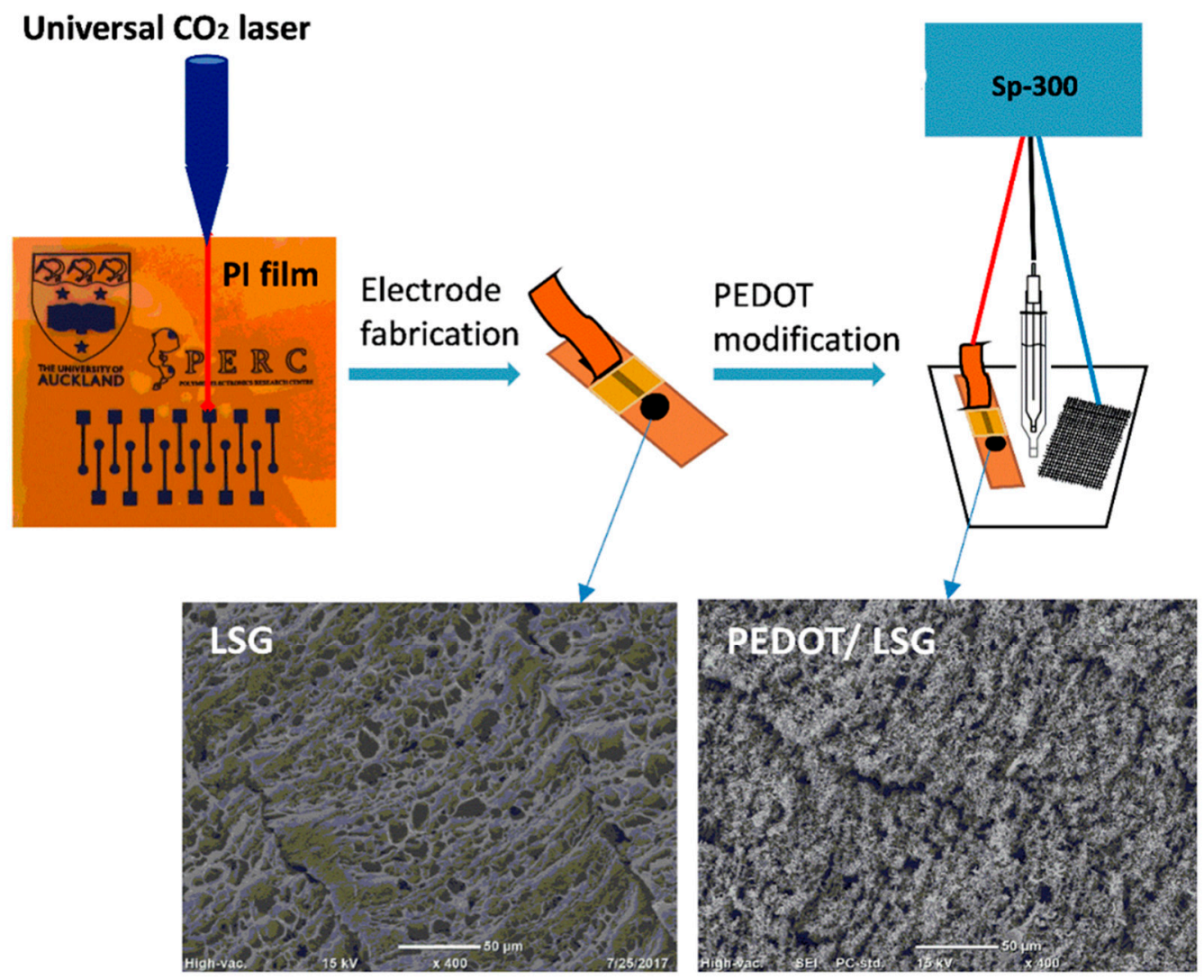

Figure 5. Schematic representation of the fabrication process of PEDOT-Modified Laser Scribed Graphene (PEDOT-LSG) electrodes, and micrographs showing the morphology of LSG and PEDOT/LSG film. Modified with permission from [112]. Copyright 2018 Elsevier B.V.

Sandoval-Rojas et al. fabricated poly (3,4-ethylenedioxythiophene) doped with a bis(pyrazolyl)methane disulfonate sensors (PEDOT/LSA) for DA detection [113]. This electrode was synthesized over a glassy carbon electrode using potentiodynamic voltammetry from an EDOT and sodium salt of bis(3,5-dimethyl-4-sulfonate-pyrazole-1-yl)methane solution in acetonitrile/deionized water. The dopant produced large globular structures on the polymer surface. A LOD of $0.26 \mu \mathrm{M}$ within a linear range from $0 \mu \mathrm{M}$ to $5 \mu \mathrm{M}$ was obtained using DPV. Monodispersed poly (3,4-ethylenedioxythiophene)/gold hollow nanospheres (PEDOT/Au) electrodes were also designed for DA sensing [114]. The composite was synthesized over a glassy carbon electrode in the aqueous phase. Hollowed nanospheres template was precipitated from a stirred $\mathrm{Na}_{2} \mathrm{~S}_{2} \mathrm{O}_{3}$ /PVP solution. Then PEDOT / Au hollow nanospheres were produced by stirring PVP modified sulfur nanospheres in an EDOT $/ \mathrm{HAuCl}_{4}$ solution (see Figure 6). SEM micrographs revealed a 3D globular structure with a size of $300 \mathrm{~nm}$ to $1000 \mathrm{~nm}$. Linear range and LOD values of $0.15 \mu \mathrm{M}$ to $330 \mu \mathrm{M}$ and $70 \mathrm{nM}$ respectively, were reported by using DPV. The excellent performance of this electrode was ascribed to the fast electron charge transfer kinetics of this composite. 

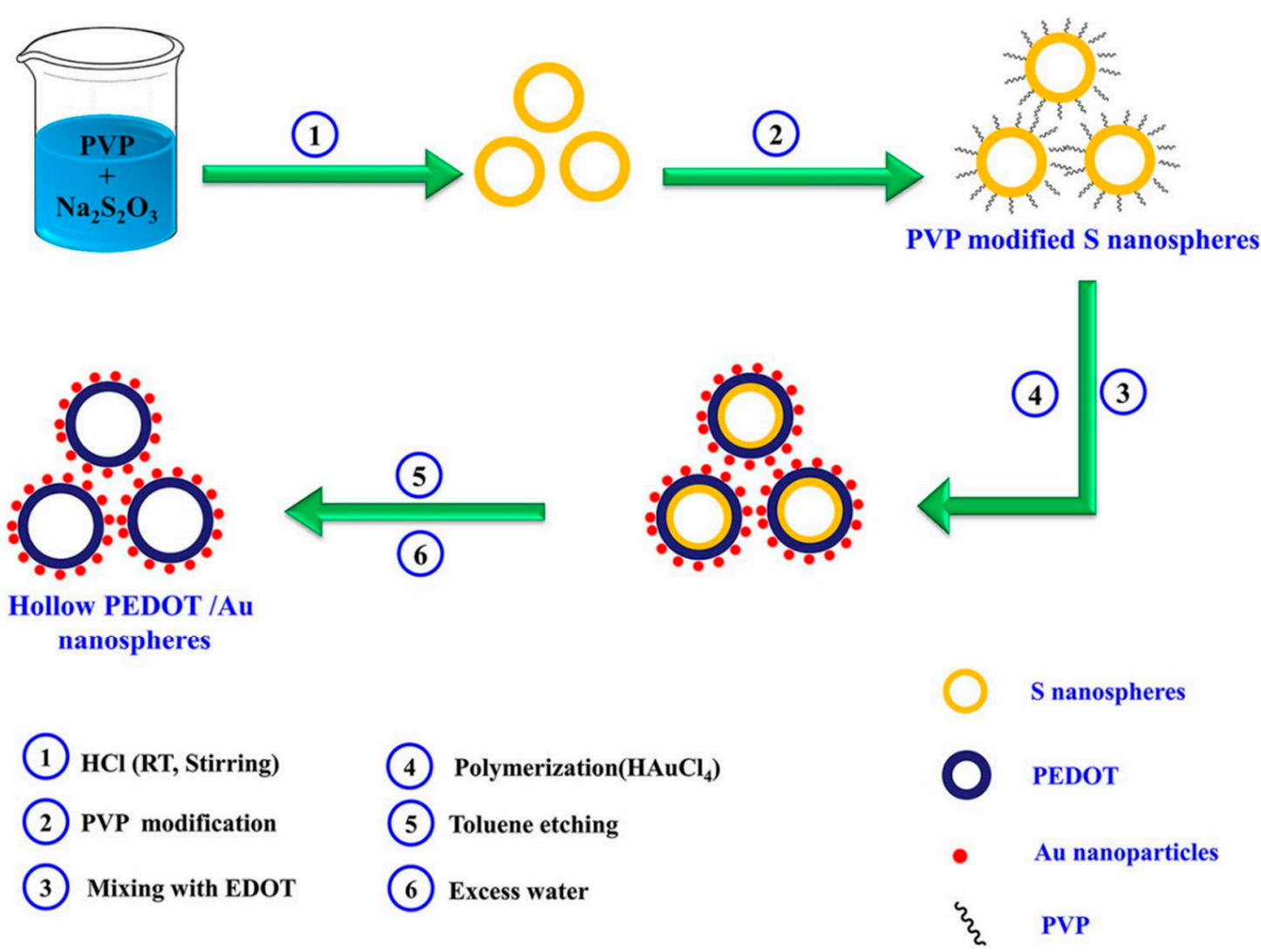

Figure 6. Schematic representation of the fabrication process of PEDOT/Au composites. Reproduced with permission from [114]. Copyright 2017 Elsevier B.V.

Composites of multi-walled carbon nanotubes and nanoceria-poly (3,4-ethylenedioxy thiophene) (MWCNTs/ $\mathrm{CeO}_{2}$-PEDOT) has been used for DA detection [115]. PEDOT films agglomerated into sphere-like grains preserving this structure in the composite with diameters of the particle between $200 \mathrm{~nm}$ and $450 \mathrm{~nm}$. A LOD of $30 \mathrm{nM}$ within a linear range of 0.1-10 $\mu \mathrm{M}$ was determined by DPV measurements. Poly (3,4-ethylenedioxythiophene)/ reduced graphene oxide/manganese dioxide modified glassy carbon electrodes $\left(\mathrm{PrGO} / \mathrm{MnO}_{2}\right)$ were built for simultaneous detection of DA, UA, and AA [116]. After potentiodynamic electrodeposition of $\mathrm{PrGO}$ on a glassy carbon electrode, $\mathrm{MnO}_{2}$ was deposited using a solution of $\mathrm{KMnO}_{4}$ and $\mathrm{H}_{2} \mathrm{SO}_{4}$. PEDOT appears as a granular film deposited over rGo. The $\mathrm{MnO}_{2}$ is observed as small particles onto PrGO. The sensor structure provided a high surface area which increases the sensitivity. This composite shows high electrocatalytic activity that generated a well-separated oxidation potential of UA, DA, and AA. Simultaneous detection gave LOD values of $50 \mathrm{nM}$ (UA), $20 \mathrm{nM}$ (DA), and $1.0 \mu \mathrm{M}$ (AA) in PBS solution at pH 6. Poly (3,4-ethylenedioxythiophene) doped with ionic liquid (1ethyl-3-methylimidazolium bis(trifluoromethylsulfonyl)imide) on glassy carbon electrode (PEDOT/IL/GCE) has been also used as biofouling resistant DA electrode showing porous microstructure, high electrical conductivity, and good stability [117]. LOD and linear range values of $33 \mathrm{nM}$ and $0.2 \mu \mathrm{M}$ to $328 \mu \mathrm{M}$, respectively, were found for DA sensing in presence of proteins such as bovine serum albumin (BSA), human serum albumin (HSA), and chicken egg white lysozyme (LZM). Spin coated poly (3,4-ethylenedioxythiophene):polystyrene functionalized with beta-cyclodextrin sensors (CD-f-PEDOT:PSS) for DA and catechol were fabricated by Qian et al. [118]. AFM images showed PEDOT: PSS surface changes by treatment with $\mathrm{H}_{2} \mathrm{SO}_{4}$ from polymer particles to entangled wires boosting the electrical conduction. The obtained LOD and linear range were $9.6 \mathrm{nM}$ and $50 \mathrm{nM}$ to $200 \mu \mathrm{M}$, respectively, by using DPV into a PBS buffer solution at pH 7.4. Highly sensitive DA sensors were developed by Pananon et al. using a nanocomposite made of gold nanoparticles, 
graphene (GP), and poly (3,4-ethylenedioxythiophene):polystyrene sulfonate (AuNP-GPPEDOT:PSS/GCE) using a green synthetic method [119]. SEM images proved a uniform distribution of gold nanoparticles onto the surface. This sensor shows one of the lowest detection limits for DA of $100 \mathrm{pM}$ with linear dynamic range from $1 \mathrm{nM}$ to $300 \mu \mathrm{M}$ related to an increased surface area, high catalytic activity of AuNP and a superior conductivity of GP and PEDOT:PSS. Moreover, thin polythiophene films composed with gold nanoparticles and carbon nanotubes (PT/Au/CNT) were synthesized by liquid-liquid interfacial reaction [120]. The construction of this composite required an aqueous mixture of dispersed $\mathrm{CNT}, \mathrm{HCl}, \mathrm{HAuCl}_{4} \cdot 3 \mathrm{H}_{2} \mathrm{O}$, and thiophene, in a molar relation 1:1 with $\mathrm{HAuCl}_{4}$. Modified electrodes were self-assembled by putting a substrate (silicon, quartz or glass) into a stirred solution for $4.5 \mathrm{~h}$ (see Figure 7). This method resulted in a sensor with a LOD of $0.69 \mu \mathrm{M}$ for DA using DPV. A relative standard deviation (RSD) of 3.96\% was obtained using three modified electrodes which performed 25 measurements each one. These results pointed out an enhanced charge transfer related to the presence of CNT.

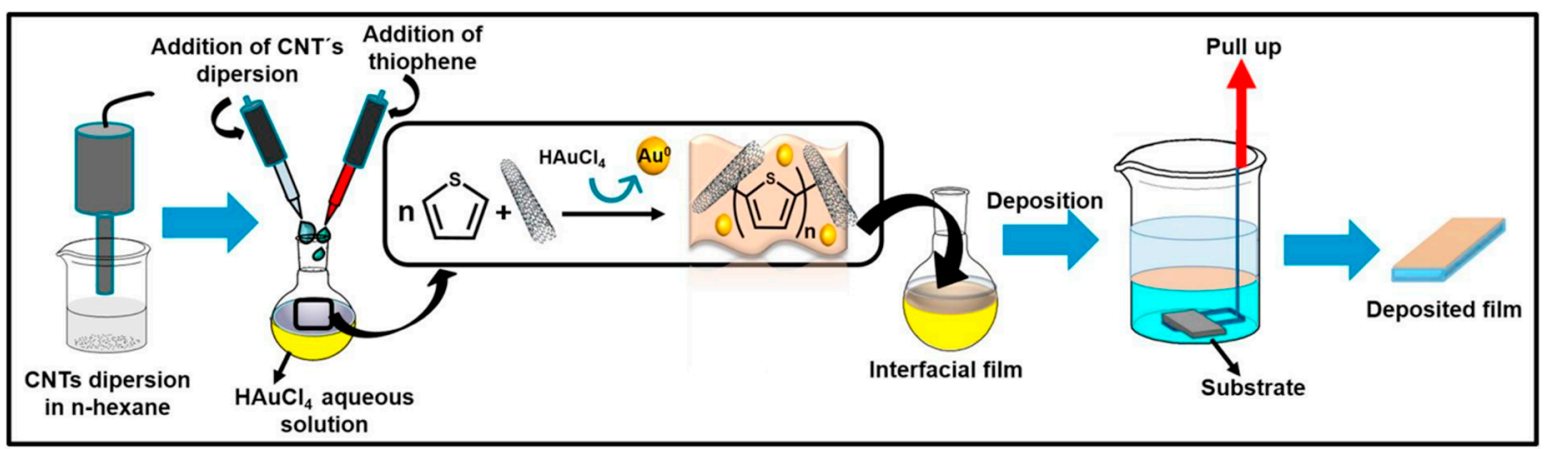

Figure 7. Schematic representation of the fabrication process of PT/Au/CNT electrodes. Reproduced with permission from [120]. Copyright 2019 Elsevier B.V.

Unconventional conducting polymers have also been used for electrochemical sensing. Poly (Sudan III) was potentiodynamically deposited over carbon paste electrodes (PS/MCPE) from a solution containing $\mathrm{NaOH}$ and Sudan III [121]. SEM images showed irregularly shaped graphite flakes at the surface. A LOD of $9.3 \mu \mathrm{M}$ with a linear range of 10-90 $\mu \mathrm{M}$ was determined by DPV. Polyphenol red film on glassy carbon electrode was used for detection of DA and acetaminophen [122]. Potentiodynamic polymerization of this molecule is possible through the quinone methide group. Sensing experiments were carried out in PBS solutions at different $\mathrm{pH}$ values. A LOD and linear range for DA were $1.6 \mu \mathrm{M}$ and $20-60 \mu \mathrm{M}$, respectively. The value of the catalytic rate constant $\left(8.45 \times 10^{2} \mathrm{M}^{-1} \mathrm{~s}^{-1}\right)$ demonstrates that $\mathrm{p}-\mathrm{PhR} / \mathrm{GCE}$ has a catalytic oxidative reaction for DA. Poly (procaterol hydrochloride) modified glassy carbon electrodes (p-ProH/GCE) were used for DA and UA detection in human serum [123]. These sensors were built by a potentiodynamic method in a PrOH solution on glassy carbon electrodes. Modified electrodes showed a high affinity for DA with a LOD value of $0.3 \mu \mathrm{M}$ within a linear range of $1-100 \mu \mathrm{M}$ by square wave voltammetry in PBS at $\mathrm{pH} 5$. Composites of poly (glyoxal-bis(2-hydroxyanil)), amino-functionalized graphene quantum dots, and $\mathrm{MnO}_{2}$ nanoclusters were deposited over glassy carbon electrodes (GCE/PGBHA-afGQDs- $\mathrm{MnO}_{2}$ ) for vitamin B12 and DA sensing [124]. SEM images displayed a rough and dense film with GQDs clusters made of particles with a size less than $50 \mathrm{~nm}$ which increased the roughness hence the surface area and electroconductivity resulting in LOD of $50 \mathrm{nM}$ for DA by DPV. Poly (hydroquinone)/gold nanoparticles/nickel foam (pHQ/AuNPs/NF) were used for DA sensitive detection [125]. First, gold nanoparticles were deposited from a solution containing $\mathrm{HAuCl}_{4}$, over previously cleaned nickel foam, by potentiostatic methods. Then potentiodynamic polymerization of hydroquinone was performed in phosphate-buffered solution at pH 5 (see Figure 8). Micrographs showed a porous 3D network structure 
of NF with a rough surface due to the deposited pHQ/AuNPs. These modifications of Nickel foam provide a large surface area and high conductivity. Determination of DA was made using DPV resulting in a LOD and linear range of $41.9 \mathrm{nM}$ and $1.0 \times 10^{-7} \mathrm{M}$ to $1.0 \times 10^{-5} \mathrm{M}$, respectively.

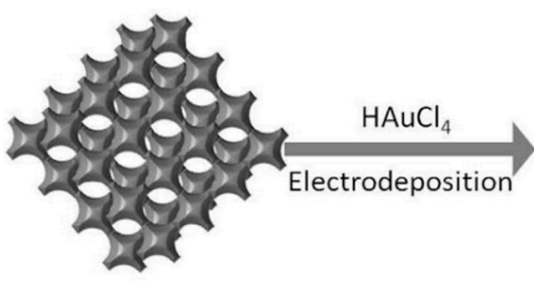

Ni Foam

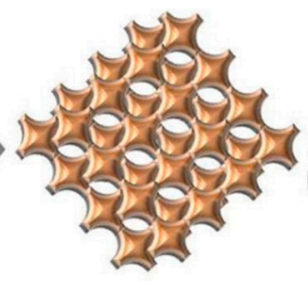

AuNPs/Ni Foam

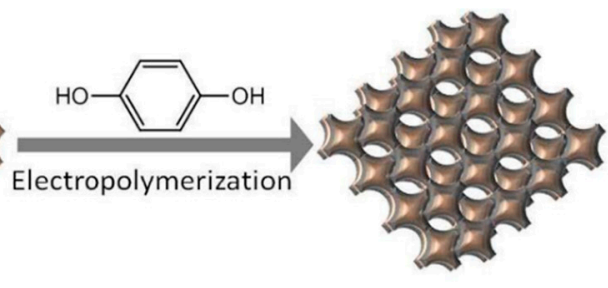

pHQ/AuNPs/Ni Foam

Figure 8. Schematic representation of the fabrication process of $\mathrm{pHQ} /$ AuNPs over Ni Foam. Reproduced with permission from [125]. Copyright 2017 Elsevier B.V.

Simultaneous detection of AA, DA, and UA was performed using a sensor based on electrochemically reduced graphene oxide-poly (eriochrome black T)/gold nanoparticles (ERGO-pEBT/AuNPs) modified glassy carbon electrodes [126]. FESEM technique showed a uniformly rough composite surface with Au nanoparticles homogeneously distributed leading to LOD values of $9.0 \mathrm{nM}$ for DA. Carboxylic acid functionalized multi-walled carbon nanotubes/polytoluidine blue over glassy carbon electrodes (MWCNTs-COOH/Poly (TB)/GCE) showed high sensitivity to DA $(\mathrm{LOD}=0.39 \mathrm{nM})$ related to the high surface area of the net-structure MWCNTs-COOH and the electrocatalytic activity of polymer [127]. Arroquia et al. fabricated self-assembled gold-decorated-polydopamine nanospheres (Au PDNs) for simultaneous detection of AA, DA, UA, and tryptophan [128]. First, synthesis of polydopamine nanospheres (PDNs) involved $3 \mathrm{~h}$ of stirring in DA hydrochloride/ $\mathrm{NaOH}$ solution at $50{ }^{\circ} \mathrm{C}$. Next, the suspension of PDNs was mixed with $\mathrm{HAuCl}_{4}$ and AA to get $\mathrm{Au}$ nanospheres (Au-PDNs). Finally, Au-PDN composite was deposited onto a screenprinted carbon electrode previously modified with gold nanoparticles, cysteamine, and glutaraldehyde (see Figure 9). Electronic microscopy showed a homogeneous distribution of Au-PDN nanospheres onto modified electrodes resulting in high surface areas with an improved charge transfer process. A remarkable LOD of $0.1 \mathrm{nM}$ was determined for DA with a linear range from $1 \mu \mathrm{M}$ to $160 \mu \mathrm{M}$ by DPV. This electrode was employed for extended periods (70 work hours and 200 measurements) showing no loss in the intensity of the signal.

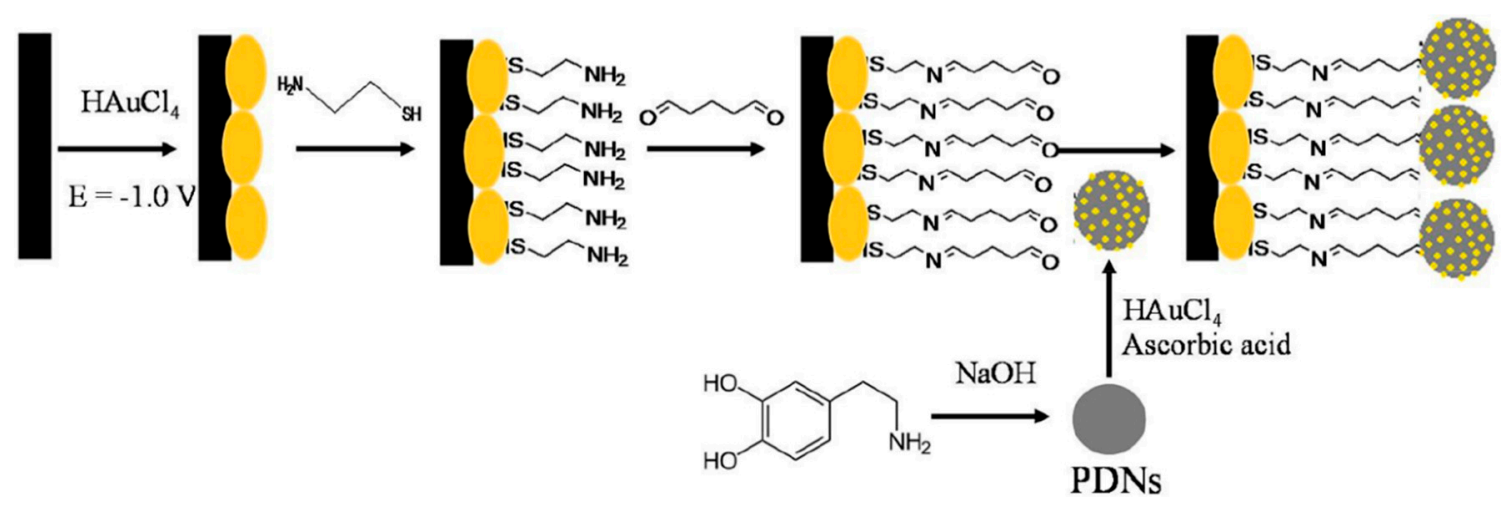

Figure 9. Schematic representation of the fabrication process of Au-PDNs (polydopamine nanospheres) electrodes. Reproduced with permission from [128]. Copyright 2019 Elsevier B.V.

Dopamine sensors have shown high sensitivity due to the high surface area of the conducting polymer films and small charge/transfer resistance generated by materials 
such as metal nanoparticles, RGO, and MWCNT. Besides, these materials have the role to boost the negative charge of the electrode surface establishing a strong electrostatic interaction with the positively charged analyte. The fact that dopamine is required to be detected usually in the presence of UA and AA represents a big challenge for researchers; however, this issue has been tackled by using molecular imprinted polymers as well as voluminous molecules such as B/cyclodextrin. In this way, a strong and specific interaction is generated with the analyte resulting in the separation between the oxidation potential of DA and the interferences.

\subsubsection{Epinephrine (EP)}

Electron beam irradiated polypyrrole nanospheres/bovine serum albumin onto glassy carbon electrodes (EB-PPy-BSA/GCE) were used for EP and L-tyrosine detection [129]. A mixture of methyl orange, $\mathrm{FeCl}_{3}$, and pyrrole was used to prepare polypyrrole nanospheres which were treated with electron beam radiation. Polypyrrole nanospheres and bovine serum albumin solution were sonicated for $2 \mathrm{~h}$ followed by drop-casting onto a glassy carbon electrode. SEM revealed that PPy nanospheres were embedded into a porous structure of BSA (see Figure 10). SWV was used for analyte determination obtaining a LOD of $7.1 \mathrm{nM}$. Seven different electrodes were potentiodynamically tested in solutions containing $200 \mathrm{uM}$ EP giving an RSD of 5.3\%. The use of BSA provided a large surface area, excellent structure stability, rich pore channels, and a redox mediator role. Tea and chicken extracts were evaluated with this sensor giving promising results for biological and healthcare applications. Ghanbari and Hajian reported the fabrication of gold nanoparticles/Zinc oxide/polypyrrole/reduced graphene oxide nanocomposite (Au/ZnO/PPy/RGO) on glassy carbon electrode for detection of AA, EP, and UA [130]. Polypyrrole deposits appeared as nanofibers onto RGO surface. LOD of $58 \mathrm{nM}$ and linear range from $0.6 \mu \mathrm{M}$ to $500 \mu \mathrm{M}$ was obtained by DVP in PBS solution at $\mathrm{pH}$ 7. This sensor was tested in a human serum sample giving recovery values above $97 \%$.
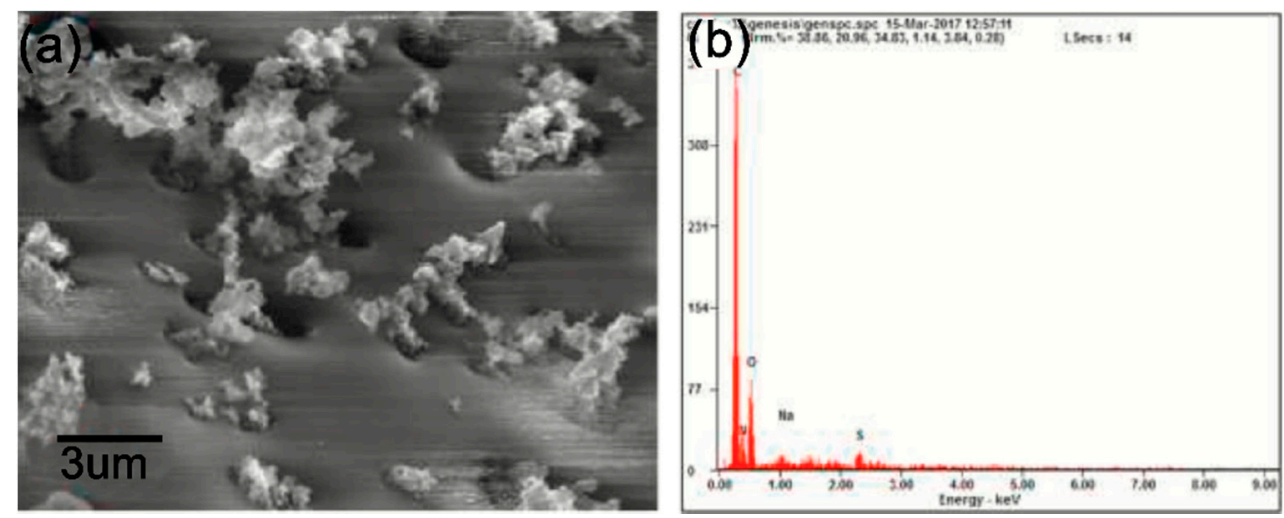

Figure 10. SEM analysis of EB-PPy-BSA hybrid structure (a) micrograph, and (b) EDS spectrum. Modified with permission from [129]. Copyright 2018 Elsevier B.V.

Three-dimensional mesoporous polymeric graphitic- $\mathrm{C}_{3} \mathrm{~N}_{4}$ /polyaniline/CdO nanocomposite (mpg- $\mathrm{C}_{3} \mathrm{~N}_{4} / \mathrm{PANI} / \mathrm{CdO}$ ) was electrochemically synthesized by Bonyadi et al. for simultaneous sensing of EP, paracetamol, mefenamic acid, and ciprofloxacin [131]. FESEM exposed a nanofiber-like structure of PANI deposited over the $3 \mathrm{D}$ structure made by $\mathrm{C}_{3} \mathrm{~N}_{4}$ resulting in a tremendous increase of the electrode surface area. A LOD of $11 \mathrm{nM}$ and two linear ranges from $0.05 \mu \mathrm{M}$ to $80 \mu \mathrm{M}$ and from $100 \mu \mathrm{M}$ to $1000 \mu \mathrm{M}$ were obtained for EP using DPV in PBS solution at $\mathrm{pH}$ 7.4. A 98.9-102.6\% recovery for EP was obtained in human blood serum samples. Polyaniline nanocomposite films have also been doped with $\mathrm{TiO}_{2}$ and $\mathrm{RuO}_{2}$ nanoparticles on multi-walled carbon nanotubes (MWCNT-PANI-TiO 2 and MWCNT-PANI-RuO ${ }_{2}$ ) for EP sensing [132]. $\mathrm{TiO}_{2}$ or $\mathrm{RuO}_{2}$ nanoparticles, MWCNT, and PANI were dissolved in DMF followed by sonication for $24 \mathrm{~h}$ to generate the nanocomposite. 
This suspension was drop coated onto Au bare electrode. PANI/MWCNT fibers formed tube-like structures with $\mathrm{TiO}_{2}$ and $\mathrm{RuO}_{2}$ spherical shaped particles that increased the porosity of the composite and its surface area. EP determination was performed using DPV in a PBS solution at $\mathrm{pH} 7$ with concentrations from $4.9 \mu \mathrm{M}$ to $76.9 \mu \mathrm{M}$. LODs of $0.16 \mu \mathrm{M}$ for MWCNT-PANI-TiO 2 and $0.18 \mu \mathrm{M}$ for MWCNT-PANI-RuO $\mathrm{M}_{2}$ were obtained. Both sensors were tested in an EP injection given more than 99\% recovery. PANI derivatives such as molecular imprinted poly (3-aminophenylboronic acid) has also been composited with multi-walled carbon nanotubes (PAPBA(MIPs)/MWCNTs) onto glassy carbon electrode for EP sensing showing a LOD of $35 \mathrm{nM}$ [133]. Molecular printing provides selectivity to distinguish EP from potential inferences. Following a similar strategy, molecularly imprinted poly 3-thiophene boronic acid (P3-TBA)/gold nanoparticles (MIP/AuNP) composite was developed by Liu and Kan obtaining a selective sensor of EP from its analogs resulting in a LOD of $76 \mathrm{nM}$ by DPV in PBS solution at pH 7 [134]. This sensor had double recognizing ability due to (i) reversible covalent interaction between boronic acid of 3-TBA and cis-diol of EP, and (ii) size and shape complementarity between template molecules and imprinted sites. A $90.6 \%$ to $103.5 \%$ recovery was obtained in a real EP injection using this sensor.

A glassy carbon electrode modified with gold nanoparticles into poly-fuchsine (FA) acid film (poly (FA)/AuNP/GCE) was used for simultaneous detection of AA, EP, and UA [135]. The poly (FA) was deposited by CV from a solution of fuchsine acid and $\mathrm{NaOH}$. Then, AuNPs were electrodeposited by immersing the electrode into a solution of $\mathrm{HAuCl}_{4}$ and $\mathrm{KNO}_{3}$. This electrode had a LOD of $10 \mathrm{nM}$ for EP and $9 \mathrm{nM}$ for AA in a buffer solution at $\mathrm{pH}$ 3. This method was proved in real samples using the standard addition method obtaining recovery values of $87.0 \%$ in hydrochloride injection and $102.0 \%$ in urine for EP. Potentiodynamic generation of poly (brilliant cresyl blue) on graphene/glassy carbon electrode (PBCB/graphene/GCE) was employed for detection of EP resulting in a LOD of $0.24 \mu \mathrm{M}$ by $\mathrm{CV}$ in PBS solution at $\mathrm{pH} 7$ for an EP concentration ranging from $1 \mu \mathrm{M}$ to $1000 \mu \mathrm{M}$ [136].

\subsubsection{Serotonin (SER)}

Poly (pyrrole-3-carboxylic acid) modified pencil graphite electrodes ( $p(\mathrm{P} 3 \mathrm{CA}) / \mathrm{PGE})$ were electrochemically generated for SER sensing in biological samples [137]. SEM micrographs showed cauliflower-like structures of P3CA (see Figure 11) that increase the surface area in comparison with a flat surface of the bare GE. Adsorptive differential pulse stripping voltammetry (AdSDPV) was applied for the determination of SER concentrations from $0.01 \mu \mathrm{M}$ to $1.0 \mu \mathrm{M}$ in a PBS solution at $\mathrm{pH} 5$ resulting in a LOD of $2.5 \mathrm{nM}$. This sensor was tested in blood serum and urine samples giving a $97.7 \%$ to $100.6 \%$ recovery and $93.8 \%$ to $97.4 \%$ recovery, respectively.
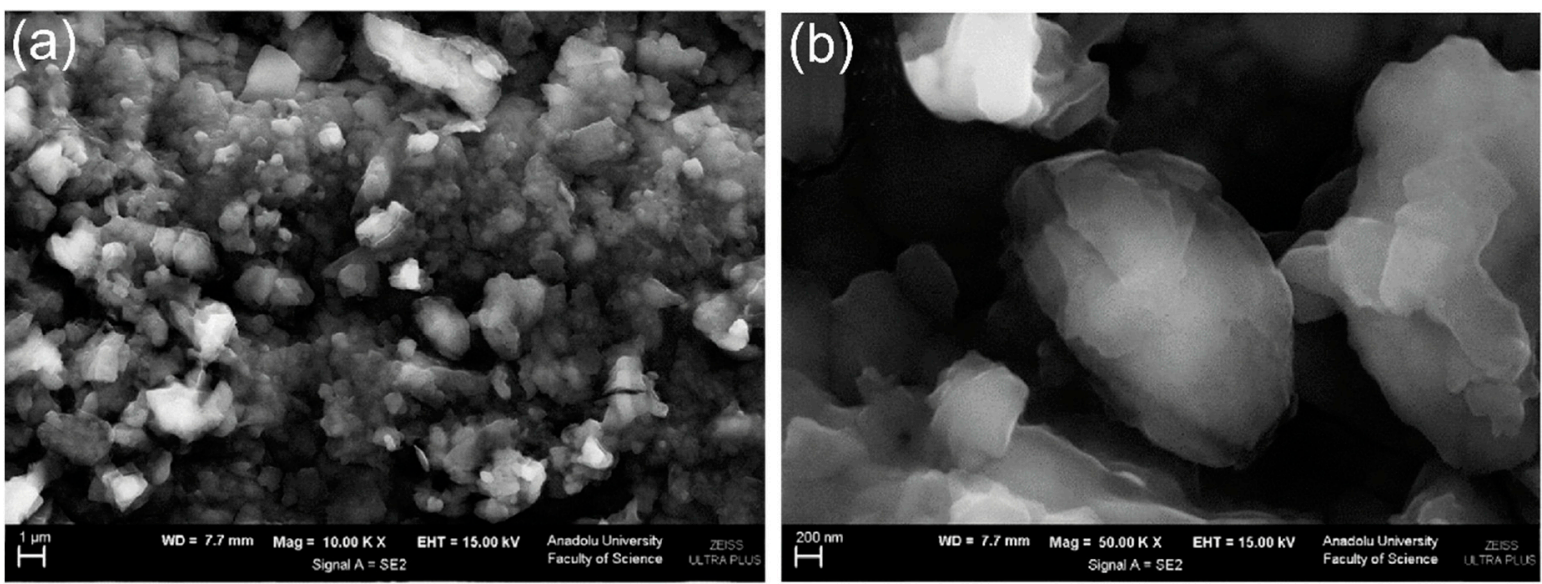

Figure 11. SEM image of $p(P 3 C A) / P G E$ surface in a magnification of (a) $10,000 \times$ and (b) $50,000 \times$. Modified with permission from [137]. Copyright 2015 Elsevier B.V. 
Ran et al. fabricated a poly (p-amino benzene sulfonic acid), multi-walled carbon nanotubes, and chitosan nanocomposite on glassy carbon sensor (MWCNTs-CS-poly (p-ABSA)/GCE) for SER detection [138]. Poly (p-ABSA) film was potentiodynamically obtained over GCE followed by drop-casting of MWCNTs-CS suspension. DPV sensor for SER displayed a linear range of $0.1-100 \mu \mathrm{M}$ and a LOD of $80 \mathrm{nM}$ in PBS buffer solution at $\mathrm{pH}$ 7. A recovery between $97 \%$ and $98 \%$ was obtained in human blood serum. A similar monomer derivative was used for the construction of a graphene (GR)/poly 4-amino-3hydroxy-1-naphthalenesulfonic acid-modified sensor onto a screen-printed carbon (GR/pAHNSA/SPCs) for simultaneous detection of DA and SER [139]. FE-SEM micrographs exposed that p-AHNSA was deposited over SPC generating nano-rod shape structures interconnected by GR resulting in large surface areas with high electrocatalytic activity. SWV sensor showed a LOD of $3 \mathrm{nM}$ for the SER concertation range of $0.05-150 \mu \mathrm{M}$ in a PBS solution at $\mathrm{pH}$ 7.4. This sensor was used for the determination of SER in plasma and urine obtaining recovery values of $98.1 \%$ to $101.2 \%$. The sensor can be used up to 3 times without significant loss in the current response. A well-known $\mathrm{pH}$ indicator has also been used for the fabrication of nanocomposites based on poly (bromocresol green), iron oxide nanoparticles, and multiwalled carbon nanotubes $\left(\mathrm{Fe}_{3} \mathrm{O}_{4}-\mathrm{MWCNT}-\right.$ poly (BCG) for the detection of SER [140]. This DPV sensor showed a LOD of $80 \mathrm{nM}$ with a linear range of $0.5-100.0 \mu \mathrm{M}$ in PBS solution at $\mathrm{pH}$ 7. A human blood serum sample was used for testing this sensor which provided recovery values of ca. 93\%. Reduced graphene oxide/poly (ethylene-3,4-dioxythiophene)/poly (styrene sulfonic acid)/nafion (rGO-PEDOT/PSSnafion) films were drop-cast by Al-Graiti et al. to detect SER (see Figure 12) [141]. SEM images showed PEDOT/PSS avoid the restacking of rGO resulting in a GO-PEDOT/PSS smooth film. This sensor allowed the simultaneous detection of SER and DA displaying a LOD of $0.1 \mu \mathrm{M}$ and linear range of 1 to $10 \mu \mathrm{M}$ for SER by employing DVP in PBS solution at $\mathrm{pH}$ 7.4.

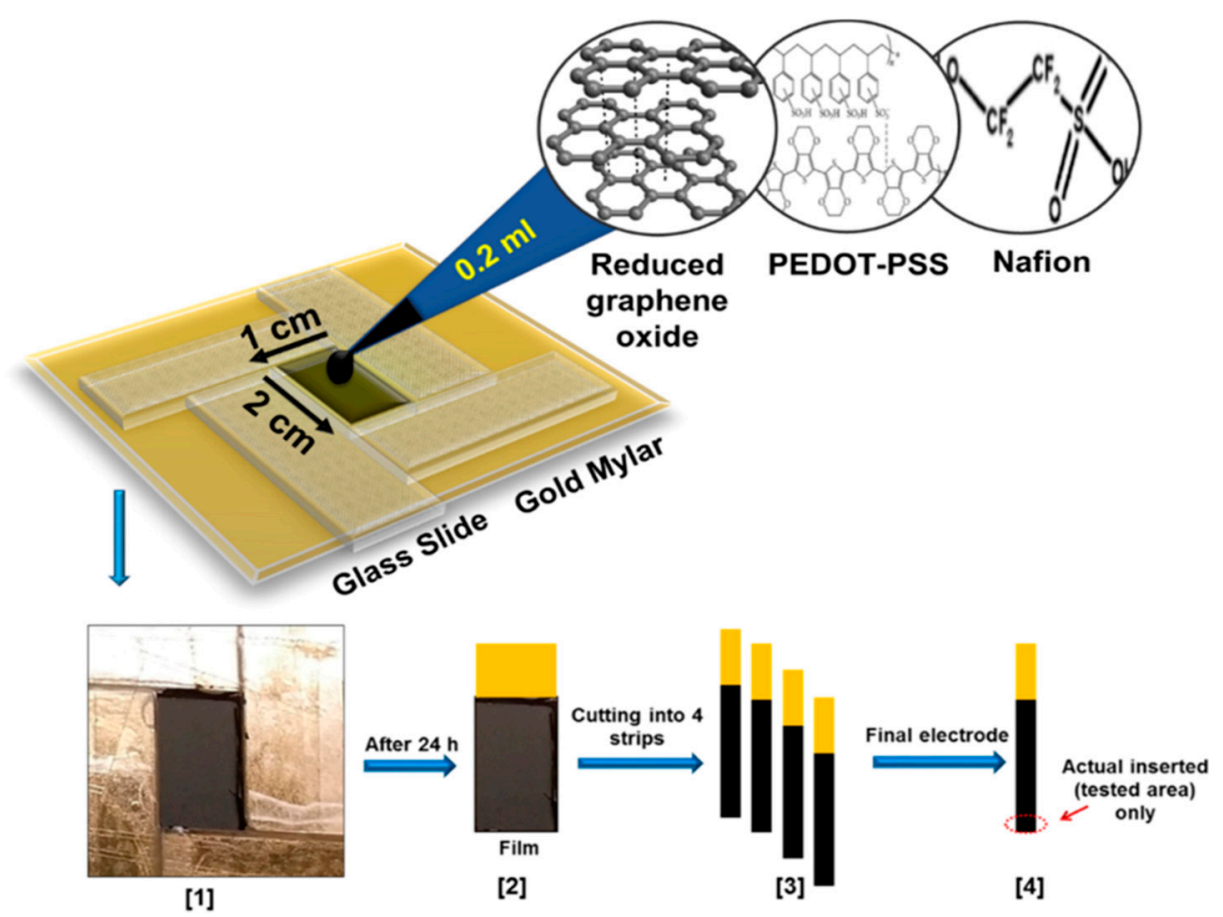

Figure 12. Schematic representation of the casting process of $\mathrm{rGO}-\mathrm{PEDOT} / \mathrm{PSS}$-nafion composite onto gold mylar substrates. Reproduced with permission from [141]. Copyright 2019 American Chemical Society.

Chung et al. designed a DA and SER sensor based on palladium complex $\operatorname{Pd}\left(\mathrm{C}_{2} \mathrm{H}_{4} \mathrm{~N}_{2} \mathrm{~S}_{2}\right)_{2}$ anchored to poly-2,2:5,2-terthiophene-3-(p-benzoic acid) on AuNPs decorated reduced 
graphene oxide substrates (AuNPs@rGO/pTBA-Pd $\left.\left(\mathrm{C}_{2} \mathrm{H}_{4} \mathrm{~N}_{2} \mathrm{~S}_{2}\right)_{2}\right)$ [142]. After drop-casting AuNPs@rG onto a screen-printed carbon electrode, pTBA was electrodeposited over the modified working electrode by $\mathrm{CV}$. Activated $\mathrm{COOH}$ groups allowed the immobilization of the $\mathrm{Pd}\left(\mathrm{C}_{2} \mathrm{H}_{4} \mathrm{~N}_{2} \mathrm{~S}_{2}\right)_{2}$ on the polymer layer by covalent bond formation. A LOD of $2.5 \mathrm{nM}$ was found by SWV in a buffer solution at $\mathrm{pH}$ 7.4. This sensor was used for the quantification of SER in breast cancer cells (MCF-7) by standard addition method obtaining recoveries from $97.2 \%$ to $103.8 \%$.

\subsection{Uric Acid (UA)}

UA levels in the human body provide information about the metabolic alterations or diseases such as metabolic syndrome, hypertension, kidney injury, and cardiovascular problems [143] because it is the final product of different metabolic pathways [5].

A composite of polytetraphenylporphyrin, polypyrrole, and graphene oxide ( $\mathrm{p}$ TPP/PPy/GO) deposited onto glassy carbon electrode was used for detection of UA resulting in a LOD of $1.15 \mu \mathrm{M}$ with a linear range of $5-200 \mu \mathrm{M}$ by DPV in PBS solution at $\mathrm{pH} 7$ [144]. P-TPP was used for boosting the electrocatalytic activity towards the oxidation of the analytes. $\alpha-\mathrm{Fe}_{2} \mathrm{O}_{3} /$ polyaniline nanotubes $\left(\alpha-\mathrm{Fe}_{2} \mathrm{O}_{3} /\right.$ PANI NTs) were synthesized by Mahmoudian et al. for UA sensing [145]. Polyaniline nanotubes were fabricated from a solution of acetic acid, methanol, aniline, and ammonium persulfate by static synthesis for $10 \mathrm{~h}$. Then, $\alpha-\mathrm{Fe}_{2} \mathrm{O}_{3} /$ polyaniline nanocomposite was assembled by stirring a solution of $\mathrm{FeSO}_{4} \cdot 7 \mathrm{H}_{2} \mathrm{O}$ and polyaniline nanotubes. TEM and FESEM allowed confirming the formation of PANI NTs with the presence of $\alpha-\mathrm{Fe}_{2} \mathrm{O}_{3}$ spherical and hexagonal nanoparticles that increased the electrode surface area. A DPV sensor was used for UA determination in concentrations from $0.01 \mu \mathrm{M}$ to $5 \mu \mathrm{M}$ in PBS solution at $\mathrm{pH} 7$ obtaining a LOD of $38 \mathrm{nM}$. UA was determined in a real urine sample giving recovery values between $98.58 \%$ and $101.98 \%$. A sensor based on functionalized polyaniline derivatives of nanostructured polyortho-methoxyaniline/multi-wall carbon nanotube onto a graphite paste electrode (POMANS-MWCNT/GPE) was used for simultaneous detection of UA and folic acid [146]. A LOD of $0.157 \mu \mathrm{M}$ and a linear range of $0.6-52 \mu \mathrm{M}$ was determined for an LSV sensor in PBS solution at $\mathrm{pH}$ 6. This electrode was tested in urine and blood serum samples given recovery values higher than $99.6 \%$. A sensitive sensor based on over-oxidized poly (3,4-ethylenedioxythiophene) nanofibers modified pencil graphite (Ox-PEDOT-nf/PGE) was developed for UA detection resulting in a detection limit of $1.3 \mathrm{nM}$ and a linear range of $0.01-20 \mu \mathrm{M}$ by DPV in PBS at pH 2 [147]. UA was sensed in urine and blood serum samples by standard addition method giving recovery values from $104 \%$ to $107 \%$. Huang et al. synthesized poly (3,4-ethylenedioxythipohene)/graphene oxide composites onto ITO electrodes (PEDOT/GO/ITO) for UA determination into saliva [148]. Figure 13 shows the fabrication procedure for this paper-based electroanalytical device. After adding EDOT-GO suspension on ITO substrate, a potentiostatic polymerization was performed in a thin electrochemical cell resulting in a porous film. SEM showed PEDOT-GO films as porous and rough networks. A DPV sensor displayed a LOD of $1.3 \mathrm{nM}$ and a linear range from $2 \mu \mathrm{M}$ to $1000 \mu \mathrm{M}$ in buffer solution at $\mathrm{pH} 6.8$.

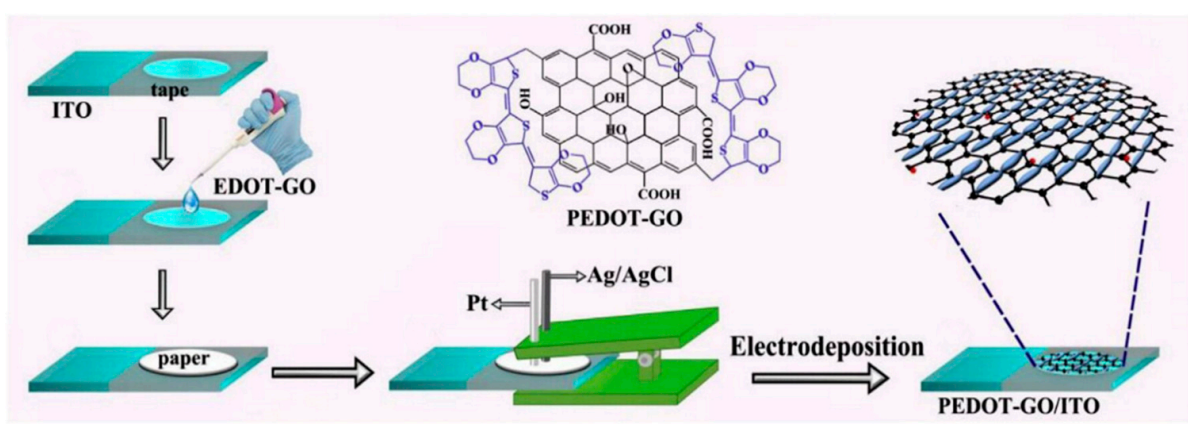

Figure 13. Schematic representation of the fabrication process of PEDOT/GO/ITO electrodes. Modified with permission from [148]. Copyright 2019 Elsevier B.V. 
Molecular imprinted poly (2-amino-5-mercapto-1, 3, 4-thiadiazole) (PAMT) and reduced graphene oxide (MIP/RGO) composite was used for simultaneous determination of UA and tyrosine obtaining a LOD of $3.2 \mathrm{nM}$ for UA by DPV in PBS at pH 5 [149]. This sensor was tested in urine and serum showing recoveries between $94.0 \%$ and $106.0 \%$. MIP/RGO sensor was tested 11 consecutive times in $0.4 \mu \mathrm{M}$ UA resulting in an RSD of $4.23 \%$. Poly (sulfosalicylic acid) and carboxylated graphene modified glassy carbon electrode (PSA/ERCG/GCE) sensor was employed for isoniazid and UA sensing [150]. A DPV sensor gave a LOD of $12 \mathrm{nM}$ for UA in ammonia buffer solution at $\mathrm{pH}$ 9.0. Taei et al. fabricated a gold-nanoparticles/poly-Trypan Blue modified glassy carbon electrode (AuNPs/poly-TrB/GCE) for determination of cysteine (Cys), UA, and tyrosine (Tyr) [151]. After potentiodynamic deposition of polymeric film onto the GCE, gold nanoparticles were deposited from AuNPs suspensions by chronopotentiometry. The polymeric films appeared as effective support for AuNPs according to SEM images. A DPV sensor gave a LOD of $70 \mathrm{nM}$ and a linear range from $1 \mu \mathrm{M}$ to $550 \mu \mathrm{M}$ for the sensing of UA in PBS solution at $\mathrm{pH}$ 3. A film of poly (6-thioguanine) on a glassy carbon electrode (P6-TG/GCE) was electrogenerated by Lan and Zhang for simultaneous detection of DA, UA, xanthine (XA), and hypoxanthine (HXA) [152]. SEM images showed a rough polymeric film (see Figure 14) providing an increased effective surface area of the electrode. A LOD of $60 \mathrm{nM}$ and a linear range from $2 \mu \mathrm{M}$ to $1600 \mu \mathrm{M}$ was determined for UA by DVP in PBS solution at $\mathrm{pH}$ 7. UA was determined in real samples of urine and blood serum showing recoveries $>98 \%$.

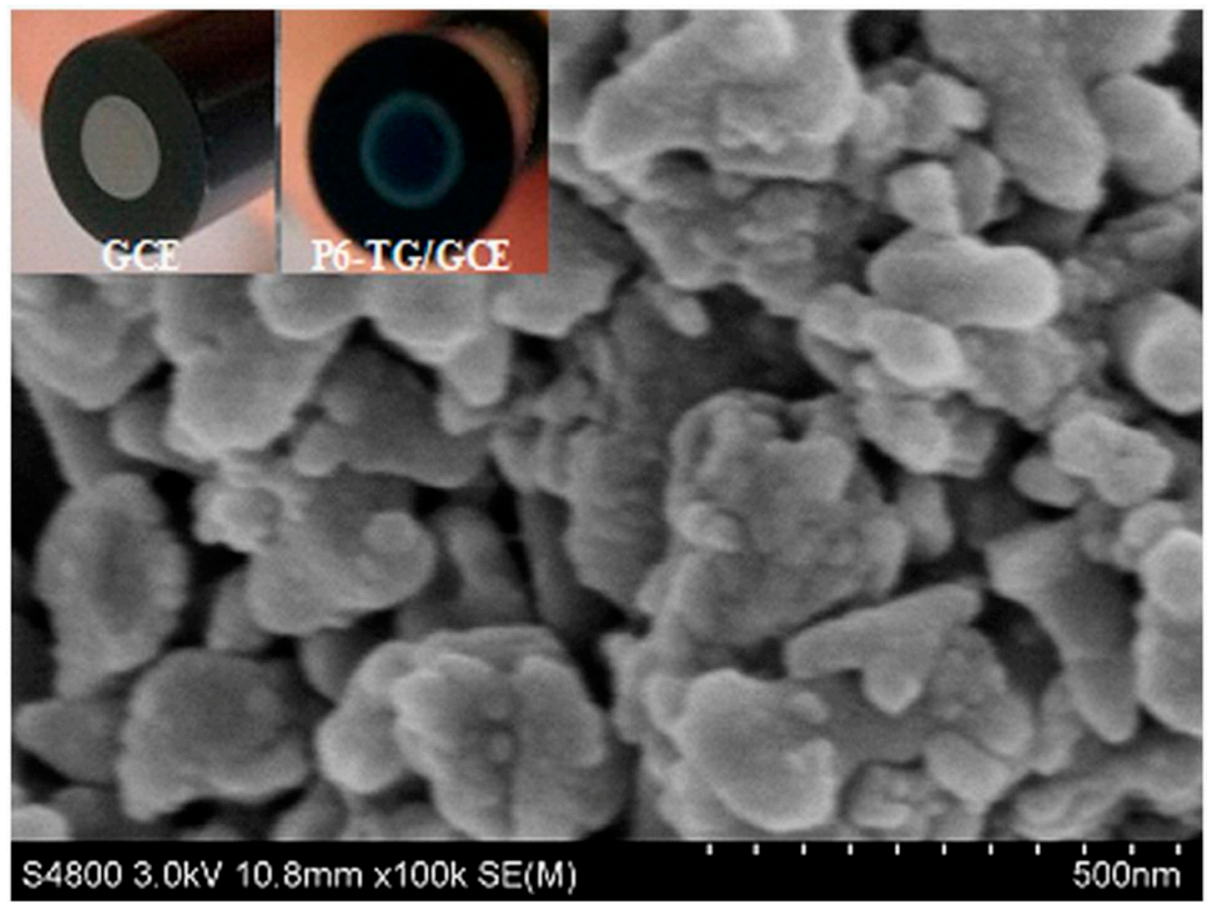

Figure 14. Micrograph of poly (6-thioguanine) film (P6-TG) deposited over glassy carbon electrode. Reproduced with permission from [152]. Copyright 2015 Elsevier B.V.

\subsection{Ascorbic Acid (AA)}

Shalini A. et al. reported a nanocomposite of polypyrrole with cellulose for AA sensing [153]. The polymer was grafted on cellulose by homogeneous oxidation of the monomer with ammonium peroxydisulfide, then PPy@C was immobilized onto GCE. SEM images showed spherical particles of PPy with 100-200 nm size, coating cellulose. Voltammograms of AA in aqueous solution at $\mathrm{pH} 7.0$ shows oxidation electrocatalytic attributed to a large area of the nanocomposite. A LOD of $75 \mu \mathrm{M}$ was chronoamperometrically determined for AA at aqueous solutions. Additionally, this modified electrode achieved recoveries ranging between $97.1 \%$ to $102.9 \%$ for real samples of commercial fruit juices of papaya, tomato, and 
orange. A layer-by-layer modification of GCE was presented by Fang Y. et al. [154]. After potentiostatic deposition of nickel on glassy carbon electrode, CNTs were grown by catalytic chemical vapor deposition (CCVD) followed by PANI potentiodynamic polymerization from aqueous aniline solution. A three-dimensional network structure was observed by SEM analysis. Voltammograms of hexacyanoferrate(III) with the final modified surface exhibits a peak current increase of ten with respect to bare glassy carbon electrode, due to the enlarged surface area caused by the conducting polymer and the carbon material. AA was determined by DPV measurements obtaining a LOD of $0.1 \mu \mathrm{M}, \mathrm{mol} \cdot \mathrm{L}^{-1}$, and recoveries of $97.4-101.2 \%$. In addition, this sensor showed no loss of electroactivity after 30 continuous CVs in $0.2 \mathrm{mM}$ of AA. Two organo-soluble polyimides were synthesized to overcome common problems of commercial conducting polymers as solubility and processing [155]. Electroactive polyimides EPI-3 and EPI-4 were immersed into a $\mathrm{HAuCl}_{4}$ aqueous solution for gold nanoparticle formation. Voltammograms of $2 \mathrm{mM}$ AA with different composites shown a peak current for EPI-4 higher in a factor of ten with respect to EPI-3 signal indicating that EPI-4, a longer conjugated structure of diamine, has higher redox capability (see Figure 15). For AA determination EPI-4 was mixed with graphite powder and paraffin oil to prepare a carbon paste electrode. A LOD of $18.5 \mu \mathrm{M}$ was determined by chronoamperometry within a linear range of $1.0 \times 10^{-5} \mathrm{M}$ to $1.0 \times 10^{-3} \mathrm{M}$.

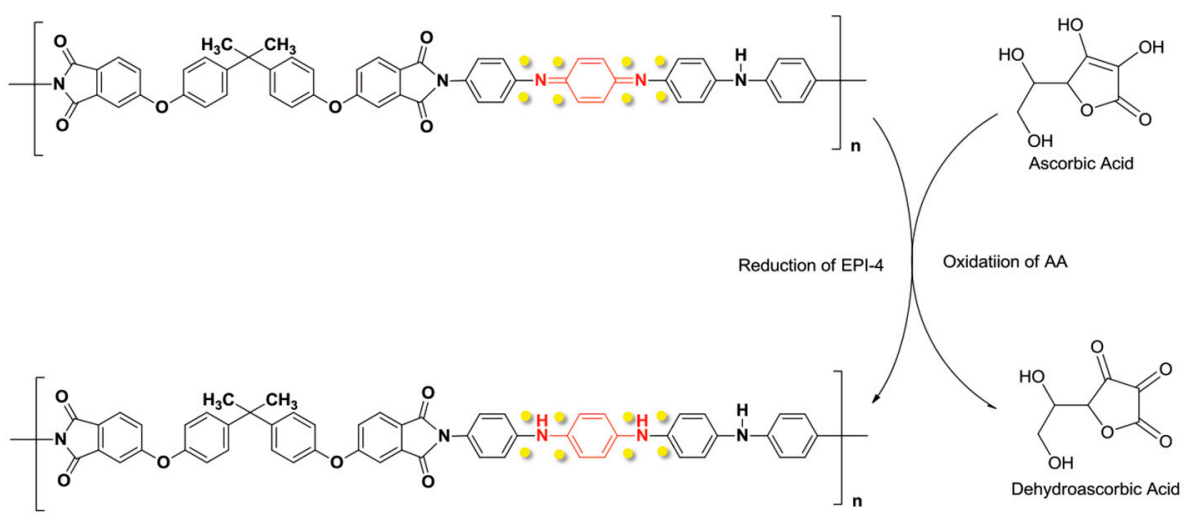

Figure 15. Scheme of EPI-4 structure used into a CPE to determinate AA. Yellow points represent gold nanoparticles. Reproduced with permission from [155]. Copyright 2017 Elsevier.

A poly (amido amine) dendrimer, silver nanoparticles, and multi-walled carbon nanotubes composite with poly (neutral red) (PAMAM/AgNPs-MWCNT/PNR film) prepared on a paraffin wax impregnated graphite electrode was reported by Lackshmi C. et al. [156]. A linear range for AA signal was obtained from $2.0 \times 10^{-7} \mathrm{M}$ to $2.5 \times 10^{-3} \mathrm{M}$ with a LOD of $53 \mathrm{nM}$ with DPV at optimal $\mathrm{pH}$ of 4.0. The reproducibility was determined for 60 days measuring $81.5 \mathrm{mM}$ of AA every 5 days. The sensor retained $94 \%$ of the initial response. The best performance of this sensor is due to the large surface achieved by a combination of the carbon materials, metallic particles, and conducting polymer. Glassy carbon surface was modified by potentiodynamic polymerization of EDOT into a propylene carbonate solution [157]. PEDOT film was oxidized to increase area and roughness. Voltammograms of a mix of AA and UA shows a signal separation of ca. $300 \mathrm{mV}$. Linear sweep voltammetry was employed for AA determination achieving a LOD of $45 \mu \mathrm{M}$. Commercial CNTs were carboxylated by oxidization into a mix of nitric and hydrochloric acid, then the nanotubes were drop-cast on top of glassy carbon electrode from aqueous suspension [158]. This surface was covered with PEDOT by potentiostatic polymerization. Voltammograms of $1 \mathrm{mM}$ AA solution showed a current signal 10-fold larger with final modified surface respect to bare electrode signal, and a separation of $520 \mathrm{mV}$ between UA and AA. Chronoamperometric techniques were used for AA determination reporting a linear range of $1.0 \times 10^{-4}-2.0 \times 10^{-2} \mathrm{M}$ with a LOD of $4.2 \mu \mathrm{M}$. Similarly, Sener C. et al. developed a sensor by polymerization of glyoxal-bis(2-hydroxyanil) onto a glassy carbon 
electrode [159]. Voltammograms with the modified surface show separated signals for AA and UA of ca. $230 \mathrm{mV}$. A LOD of $0.26 \mu \mathrm{M}$ was reported using DPV with recoveries of $97.7-101.2 \%$. The selectivity can be attributed to functional oxygen groups of the polymer involved in the electron transfer process.

\subsection{Glucose}

Perhaps the most widely recognized electrochemical sensor is the glucometer [160]. The first electrochemical biosensor was developed by Clark and Lyons in 1962 [161], where Glucose oxidase (GOx) was used as the enzyme to catalyze glucose oxidation at its flavin adenine dinucleotide cofactor FAD. Currently, sensor research is focused on developing non-invasive devices for glucose determination using new materials as conducting polymers, carbon materials, or metallic nanoparticles [162].

\subsubsection{Enzymatic Sensors}

Thunyakontirakun W. et al. built a biosensor based on electrogenerated poly (pyrrole3-carboxylic acid) into a composite film with GO and immobilized GOx [163]. A LOD of $50 \mu \mathrm{M}$ was obtained by amperometric measurements. A novel subcutaneous needle-like device was developed for monitoring glucose [164]. The sensor contains four layers (i) potentiodynamically plated platinum on a gold surface, (ii) electrochemically deposited PANI film, (iii) GOx cross-linked with glutaraldehyde, and (iv) a bi-layer membrane of polyurethane of different thickness. SEM micrographs showed PANI nanofibers with a diameter size between $80 \mathrm{~nm}$ and $110 \mathrm{~nm}$ and length about $1 \mathrm{~mm}$, interconnected each other to form a network. The sensor Pt/PANI/GOx/PU/E-PU was subcutaneously implanted in male Sprague-Dawley rats showing a lifetime of 26 days. A composite was prepared on a glassy carbon electrode by potential sweeps from an aqueous dispersion containing polyvinylpyrrolidone, polyaniline, and gold nanoparticles [165]. After the electropolymerization, GOx was absorbed on top of the composite, and a Nafion film was dropped onto the surface. The surface denoted as PANI-PVP-AuNP, showed a regular flower-like structure with a rough surface. A LOD of $10 \mu \mathrm{M}$ was reported for glucose by chronoamperometric measurements. A sensor composed of PANI, graphene, and GOx was prepared for glucose determination [166]. Pt/PANI-GRA/GS-GOx electrodes show PANI rod-like structures with a diameter of about $300 \mathrm{~nm}$ and a length of some $1.5 \mathrm{~mm}$. The amperometric technique was employed for glucose determination achieving a LOD of $2.77 \mu \mathrm{M}$ and linear range of $1.0 \times 10^{-5}-1.48 \times 10^{-3} \mathrm{M}$. The sensor showed high selectivity and recoveries ranging from $95.6 \%$ to $104.9 \%$ for glucose determination in plasma samples. Hybrid composite of PANI, montmorillonite (MMT), and palladium nanoparticles was reported by Zheng H., et al. [167]. The composite was electrochemically polymerized from an aqueous dispersion of aniline with MMT by potential sweeps. Then, the surface was decorated with PtNP by electrochemical deposition from $\mathrm{H}_{2} \mathrm{Pt}_{2} \mathrm{Cl}_{6}$ solutions followed by deposition of a mix of chitosan-GOx. SEM analysis reveals a rod-like PANI structure uniformly distributed on the platinum surface, decorated with MMT and spherical PtNP with an average size of $60 \mathrm{~nm}$. Glucose determination was carried out employing a chronoamperometric method achieving a LOD of $0.1 \mu \mathrm{M}$, with a linear range $1.0 \times 10^{-5}-1.94 \times$ $10^{-3} \mathrm{M}$ and recoveries of $95.1-103.2 \%$ into human serum blood samples. A complex biocomposite design for glucose determination was presented by Sun L. et al. [168] based on poly (3-anilineboronic acid) (PAB). Sensors denoted as $\mathrm{Au} / \mathrm{MWCNT} / \mathrm{Pd}_{\text {plate }} / \mathrm{GOx}-\mathrm{PAB}-$ $\mathrm{PdNP} / \mathrm{CS}$ were tested for glucose determination by chronoamperometric methods into aqueous PBS solutions at $\mathrm{pH} 7.0$. A LOD of $0.1 \mu \mathrm{M}$ with a linear range of $2 \times 10^{-6}-4.5$ $\times 10^{-3} \mathrm{M}$, and a repeatability of $7.1 \%$ as RSD $(n=5)$ for $5 \mathrm{mM}$ glucose in the presence of $0.5 \mathrm{mM}$ of AA and UA. PEDOT films were electrochemically deposited on a Pt electrode with bovine serum albumin as a platform for Pt/PEDOT-BSA/AuNP-GOx sensors [169]. FTIR, analysis shows no disruption of PEDOT film by the posterior modifications. Glucose determination was carried out with chronoamperometric measurements achieving a linear range of $4.16 \times 10^{-4}-5.0 \times 10^{-2} \mathrm{M}$ with an $\mathrm{R}^{2}$ of 0.9967 . 1,3-Bis(2-pyridylimino)isoindole 
palladium complex bearing 3,4-ethylenedioxitiophene (EDOT-PdBPI) was electrochemical co-polymerized with 4-amino-N-(2,5-di(thiophene-2yl)-1H-pyrrol-1-yl)benzamide (HKCN) by potential sweeps onto a graphite rod electrodes [170]. An amperometric technique was employed for glucose determination achieving a LOD of $176 \mu \mathrm{M}$. The sensor performance was evaluated with commercial beverages and compared with a spectrophotometric method achieving recoveries of ca. $98 \%$. A film composed of PEDOT, polyacrylic acid, and poly (4-lithium styrenesulphonic acid) PSSLi was electrodeposited on platinum electrode followed by GOx immobilization assisted with a carbodiimide [171]. Glucose determination was carried out into commercial juice and honey samples achieving a LOD of $290 \mu \mathrm{M}$ with a linear range $9.6 \times 10^{-4}-3.0 \times 10^{-3} \mathrm{M}$. The same research group reported the synthesis of similar surfaces employing the same basic principles and optimizing the procedure of GOx immobilization [172]. Methylene blue (MB) was electrochemically polymerized onto PAMAN dendrimer/pencil graphite electrode (PGE) followed by glucose dehydrogenase (GHD) immobilization to build a biosensor for flow injection analysis (FIA) [173]. Voltammograms of aqueous glucose solution with NAD+ on PGE/PAMAN/pMB-GHD surface showed an electrocatalytic signal with a reduction of onset potential of ca. $400 \mathrm{mV}$ with respect to the surface without the conducting polymer. A LOD of $4.0 \mu \mathrm{M}$, with a linear range of $1.0 \mathrm{mM}-1000 \mu \mathrm{M}$ and recoveries ranging from $96 \%$ to $104 \%$ were reported into samples of artificial blood serum.

\subsubsection{Non-Enzymatic Sensors}

A conducting composite of PPy with silver nanoparticles was reported by Poletti et al. for glucose sensing [174]. The pPy-AgNP composite was dispersed into water and then drop-cast on a glassy carbon electrode. SEM and TEM analysis confirmed the formation of spherical silver particles incorporated and distributed in the polymeric matrix. $\mathrm{Ag}^{+}$reduction was accompanied by monomer oxidation which led to Py polymerization. The glucose determination was evaluated chronoamperometrically using artificial human saliva, achieving a LOD of $3.6 \mu \mathrm{M}$. PPy was also potentiostatically electrodeposited on a graphite electrode [175]. SEM micrographs revealed polymer wire-like structures covered with nickel nanoflakes. Chronoamperometry was used to determine glucose in alkaline solution, achieving a linear range $1.0 \times 10^{-6}-4.86 \times 10^{-3} \mathrm{M}$ with a LOD of $0.3 \mu \mathrm{M}$ attributed to the chemical reactivity of the redox pair $\mathrm{Ni}(\mathrm{OH})_{2} / \mathrm{NiOOH}$, which showed excellent electrocatalysis behavior for glucose. PANI was drop-cast onto a clean glassy carbon surface followed by dipping into a gold nanoparticle dispersion to obtain a GC/PANI/AuNP sensor with a LOD of $100 \mathrm{mM}$ to glucose [176]. A hybrid nanostructure composed of MWCNT, gold nanoparticles, and poly (2-aminothiophenol) (pAT), were deposited on a glassy carbon electrode, for glucose determination [177]. Glucose voltammograms showed a well-defined peak obtained in the reversal sweep because of the gold oxide formation indicating an electrocatalytic effect. The peak current of LSV shows a linear dependence with the glucose concentration from $1.0 \times 10^{-4} \mathrm{M}$ to $3.0 \times 10^{-2} \mathrm{M}$ achieving a LOD of $3.7 \mu \mathrm{M}$. A fluorine-doped tin oxide, (FTO) surface was modified with a nanocomposite of electrodeposited poly (aniline blue) PAnB and gold nanoparticles on FTO/AnB/AuNP [178]. SEM micrographs showed aggregated gold nanoparticles with (111) and (200) crystal planes. Voltammograms of glucose showed oxidation and reduction current peaks in the modified electrodes (not appreciated on non-modified surfaces). Glucose detection was carried out with an amperometric technique achieving a LOD of $0.4 \mu \mathrm{M}$, and a linear range of 0 to $50 \mu \mathrm{M}$. Synergic effect in the nanomaterial-polymer ensured good contact and high electron transfer rate. A similar composite PANI-nickel nanoparticles was reported for glucose detection [179]. Face-centered cubic nickel oxide was dispersed in the polymer matrix which catalyzed the glucose reaction with respect to the bare electrode increasing with the $\mathrm{pH}$ value of the solution. An amperometric determination was tested by successive addition of glucose, reporting a LOD of $0.19 \mu \mathrm{M}$. Poly (hydroxymethyl-3,4-ethylendioxythiophene) (PHMeDOT) films were deposited by chronoamperometric techniques on a clean glassy carbon electrode [180]. This surface was used for the glucose determination in real blood 
samples extracted from different individuals. The results were compared with a commercial "One TouchMini ${ }^{\circledR}$ " blood glucose meter, obtaining a relative difference of ca $1.75 \%$. Another sensor based on a composite of PEDOT:PSS with MWCNTs and copper oxide particles has been used for the glucose determination with a linear range up to $10 \mathrm{mM}$ and a LOD of $230 \mathrm{mM}$ by chronoamperometry [181]. A electrochemically nanostructured phenylboronic acid-grafted poly (3,4-ethylenedioxythiophene) (poly (EDOT-PBA)) was developed for glucose determination [182]. SEM micrographs revealed a tubular-type structure while contact angle analysis showed film hydrophilicity. The trials of the absorption of glucose onto the modified surface were carried out with the QCM technique, shown a dependence between the frequencies of crystal with glucose concentrations. A linear range of 0.1 to $50 \mathrm{mM}$ and a LOD of $5.0 \mu \mathrm{M}$ was achieved with the EIS technique. A nanocomposite of rGO, PEDOT, and nickel nanoparticles was prepared by electrochemical deposition [183]. SEM analysis showed a rough 3D microstructure, due to the GO presence decorated with nickel rod-like structures with an average length of ca 50-100 nm and a diameter of $20 \mathrm{~nm}$. Amperometric measurements were made in $\mathrm{NaOH}$ aqueous solution obtaining a LOD of $0.8 \mu \mathrm{M}$. Aqueous solutions of $0.1 \mathrm{mM}$ of DA, UA, and AA were used as interferents founding an excellent selectivity to glucose. The selectivity of this sensor was attributed to the nickel nanoparticles. Similarly, a film of PEDOT:PSS decorated with nickel nanostructures was reported by Mazloum-Ardakani et al. [184]. A LOD of $0.69 \mu \mathrm{M}$ and a linear range of 2.5 to $1100 \mu \mathrm{M}$ were obtained for glucose in chronoamperometric measurements. A MIP composed of acrylamide and aminophenyl boronic acid on poly(tertiophene), pTBA was developed by Kim et al. [185]. The film was deposited on a screen-printed carbon electrode previously covered with gold nanoparticles (SPCE/AuNP/pTBA-MICP). This sensor was employed for glucose determination into physiological samples like saliva and finger-prick blood. A LOD of $0.19 \mu \mathrm{M}$ with a linear range of $3.2 \times 10^{-7}-1.0 \times 10^{-3} \mathrm{M}$ was reported using amperometric measurements. Poly (terthiophene) played an important role as a template for boosting the surface area as well as the conductivity. A composite of PEDOT, GO, and copper nanoparticles was electrogenerated for glucose determination [186]. SEM micrographs showed a rough and wrinkled yet uniform microstructure of polymer with well-distributed GO and cubic copper particles of ca. $100 \mathrm{~nm}$. A chronoamperometric technique was employed to measure glucose in real human serum samples reporting a LOD of $47 \mathrm{nM}$ with a linear range of $1.0 \times 10^{-7}-1.3 \times 10^{-3} \mathrm{M}$ and a repeatability of $3.3 \%$ as RSD for measuring $0.1 \mathrm{mM}$ glucose with a single modified electrode 10 times. The sensor was also compared with a commercial automatic analyzer achieving an RSD of $4.6 \%$. The good performance of this sensor is attributed to good contact and synergic effect between metallic particles, carbon materials, and conducting polymer. A very similar composite was reported by Wu et al. [187]. This sensor was composed of PEDOT, carbon nanotubes, and copper oxide nanoparticles (GC/PEDOT-CNT-Cu ${ }_{2} \mathrm{ONP}$ ). SEM and TEM micrographs showed well defined six corner star-like microcrystal particles of copper(I) oxide that increase surface area. Amperometric measurements were made by adding successively amounts of glucose. A fast-current response $(<4 \mathrm{~s})$ was observed for each glucose addition with a LOD of $40 \mathrm{nM}$. In addition, the sensor retains $94.9 \%$ of its initial current response after 28 days measuring $4 \mathrm{mM}$ glucose. A poly (o-phenylenediamine) (pPD) film covered with silver nanoparticles was employed for the electrochemical determination of glucose [188]. Chronoamperometry was employed for the glucose determination reporting a LOD of $12 \mu \mathrm{M}$ and recoveries of $94.2-103.4 \%$ in human blood samples. Following the same line, Wang et al. reported a similar pPD modified surface with copper nanoparticles resulting in a LOD of $0.25 \mathrm{mM}$ and a linear range of $5.0-1.6 \mathrm{mM}$ for glucose in human blood samples [189].

Glucose sensors based on glucose oxidase usually show high selectivity; however, the scientific community still needs to face important challenges such as the preservation of the surface conductivity and the homogeneous immobilization of the enzyme in the conducting polymer. Carbon materials and metallic nanoparticles in a conducting polymer matrix boost the sensor conductivity resulting in relatively good LODs. On the other 
hand, the design and construction of orderly-nanostructured enzyme sensors remain an unexplored potential research area aiming to avoid blocking active sites on the electrode surface. Developing enzyme-less sensors for glucose determination is an active field of research. Good results are obtained by preparing nanocomposites of functionalized conducting polymers e.g., with boronic acids. Molecular imprinted polymers are also used as another interesting way for selective glucose determination. Selectivity is enhanced by using metallic nanoparticles where the metal or metal oxides onto the surface play a crucial role in the mechanism of the electronic exchange process.

\subsection{Hydrogen Peroxide}

Hydrogen peroxide, $\mathrm{H}_{2} \mathrm{O}_{2}$, is widely used in many fields such as clinical [190], industrial [191], and environmental analysis [192]; it is also a byproduct of several oxidative biological reactions. It is essential to determine $\mathrm{H}_{2} \mathrm{O}_{2}$ concentration for studying different kinds of disorders in the human body such as cancer, Alzheimer's, and Parkinson's, as well as in various industrial applications [193]. Electrochemical sensors based on enzymes were developed as the third-generation of biosensors [194]. Nevertheless, enzymefree sensors have attracted increasing interest due to their high stability and low-cost [195]

\subsubsection{Enzymatic Sensors}

Hydrogen peroxide was sensed by a ternary nanocomposite of PEDOT:PSS, reduced graphene oxide and gold nanoparticles assembled with horseradish peroxidase (HRP) on a screen-printed gold electrode (HRP/AuNPs/rGO/PEDOT:PSS/SPGE) [196]. PEDOT:PSS acted as an effective $\pi-\pi$ stacking stabilizer for rGO. AuNPs were distributed homogeneously working as nanoscale spacers which allowed access to both faces of PEDOT:PSS and graphene sheets increasing significantly the active surface area of the electrode. Amperometric measurements were used to sensed $\mathrm{H}_{2} \mathrm{O}_{2}$ concentration in a linear range from $5 \mu \mathrm{M}$ to $400 \mu \mathrm{M}$ and with a LOD of $80 \mathrm{nM}$. The repeatability for $n=5$ showed an RSD of $4.2 \%$ for $50 \mu \mathrm{M} \mathrm{H}_{2} \mathrm{O}_{2}$. A film consisting of poly ( $\gamma$-glutamic acid) modified with 3-aminothiophene (ATh- $\gamma$-PGA) was prepared together with HRP and nafion for the determination of $\mathrm{H}_{2} \mathrm{O}_{2}$ [197]. By cyclic voltammetry, thiophene groups in the ATh- $\gamma$-PGA/GE were electropolymerized into acetonitrile solution containing $\mathrm{LiClO}_{4}$. Nafion/HRP/ATh- $\gamma$-PGA/GE sensors showed two linear ranges for $\mathrm{H}_{2} \mathrm{O}_{2}$ concentrations, from $10 \mathrm{pM}$ to $10 \mathrm{nM}$ and from $10 \mathrm{nM}$ to $10 \mu \mathrm{M}$, with a LOD of $3 \mathrm{pM}$. The sensor showed an RSD of $2.4 \%$ for eight assays in $10 \mathrm{nM} \mathrm{H}_{2} \mathrm{O}_{2}$. Chen et al. fabricated a hydrogen peroxide sensor of HRP in an electrogenerated poly (aniline-co-N-methylthionine) film on platinum foil [198]. After enzyme immobilization, smaller nanoparticles appeared increasing the roughness and surface area of the electrode. Copolymer film reduced the background interference from the platinum electrode, acting also as a mediator which formed HRP $\left(\mathrm{Fe}^{3+}\right)$. The PAN-PNMThH film also provided a biocompatible platform for HRP immobilization. Amperometric detection of $\mathrm{H}_{2} \mathrm{O}_{2}$ showed a linear response ranging from $5.0 \mu \mathrm{M}$ to $60.0 \mathrm{mM} \mathrm{H}_{2} \mathrm{O}_{2}$ with a detection limit of $3.2 \mu \mathrm{M}$. A hydrogen peroxide sensor based on PANI together with acrylic acid (AcA), ethylene glycol diglycidyl ether (EGDE), and Soybean seed coat peroxidase (SBP) (SBP/poly (EGDE-AcA-ANI)/GCE) was developed by Torres et al. [199]. PANI enhanced the electron transfer process acting as a good electronic conductor, the acrylate played a role as counter ion achieving electrical neutrality and EGDE worked as a cross-linker. The quantitative analysis of $\mathrm{H}_{2} \mathrm{O}_{2}$ using an amperometric technique showed a linear response in the range of 5.0-50 $\mu \mathrm{M}$ with a LOD of $2.2 \mu \mathrm{M}$.

\subsubsection{Non-Enzymatic Sensors}

A PEDOT film together with rGO was deposited on a GCE for hydrogen peroxide determination [200]. EDOT and GO were mixed in acetonitrile and drop-cast in the GCE, then potential sweeps were applied for EDOT polymerization and GO reduction. A crumpled and rough surface was observed for the PEDOT/rGO film. This morphology produced a larger electrochemically active area which enhanced radical oxygen reduction 
reaction (ORR) activity. Wang et al. fabricated a selective and long-term stable electrode for $\mathrm{H}_{2} \mathrm{O}_{2}$ determination with Prussian blue (PB) nanoparticles and PEDOT on glassy carbon electrode (PEDOT/PBNPs/GCE) [201]. PEDOT was polymerized around the PB nanoparticles connecting them as a covering shell. As a result, the PEDOT/PBNPs film showed a porous grape-like microstructure. The composite enhanced the electron transfer and conductivity allowing detection of $\mathrm{H}_{2} \mathrm{O}_{2}$ in concentrations ranging from $0.5 \mu \mathrm{M}$ to $839 \mu \mathrm{M}$, with a LOD of $0.16 \mu \mathrm{M}$. Following the same line, a PEDOT/PBNPs $/ \mathrm{Pt}$ sensor was developed by Lete et al. obtaining an amperometric linear response for $\mathrm{H}_{2} \mathrm{O}_{2}$ concentration ranging from $5 \mu \mathrm{M}$ to $1 \mathrm{mM}$ with a LOD of $1.4 \mu \mathrm{M}$ [202]. Electrogenerated poly (2-aminophenylbenzimidazole) (poly2AB) and gold nanoparticles on pencil graphite electrode (poly2AB/AuNPs/PGE) has also been used as $\mathrm{H}_{2} \mathrm{O}_{2}$ sensor [203]. AuNPs appeared as homogeneous spherical particles that increased the conductivity of the $\mathrm{P} 2 \mathrm{AB}$ catalyzing the reduction reaction of $\mathrm{H}_{2} \mathrm{O}_{2}$. Amperometric measurements in PBS solution at $\mathrm{pH} 6.5$ revealed a linear response in the range of $60 \mu \mathrm{M}$ to $100 \mathrm{mM}$ with a LOD of $36.7 \mu \mathrm{M}$ of $\mathrm{H}_{2} \mathrm{O}_{2}$. Poly (methylene blue) (PMB), Ag nanocrystals (AgNCs), and graphene carbon spheres (GS) nanocomposite on glassy carbon electrode (Ag/PMB/GS/GCE) were used for hydrogen peroxide detection [204]. GS had a wrinkled texture, showing a rough surface with pores that favor electron transport. The thin PMB layer acted as a mediator adsorbing and binding the $\mathrm{Ag}^{+}$ions. The morphology of AgNCs showed dendriticlike structures. The carbon spheres act as nano-spacers preventing the aggregation of graphene, while poly(MB) benefits the crystals' growth during the reduction of AgNCs. $\mathrm{Ag} / \mathrm{PMB} / \mathrm{GS} / \mathrm{GCE}$ amperometric sensor showed a linear response for $\mathrm{H}_{2} \mathrm{O}_{2}$ concentration ranging from $0.5 \mu \mathrm{M}$ to $1.11 \mathrm{mM}$ with a LOD of $0.15 \mu \mathrm{M}$. The sensor retained $96.5 \%$ of the original value after one week of consecutive measurements. A copolymer of poly (pyrrole-3-carboxylic acid) (PPy3C) with polypyrrole on mesoporous platinum (MPrPt) at a boron-doped diamond electrode (BDD) was used for nonenzymatic, free of oxygen interference sensing of hydrogen peroxide [205]. After Pt deposition, mesoporous and snow-flake-like nanoclusters were formed. Electrodeposited copolymer increased the porosity of the structure allowing molecules to permeate through the polymer film. The PPy3C-PPy/MPrPt/BDD electrode showed an amperometric linear response for $\mathrm{H}_{2} \mathrm{O}_{2}$ concentration from $5 \mu \mathrm{M}$ to $49 \mathrm{mM}$ with a LOD of $2 \mu \mathrm{M}$. The enhancement of the current peak was related to the increased conductivity by the copolymer and the electrocatalytic reduction of $\mathrm{PtO}_{2} / \mathrm{PtO}$.

The ability of the sensors to give an accurate measurement of $\mathrm{H}_{2} \mathrm{O}_{2}$ in the presence of interfering species is fundamental. The interferences usually present in the biomedical samples are $\mathrm{DA}, \mathrm{UA}, \mathrm{KNO}_{2}, \mathrm{KNO}_{3}$, and $\mathrm{AA}$. Chronoamperometric techniques allow for the possibility of good separation between species because each of them has a different potential at which they reduce or oxidize. Enzymatic sensors display high selectivity towards interfering species ensuring the specific reduction of hydrogen peroxide. However, the stabilization of enzymes might be a hard issue to overcome. Enzymes are easily degraded, thus enzyme-less sensor fabrication may also result in an interesting approach. Researchers tackle the loss of selectivity by the lack of an enzyme using conducting polymers composites with e.g., Prussian blue which acts as a more stable artificial enzyme.

Table 1 enlists a series of electrochemical sensors based on conducting polymers for detection of the various important biomarkers reviewed up to this point. Electrode architecture, name of the conducting polymer, synthetic approach, analyte, detection technique, LOD, and linear range are provided as well as the reference where the information is available. 


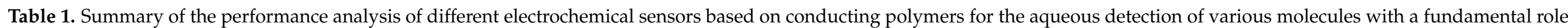
in the human body.

\begin{tabular}{|c|c|c|c|c|c|c|c|}
\hline Electrode Architecture & Conducting Polymer & Synthesis Method & Analytes & $\begin{array}{l}\text { Detection } \\
\text { Technique }\end{array}$ & LOD $(\mu \mathrm{M})$ & Linear Range $(\mu \mathrm{M})$ & Ref. \\
\hline \multicolumn{8}{|c|}{ Dopamine } \\
\hline (PPY)-Ag & Polypyrrole & $\begin{array}{c}\text { Self-assembled/liquid } \\
\text { phase }\end{array}$ & DA & LSV & 0.00005 & 0.00005 to 0.003 & [93] \\
\hline $\begin{array}{c}\text { AuNP-GP- } \\
\text { PEDOT:PSS/GCE }\end{array}$ & PEDOT:PSS & $\begin{array}{c}\text { Self-assembled/liquid } \\
\text { phase }\end{array}$ & DA & DPV & 0.0001 & 0.001 to 300 & {$[119$} \\
\hline $\mathrm{Au}-\mathrm{PDNs}$ & Polydopamine & $\begin{array}{l}\text { Self-assembled/liquid } \\
\text { phase }\end{array}$ & $\begin{array}{l}\text { DA, UA, AA, } \\
\text { tryptophan }\end{array}$ & DPV & 0.0001 & 1 to 160 & {$[128$} \\
\hline OPPy/SDS-CNT & Polypyrrole & $\mathrm{CA}$ & $\mathrm{DA}$ & DPV & 0.000136 & 0.005 to 0.010 & [92] \\
\hline GN/PoP & Poly (o-phenylenediamine) & $\mathrm{CV}$ & DA & SWV & 0.00016 & 0.001 to 150 & {$[103$} \\
\hline $\begin{array}{c}\text { MWCNTs- } \\
\text { COOH/Poly(TB)/GCE) }\end{array}$ & Poly (toluidine blue) & $\mathrm{CV}$ & DA & DPV & 0.00039 & 1 to 300 & {$[127$} \\
\hline ERGO-pEBT/AuNPs & Poly (eriochrome black T) & $\mathrm{CV}$ & $\mathrm{DA}, \mathrm{UA}, \mathrm{AA}$ & DPV & 0.009 & 0.5 to 20 & {$[126$} \\
\hline CD-f-PEDOT: PSS & PEDOT:PSS & Spin coating technique & DA, catechol & DPV & 0.009596 & 0.05 to 200 & {$[118$} \\
\hline $\mathrm{PrGO} / \mathrm{MnO} 2$ & $\begin{array}{c}\text { Poly (3,4- } \\
\text { ethylenedioxythiophene) }\end{array}$ & $\mathrm{CV}$ & DA, UA, AA & DPV & 0.02 & 0.03 to 45 & {$[116$} \\
\hline MWCNTs $/ \mathrm{CeO}_{2}$-PEDOT & $\begin{array}{c}\text { Poly (3,4- } \\
\text { ethylenedioxythiophene) }\end{array}$ & $\begin{array}{c}\text { Self-assembled/liquid } \\
\text { phase }\end{array}$ & DA & DPV & 0.03 & 0.1 to 10 & {$[115$} \\
\hline $\begin{array}{l}\text { AuNPs/PANI-co- } \\
\text { PoAN/GO }\end{array}$ & Poly (aniline-co-o-anisidine) & $\begin{array}{l}\text { Self-assembled/liquid } \\
\text { phase }\end{array}$ & DA & SWV & 0.0334 & 5 to 100 & {$[101$} \\
\hline $\mathrm{pHQ} / \mathrm{AuNPs} / \mathrm{NF}$ & Poly (hydroquinone) & $\mathrm{CV}$ & DA & DPV & 0.0419 & 0.1 to 10 & {$[125$} \\
\hline $\begin{array}{c}\text { GCE/PGBHA-afGQDs- } \\
\mathrm{MnO}_{2}\end{array}$ & $\begin{array}{l}\text { Poly (glyoxal-bis(2-hydro- } \\
\text { xyanil)) }\end{array}$ & $\mathrm{CV}$ & DA & DPV & 0.05 & 0.1 to 100 & {$[124$} \\
\hline
\end{tabular}


Table 1. Cont.

\begin{tabular}{|c|c|c|c|c|c|c|c|}
\hline Electrode Architecture & Conducting Polymer & Synthesis Method & Analytes & $\begin{array}{l}\text { Detection } \\
\text { Technique }\end{array}$ & $\operatorname{LOD}(\mu \mathrm{M})$ & Linear Range $(\mu \mathrm{M})$ & Ref. \\
\hline rGo/Pd@PPy NP & Polypyrrole & $\begin{array}{l}\text { Self-assembled/liquid } \\
\text { phase }\end{array}$ & DA, UA, AA & DPV & 0.056 & 1000 to 15,000 & [89] \\
\hline POMA-Au & Poly (o-methoxyaniline) & $\begin{array}{l}\text { Self-assembled/liquid } \\
\text { phase }\end{array}$ & DA, Folic acid & DPV & 0.062 & 10 to 300 & [100] \\
\hline PEDOT/Au & $\begin{array}{c}\text { Poly (3,4- } \\
\text { ethylenedioxythiophene) }\end{array}$ & $\begin{array}{l}\text { Self-assembled/liquid } \\
\text { phase }\end{array}$ & DA, UA & DPV & 0.07 & 0.15 to 330 & [114] \\
\hline OPPy/ERGO & Polypyrrole & $\mathrm{CV}$ & DA & DPV & 0.2 & 0.4 to 517 & [88] \\
\hline Poly-AHMP & $\begin{array}{l}\text { Poly-4-Amino-6-hydroxy-2- } \\
\text { mercaptopyrimidine }\end{array}$ & $\mathrm{CV}$ & DA, Acetominphen & DPV & 0.2480 & 2.5 to 25 & [104] \\
\hline PEDOT/LSA & $\begin{array}{c}\text { Poly (3,4- } \\
\text { ethylenedioxythiophene) }\end{array}$ & $\mathrm{CV}$ & DA & DPV & 0.26 & 0 to 5 & [113] \\
\hline p-ProH/GCE) & $\begin{array}{l}\text { Poly (procaterol } \\
\text { hydrochloride) }\end{array}$ & $\mathrm{CV}$ & $\mathrm{DA}, \mathrm{UA}$ & SWV & 0.3 & 1 to 100 & [123] \\
\hline PEDOT/IL/GCE & $\begin{array}{c}\text { Poly (3,4- } \\
\text { ethylenedioxythiophene) }\end{array}$ & $\mathrm{CV}$ & DA & $\mathrm{CV}$ & 0.33 & 0.2 to 328 & [117] \\
\hline PEDOT-LSG & $\begin{array}{c}\text { Poly (3,4- } \\
\text { ethylenedioxythiophene) }\end{array}$ & CA & DA & DPV & 0.33 & 1 to 150 & [112] \\
\hline $\mathrm{PT} / \mathrm{Au} / \mathrm{CNT}$ & Polythiophene & $\begin{array}{l}\text { Self-assembled/liquid } \\
\text { phase }\end{array}$ & DA & DPV & 0.69 & 1 to 10 & [120] \\
\hline $\mathrm{PPy} / \mathrm{C \# SiO} 2$ & Polypyrrole & $\begin{array}{l}\text { Self-assembled/liquid } \\
\text { phase }\end{array}$ & DA & DPV & 0.76 & 1 to 100 & [91] \\
\hline PPy-S $\beta C D$ & Polypyrrole & CA & DA & CA & 1 & Not reported & [87] \\
\hline
\end{tabular}


Table 1. Cont.

\begin{tabular}{|c|c|c|c|c|c|c|c|}
\hline Electrode Architecture & Conducting Polymer & Synthesis Method & Analytes & $\begin{array}{l}\text { Detection } \\
\text { Technique }\end{array}$ & LOD $(\mu \mathrm{M})$ & Linear Range $(\mu \mathrm{M})$ & Ref. \\
\hline Poly phenol red/GCE & Poly phenol red & $\mathrm{CV}$ & $\begin{array}{c}\text { DA, } \\
\text { Acetaminophen }\end{array}$ & DPV & 1.6 & 20 to 160 & [122] \\
\hline PANI-Au & Polyaniline & $\begin{array}{l}\text { Self-assembled/liquid } \\
\text { phase }\end{array}$ & DA & DPV & 5.25 & 7 to 100 & [98] \\
\hline PS/MCPE & Poly (sudan III) & $\mathrm{CV}$ & DA & DPV & 9.3 & 10 to 90 & [121] \\
\hline MIPs/ZNTs/FTO glass & Polypyrrole & $\mathrm{CV}$ & DA & DPV & $\begin{array}{c}\text { Not } \\
\text { reported }\end{array}$ & 0.02 to 5 & {$[90]$} \\
\hline \multicolumn{8}{|c|}{ Epinephrine } \\
\hline EB-Ppy-BSA/GCE & Polypyrrole & Self assemble & $\mathrm{EP}$, tyrosine & SWV & 0.0074 & 0.1 to 400 & [129] \\
\hline (FA)/AuNP/GCE & poly-fuchsine acid & $\mathrm{CV}$ & $\mathrm{EP}, \mathrm{AA}, \mathrm{UA}$ & DPV & 0.01 & 0.5 to 792.7 & [135] \\
\hline mpg-C3N4/PANI/CdO & Polyaniline & CA & $\begin{array}{c}\text { EP, PR, CFX, } \\
\text { mefenamic acid }\end{array}$ & DPV & 0.011 & 0.05 to 80 & [131] \\
\hline PAPBA(MIPs)/MWCNTs & $\begin{array}{c}\text { Poly (3- } \\
\text { aminophenylboronic acid }\end{array}$ & $\mathrm{CV}$ & $\mathrm{EP}$ & DPV & 0.035 & 0.2 to 800 & [133] \\
\hline $\mathrm{Au} / \mathrm{ZnO} / \mathrm{Ppy} / \mathrm{RGO}$ & Polypyrrole & $\mathrm{CA}$ & EP, AA, UA & DPV & 0.058 & 0.6 to 500 & [130] \\
\hline MIP/AuNP & $\begin{array}{l}\text { Poly (3-Thiophene boronic } \\
\text { acid) }\end{array}$ & $\mathrm{CV}$ & $\mathrm{EP}$, tyrosine & DPV & 0.076 & 0.09 to 100 & [134] \\
\hline MWCNT-PANI-TiO2 & Polyaniline & Self assemble & EP, tyrosine & DPV & 0.16 & 4.9 to 76.9 & [132] \\
\hline PBCB/graphene/GCE & Poly (brilliant cresyl blue) & $\mathrm{CV}$ & $\mathrm{EP}$ & $\mathrm{CV}$ & 0.24 & 1 to 1000 & [136] \\
\hline \multicolumn{8}{|c|}{ Serotonin } \\
\hline $\mathrm{p}(\mathrm{P} 3 \mathrm{CA}) / \mathrm{PGE}$ & $\begin{array}{l}\text { Poly (pyrrole-3-carboxylic } \\
\text { acid) }\end{array}$ & $\mathrm{CV}$ & SER & AdSDPV & 0.0025 & 0.01 to 1 & [137] \\
\hline $\begin{array}{l}\text { AuNPs@rGO/pTBA } \\
\text { Pd(C2H4N2S2)2) }\end{array}$ & $\begin{array}{c}\text { Poly } \\
\text { 2,2:5,2-terthiophene-3-(p- } \\
\text { benzoic acid) }\end{array}$ & $\mathrm{CV}$ & SER, DA & SWV & 0.0025 & 0.02 to 20 & [142] \\
\hline
\end{tabular}


Table 1. Cont

\begin{tabular}{|c|c|c|c|c|c|c|c|}
\hline Electrode Architecture & Conducting Polymer & Synthesis Method & Analytes & $\begin{array}{l}\text { Detection } \\
\text { Technique }\end{array}$ & $\operatorname{LOD}(\mu \mathrm{M})$ & Linear Range $(\mu \mathrm{M})$ & Ref. \\
\hline GR/p-AHNSA/SPCs & $\begin{array}{l}\text { Poly 4-amino-3-hydroxy1- } \\
\text { naphthalenesulfonic acid }\end{array}$ & $\mathrm{CV}$ & SER, DA & SWV & 0.003 & 0.05 to 150 & [139] \\
\hline $\begin{array}{l}\text { MWCNTs-CS-poly ( } \\
\text { p-ABSA)/GCE }\end{array}$ & $\begin{array}{l}\text { Poly (p-amino benzene } \\
\text { sulfonic acid) }\end{array}$ & $\mathrm{CV}$ & SER & DPV & 0.08 & 0.1 to 100 & [138] \\
\hline Fe3O4-MWCNT-poly (BCG & Poly (bromocresol green & $\mathrm{CV}$ & SER & DPV & 0.08 & 0.5 to 100 & [140] \\
\hline rGO-PEDOT/PSS & PEDOT:PSS & Self assemble & SER & DPV & 0.1 & 1 to 10 & {$[141]$} \\
\hline \multicolumn{8}{|c|}{ Uric Acid } \\
\hline Ox-PEDOT-nf/PGE & $\begin{array}{c}\text { Poly (3,4 } \\
\text { ethylenedioxythiophene) }\end{array}$ & $\mathrm{CV}$ & UA & DPV & 0.0013 & 0.01 to 20 & [147] \\
\hline $\mathrm{MIP} / \mathrm{RGO}$ & $\begin{array}{c}\text { 2-amino-5-mercapto-1, } 3 \\
\text { 4-thiadiazole }\end{array}$ & $\mathrm{CV}$ & UA and tyrosine & DPV & 0.0032 & 0.01 to 100 & [149] \\
\hline PSA/ERCG/GCE & Poly (sulfosalicylic acid) & $\mathrm{CV}$ & UA and isoniazid & DPV & 0.012 & 0.02 to 15 & [150] \\
\hline$\alpha-\mathrm{Fe}_{2} \mathrm{O}_{3} / \mathrm{PAn} \mathrm{NTs}$ & polyaniline & $\begin{array}{c}\text { Self-assembled/liquid } \\
\text { phase }\end{array}$ & UA & DPV & 0.038 & 0.01 to 5 & [145] \\
\hline 6-TG/GCE & 6-thioguanine & $\mathrm{CV}$ & $\begin{array}{c}\text { DA, UA, XA and } \\
\text { HXA }\end{array}$ & DPV & 0.06 & 2 to 1600 & [152] \\
\hline AuNPs/poly-TrB/GCE & $\begin{array}{c}\text { Au-nanoparticles/poly- } \\
\text { Trypan } \\
\text { Blue }\end{array}$ & $\mathrm{CV}$ & $\begin{array}{l}\text { UA, cysteine and } \\
\text { tyrosine }\end{array}$ & DPV & 0.07 & 1 to 550 & [151] \\
\hline POMANS-MWCNT/GPE & Polyortho-methoxyaniline & $\begin{array}{l}\text { Self-assembled/liquid } \\
\text { phase }\end{array}$ & UA and folic acid & LSV & 0.157 & 0.6 to 52 & [146] \\
\hline PEDOT/GO/ITO & $\begin{array}{c}\text { Poly (3,4 } \\
\text { ethylenedioxythiophene) }\end{array}$ & $\begin{array}{l}\text { Self-assembled/liquid } \\
\text { phase }\end{array}$ & UA & DPV & 0.75 & 2 to 1000 & [148] \\
\hline p-TPP/PPy/GO & polypyrrole & $\begin{array}{l}\text { Self-assembled/liquid } \\
\text { phase }\end{array}$ & UA & DPV & 1.15 & 5 to 200 & [144] \\
\hline
\end{tabular}


Table 1. Cont.

\begin{tabular}{|c|c|c|c|c|c|c|c|}
\hline Electrode Architecture & Conducting Polymer & Synthesis Method & Analytes & $\begin{array}{l}\text { Detection } \\
\text { Technique }\end{array}$ & LOD $(\mu \mathrm{M})$ & Linear Range $(\mu \mathrm{M})$ & Ref. \\
\hline \multicolumn{8}{|c|}{ Ascorbic Acid } \\
\hline $\begin{array}{c}\text { Graphite/PAMAN-CNT/p( } \\
\text { Neutral red) }\end{array}$ & Neutral Red & $\mathrm{CV}$ & AA & CA & 0.053 & $0.2-2500$ & [156] \\
\hline GCE/NiNP/CNT/PANI & PANI & $\mathrm{CV}$ & AA & DPV & 0.1 & 1.0 to 450 & [154] \\
\hline GCE/PGBHA & $\begin{array}{c}\text { Poly } \\
\text { (glyoxal-bis(2-hydroxyanil)) }\end{array}$ & $\mathrm{CV}$ & AA & DPV & 0.26 & 1 to 8 & [159] \\
\hline GCE/PPy@Celluloce & PPy & Homogeneous synthesis & $\mathrm{AA}$ & DPV & 0.75 & 10 to 50 & [153] \\
\hline GCE/CNT-CA/PEDOT & PEDOT & CA & AA & CA & 4.2 & 0.1 to $20 \mathrm{mM}$ & [158] \\
\hline CPE/polyamic acid-AuNP & Polyamic acid derivates & Homogeneous synthesis & $\mathrm{AA}$ & $\mathrm{CA}$ & 18.5 & 10 to $1000 \mathrm{mM}$ & [155] \\
\hline GCE/PEDOT & PEDOT & $\mathrm{CV}$ & $\mathrm{AA}$ & $\mathrm{CV}$ & 45 & 30 to $500 \mathrm{mM}$ & [157] \\
\hline \multicolumn{8}{|c|}{ Glucose } \\
\hline GC/PEDOT-CNT-Cu2ONP & PEDOT & Homogeneous synthesis & Glucose & $\mathrm{CA}$ & 0.040 & 0.495 to $374 \mathrm{mM}$ & [187] \\
\hline GC/PEDOT-GO/CuNP & PEDOT & $\mathrm{CV}$ & Glucose & CA & 0.047 & 0.1 to 1300 & [186] \\
\hline $\begin{array}{l}\text { Au/MWCNT/Pdplate/ } \\
\text { GOx-PAB-PdNP/CS }\end{array}$ & Poly (3-anileneboronic acid) & $\mathrm{CV}, \mathrm{CA}$ & Glucose & $\mathrm{CA}$ & 0.1 & 2 to 4500 & [168] \\
\hline GC/PANI-NiONP & PANI & $\begin{array}{l}\text { Homogeneus } \\
\text { preparation }\end{array}$ & Glucose & $\mathrm{CA}$ & 0.19 & Up to 100 & [179] \\
\hline SPCE/AuNP/pTBA-MICP & Poly (tertiophene), & $\mathrm{CV}$ & Glucose & Potentiometric & 0.19 & 0.32 to 1000 & [185] \\
\hline $\mathrm{GC} / \mathrm{pPD} / \mathrm{CuNP}$ & Poly (o-phenylenediamine) & $\mathrm{CV}$ & Glucose & $\mathrm{Ca}$ & 0.25 & 5.0 to 1600 & {$[179]$} \\
\hline Graphite/pPy/Ni(OH)2NP & $\mathrm{pPy}$ & CA & Glucose & CA & 0.3 & 1 to $4860 \mathrm{mM}$ & [175] \\
\hline FTO/AnB/AuNP & Poly (aniline blue) & $\mathrm{CV}$ & Glucose & $\mathrm{CA}$ & 0.4 & 0 to 50 & [178] \\
\hline GC/PEDOT.PSS/NiNP & PEDOT-PSS & $\begin{array}{l}\text { controlled potential } \\
\text { coulometry }\end{array}$ & Glucose & $\mathrm{CA}$ & 0.69 & 2.5 to 1115 & [184] \\
\hline
\end{tabular}


Table 1. Cont.

\begin{tabular}{|c|c|c|c|c|c|c|c|}
\hline Electrode Architecture & Conducting Polymer & Synthesis Method & Analytes & $\begin{array}{l}\text { Detection } \\
\text { Technique }\end{array}$ & $\operatorname{LOD}(\mu \mathrm{M})$ & Linear Range $(\mu \mathrm{M})$ & Ref. \\
\hline GC/PEDOT-GO/NiNP & PEDOT & $\mathrm{CV}$ & Glucose & CA & 0.8 & 1 to 5100 & [183] \\
\hline Pt/PANI-GRA/GS-GOx & PANI & $\mathrm{CV}$ & Glucose & CA & 2.8 & 10 to 1480 & [166] \\
\hline GC/pPy-AgNP & $\mathrm{pPy}$ & $\begin{array}{l}\text { Homogeneos } \\
\text { polymerization }\end{array}$ & Glucose & CA & 3.6 & 25 to 2500 & [174] \\
\hline $\begin{array}{l}\text { GE/CNT-COOH- } \\
\text { pAT/AuNP }\end{array}$ & Poly (2-aminothiophenol) & chemical polymerization & Glucose & LSV & 3.7 & 100 to 30,000 & [177] \\
\hline PGE/PAMAN/pMB-GHD & Poly (methylene blue) & $\mathrm{CV}$ & Glucose & $\begin{array}{l}\text { flow injection } \\
\text { analysis }\end{array}$ & 4.0 & 0.001 to 1.0 & [173] \\
\hline GC/pEDOT-PBA & Poly (EDOT-PBA) & $\mathrm{CV}$ & Glucose & EIS & 5.0 & 100 to 50,000 & [182] \\
\hline $\begin{array}{l}\text { GC/PANI-PVP-AuNP/ } \\
\text { GOx-Nafion }\end{array}$ & PANI-PVP & $\mathrm{CV}$ & Glucose & CA & 10.0 & 0.05 to 2.25 & [165] \\
\hline ITO/pPD/AgNP & Poly (o-phenylenediamine) & $\mathrm{CV}$ & Glucose & CA & 12.0 & 150 to 13,000 & [188] \\
\hline ITO/PP3C-GO/GOx & $\begin{array}{l}\text { Poly (pyrrole-3-carboxilic } \\
\text { acid) }\end{array}$ & $\mathrm{CV}$ & Glucose & CA & 50.0 & 1 to $\mathrm{mM}$ & [163] \\
\hline GC/PANI/AuNP & PANI & $\begin{array}{l}\text { Drop-cast of solution } \\
\text { polymer }\end{array}$ & Glucose & EIS & 100.0 & 300 to 1000 & [176] \\
\hline $\begin{array}{l}\text { G/p(EDOT-PdBPI)n- } \\
\text { (HKCN)m-GOx }\end{array}$ & PEDOT & $\mathrm{CV}$ & Glucose & CA & 180.0 & 250 to 2500 & [170] \\
\hline PGE/PEDOT.PSS-CuONP & PEDOT.PSS & $\begin{array}{l}\text { Homogeneous synthesis } \\
\text { and drop-cast }\end{array}$ & Glucose & CA & 230.0 & Up to $10 \mathrm{mM}$ & [181] \\
\hline Pt/PEDOT-PAA-GOx & PEDOT & CA & Glucose & CA & 290.0 & 960 to 3000 & [171] \\
\hline $\begin{array}{l}\text { Pt/PEDOT-BSA/AuNP- } \\
\text { GOx }\end{array}$ & PEDOT & $\mathrm{CV}$ & Glucose & CV, LSV, CA & $\begin{array}{l}\text { Not } \\
\text { reported }\end{array}$ & 0.416 to $50 \mathrm{mM}$ & [169] \\
\hline Pt/PANI/GOx/PU/E-PU & PANI & CA & Glucose & CA & $\begin{array}{l}\text { Not } \\
\text { reported }\end{array}$ & $0-20 \mathrm{mM}$ & [164] \\
\hline GC/PHMeDOT & $\begin{array}{l}\text { Poly (hydroxymethyl-3,4- } \\
\text { ethylendioxythiophene) }\end{array}$ & CA & Glucose & CA & $\begin{array}{c}\text { Not } \\
\text { reported d }\end{array}$ & $1-9 \mathrm{mM}$ & [180] \\
\hline
\end{tabular}


Table 1. Cont.

\begin{tabular}{|c|c|c|c|c|c|c|c|}
\hline Electrode Architecture & Conducting Polymer & Synthesis Method & Analytes & $\begin{array}{l}\text { Detection } \\
\text { Technique }\end{array}$ & LOD $(\mu \mathrm{M})$ & Linear Range $(\mu \mathrm{M})$ & Ref. \\
\hline \multicolumn{8}{|c|}{ Hydrogen Peroxide } \\
\hline $\begin{array}{c}\text { Nafion/HRP/ATh- } \gamma- \\
\text { PGA/GE }\end{array}$ & ATh- $\gamma$-PGA & $\mathrm{CV}$ & $\mathrm{H}_{2} \mathrm{O}_{2}$ & DPV & 0.0000030 & $0.00001-0.010$ & [197] \\
\hline \multicolumn{2}{|c|}{ HRP/AuNPs/rGO/PEDOT:PSS/SPGE PEDOT:PSS } & $\mathrm{CV}$ & $\mathrm{H}_{2} \mathrm{O}_{2}$ & $\mathrm{CA}$ & 0.08 & $5-400$ & [196] \\
\hline $\mathrm{Ag} / \mathrm{PMB} / \mathrm{GS} / \mathrm{GCE}$ & PMB & $\mathrm{CV}$ & $\mathrm{H}_{2} \mathrm{O}_{2}$ & $\mathrm{CA}$ & 0.15 & $0.5-1112$ & [204] \\
\hline PEDOT/PBNPs/Pt & PEDOT & SV & $\mathrm{H}_{2} \mathrm{O}_{2}$ & CA & 1.4 & $5-1000$ & [202] \\
\hline PPy3C-PPy/MPrPt/BDD & РРузС-РРy & $\mathrm{CV}$ & $\mathrm{H}_{2} \mathrm{O}_{2}$ & $\mathrm{CA}$ & 2.0 & $5-49,000$ & [205] \\
\hline $\begin{array}{c}\text { SBP/poly } \\
(\text { EGDE-AA-ANI)/GCE }\end{array}$ & PANI & radical polymerization & $\mathrm{H}_{2} \mathrm{O}_{2}$ & CA & 2.2 & $5.0-50$ & [199] \\
\hline HRP/PAN-PNMThH & PAN-PNMThH & $\mathrm{CV}$ & $\mathrm{H}_{2} \mathrm{O}_{2}$ & $\mathrm{CA}$ & 3.2 & $5-60,000$ & [198] \\
\hline poly2AB/AuNPs/PGE & poly $2 \mathrm{AB}$ & $\mathrm{CV}$ & $\mathrm{H}_{2} \mathrm{O}_{2}$ & CA & 36.7 & $60-100,000$ & [203] \\
\hline
\end{tabular}




\subsection{Diverse Pharmaceuticals}

\subsubsection{Metronidazole (MNZ)}

MNZ is a nitro-compound used for treating diseases caused by protozoa or anaerobic bacteria [206]. This nitro-compound was sensed with a duplex molecularly imprinted polymer (DMIP) hybrid film composed of poly (anilinomethyltriethoxysilane) (poly (AMTEOS)) and an imprinted polysiloxane layer on a carbon paste electrode (DMIP/CPE) [207]. Figure 16 shows a schematic preparation of DMIP/CPE for sensing of MNZ. Poly (AMTEOS) was electrogenerated at the CPE by cyclic voltammetry. Then, a solution containing 3-aminopropyltriethoxysilane (APTMS), tetraethyl orthosilicate (TEOS), 2-ethoxyethanol, and MNZ, was drop-cast onto the modified electrode, where triethoxysilyl groups were hydrolyzed forming a MIP film. DMIP/CPE exhibited a rough surface, because of the formation of imprinted MNZ cavities, which increased the surface area. Electrocatalytic activity and recognition were enhanced due to (i) the amino group from APTMS that forms hydrogen bonds with the oxygen or nitrogen atom in MNZ, and (ii) the phenyl units of the conductive polymer with " $\pi-\pi$ stacking" interaction with the aromatic heterocycle of MNZ. Under optimized conditions, the reduction peak currents were linearly proportional to the MNZ concentrations in the range from $0.4 \mu \mathrm{M}$ to $0.2 \mathrm{mM}$ with a LOD of $91 \mathrm{nM}$ by using a DPV sensor.

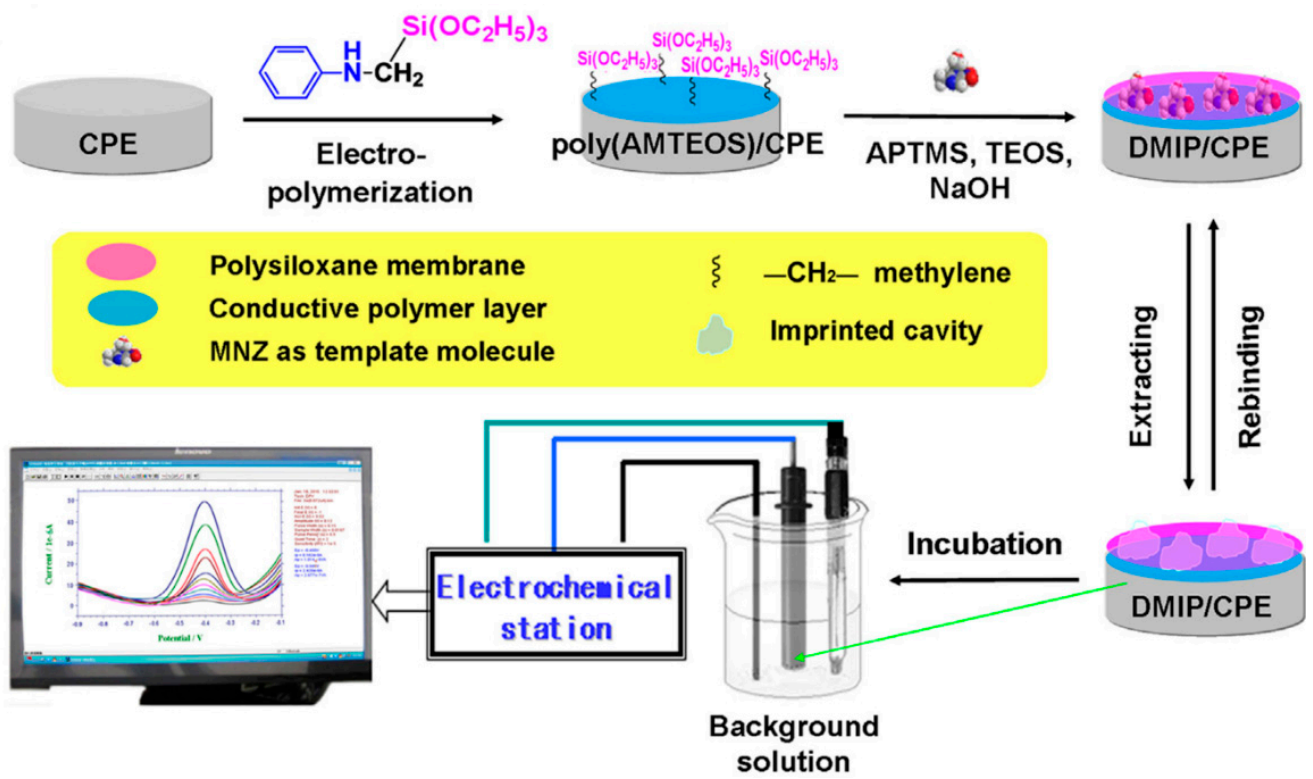

Figure 16. Schematic illustration for the preparation of duplex molecularly imprinted polymer/carbon paste electrodes (DMIP/CPE). Modified with permission from [207]. Copyright 2016 Elsevier.

Another electrode based on molecularly imprinted polymer was reported with gold nanoparticles for MNZ sensing [208]. A suspension of AuNPs and chitosan was dropped on the surface of the GCE. The modified AuNPs/GCE was immersed in an aqueous solution containing $\mathrm{CuSO}_{4}, \mathrm{H}_{2} \mathrm{SO}_{4}, \mathrm{NaCl}, \mathrm{MNZ}$, and melamine, where electrodeposition was carried by cyclic voltammetry. Then, MNZ was extracted in Britton-Robinson buffer with multiple cycles. The MIP/AuNPs/GCE showed folded polymeric layers before MNZ extraction (see Figure 17a). After the template was removed, a rougher morphology was observed (Figure 17b). The polymeric film emulates the microenvironment for the enzymatic reaction, which is better catalyzed in the large surface area of the polymer. Using $\mathrm{DPV}$, the response to metronidazole was linear in the concentration range of $0.5 \mu \mathrm{M}$ to $1000 \mu \mathrm{M}$ with a LOD of $0.12 \mu \mathrm{M}$. 


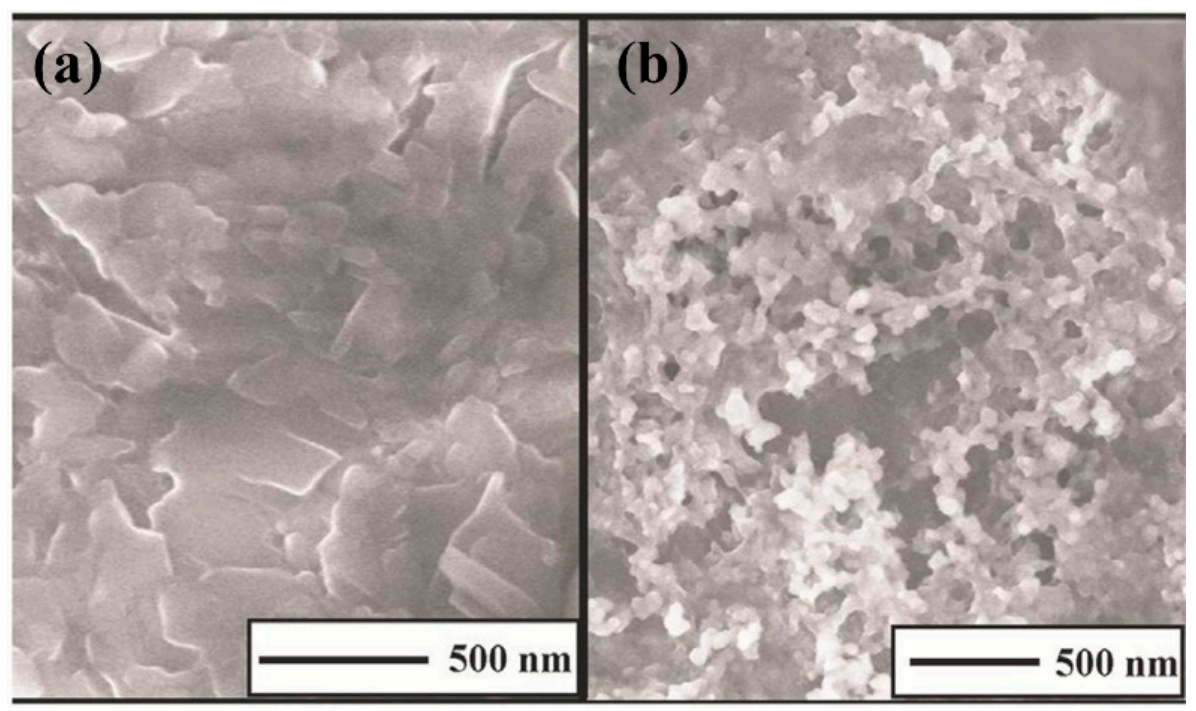

Figure 17. Micrograph of molecularly imprinted polymers/golf nanoparticles/glassy carbon electrodes (MIP/AuNPs/GCE) microstructure (a) before and (b) after metronidazole extraction. Modified with permission from [208]. Copyright 2015 Elsevier.

Similarly, MNZ was determined with a three-dimensional graphene-like carbon architecture (3D-HPG) and polythionine (PTH) modified glassy carbon electrode [209]. The PTH-modified GCE was prepared by cyclic voltammetry in $\mathrm{H}_{2} \mathrm{SO}_{4}$ solution containing thionine. The 3D-HPG suspension was cast on the surface of the modified electrode and dried under an infrared lamp. After the drop-casting, a continuous 3D porous network with macropores was observed. The PTH film increased the electrical conductivity and the 3D-HPG accelerated the electron transfer rate due to its large high surface area, greatly improving the electrochemical sensing with a LOD of $1 \mathrm{nM}$. The reusability was determined by seven successive measurements at the electrode showing an RSD of 7.3\%.

\subsubsection{2-Amino-9-[(2-Hydroxyethoxy) Methyl]-6,9-Dihydro-3H-Purin-6-One (Acyclovir)}

Acyclovir (ACV) is a synthetic deoxyguanosine analog used as an antiviral drug [210] for the treatment of herpes simplex, herpes zoster infections, primary genital herpes, herpetic encephalitis [211]. Acyclovir triphosphate also prevents DNA synthesis by acting as a chain terminator [212]. A sensitive sensor made of poly-eriochrome black T, (PEBT) deposited on a glassy carbon electrode (PEBT/GCE) was used for detecting Acyclovir by DPV [213]. The PEBT film was potentiodynamically electrogenerated on a GCE surface in $\mathrm{NaOH}$ solution. After deposition, uniform branch-like structures were observed enlarging the effective electrode surface approximately 2.4 times. The peak current was linearly related to Acyclovir concentration in an acetate buffer solution with a LOD of $12 \mathrm{nM}$. An RSD of $2.3 \%$ was obtained for ten successive measurements of $0.5 \mathrm{mM} \mathrm{ACV}$. A sensor based on MWCNTs, titanium dioxide nanoparticles $\left(\mathrm{TiO}_{2} \mathrm{NPs}\right)$, and electrogenerated polycatechol (PCC) as a polymeric matrix into a nanoporous GCE was developed for Acyclovir determination [214]. The nanoporous GCE (see Figure 18b) showed a rougher surface compared to the standard GCE (see Figure 18a). Increased porosity was observed after PCC deposition (see Figure 18c) showing randomly tangled wire-like carbon nanotubes and granular morphology of $\mathrm{TiO}_{2} \mathrm{NPs}$ (see Figure 18d). The polymeric film improved the catalytic activity toward the ACV oxidation due to its higher surface area and conductivity. The response of the electrode to the ACV concentration using DPASV was linear from $0.03 \mu \mathrm{M}$ to $1.0 \mu \mathrm{M}$ with a LOD of $10 \mathrm{nM}$. An overoxidized PPy film was electrochemically deposited on carboxylate carbon nanotubes (CNT-CA) modified glassy carbon electrode from an aqueous solution of pyrrole and tiron [215]. Micrographs showed thin PPy film densely covered CNTs as a nanosized backbone improving the surface electron transfer. A tenfold larger current signal was achieved for ACV with $\mathrm{CV}$ with respect to the bare 
GC electrode. This modified electrode was used for the determination of ACV content in tablet and ampule preparations resulting in an acceptable accuracy of $104.9 \%$ and a LOD of $10 \mathrm{nM}$.

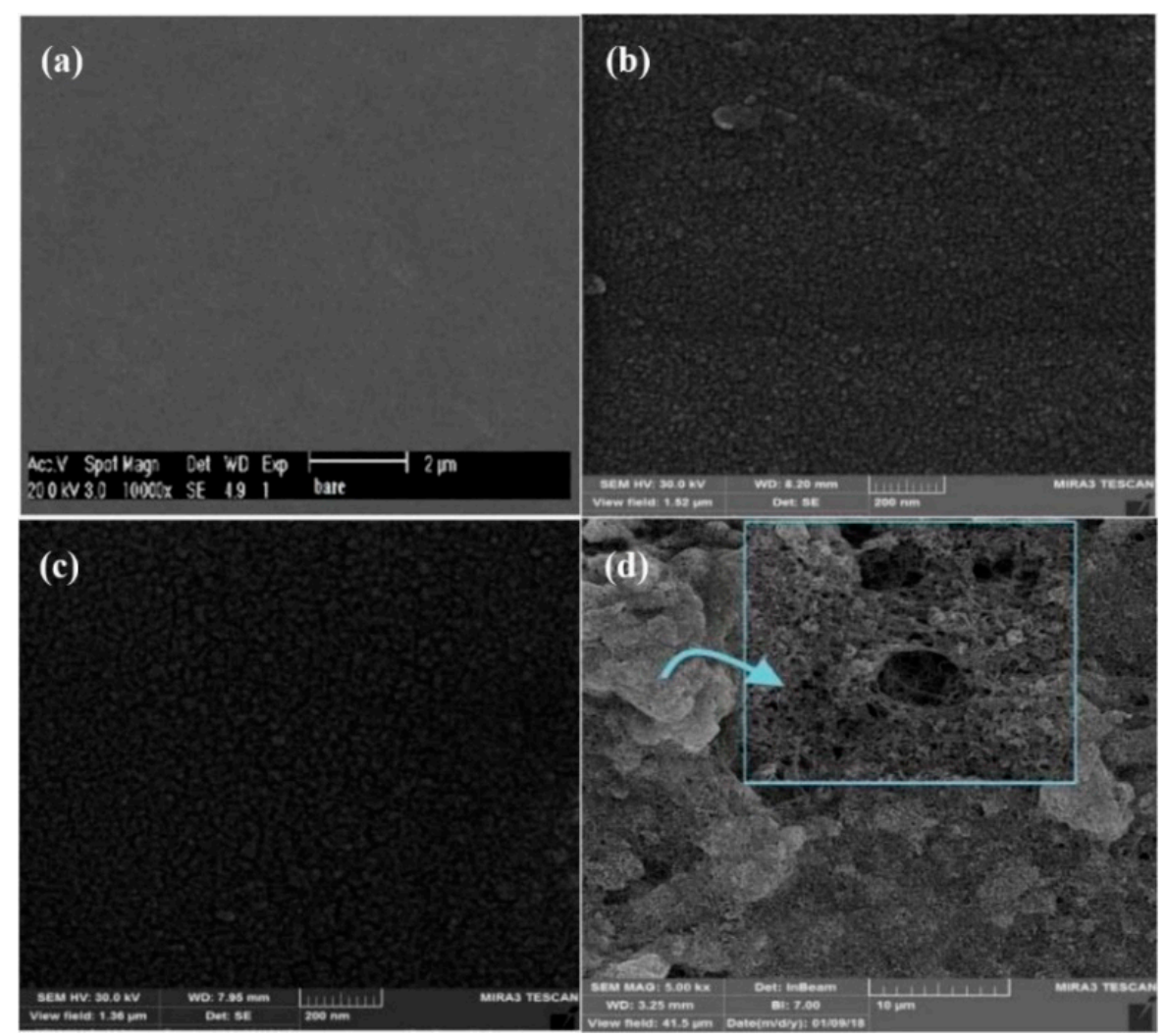

Figure 18. FESEM images of (a) bare standard GCE, (b) nanoporous GCE, (c) PCC/nanoporous GCE and (d) CS$\mathrm{MWCNTs}+\mathrm{TiO}_{2} \mathrm{NPs} / \mathrm{PCC} /$ nanoporous GCE. Reproduced with permission from [214]. Copyright 2018 Electrochemical Society, Inc.

\subsubsection{Ciprofloxacin (CFX)}

CFX is a drug widely used in the treatment of numerous bacterial diseases such as pulmonary, respiratory [216], skin, urinary, ocular, and digestive infections [217]. A novel sensor based on anionic surfactant SDS, and polymer-modified on CPE has been developed for CFX sensing [218]. Poly (evans blue) monomer was electrodeposited by cyclic voltammetry on CPE followed by SDS immobilization obtaining SDS/PEB/CPE sensor. The pristine surface contained irregular flake structures from the graphite paste (see Figure 19a). After the polymeric film was added, the surface turned more uniform and regular (see Figure 19b). Whereas at the SDS/PEB/CPE surface, the absorbed surfactant molecules showed globular structures homogeneously distributed on the surface (see Figure 19c). The synergetic effect of poly (Evans blue) and SDS catalyzed the reaction resulting in a LOD of $0.183 \mu \mathrm{M}$ for CFX. The repeatability was tested by recording the CV outcome for five times at the same electrode giving an RSD of $1.77 \%$. A highly selective electrode based on reduced GO and electrogenerated poly-phenol red (PPR) was designed for CFX detection [219]. The rGO/PPR composite exhibited both characteristics, in which a spongy sheet-like polymer structure was covered by wrinkled rGO nanosheets. The porosity observed in the rGO/PPR film increased the total surface area because of the electrostatic interactions between unoxidized oxygen atoms and the conducting polymer. Under optimal conditions, current response showed a linear relationship for CFX concentration ranging from $50 \mathrm{nM}$ to $400 \mu \mathrm{M}$ with a low LOD of $2 \mathrm{nM}$. 


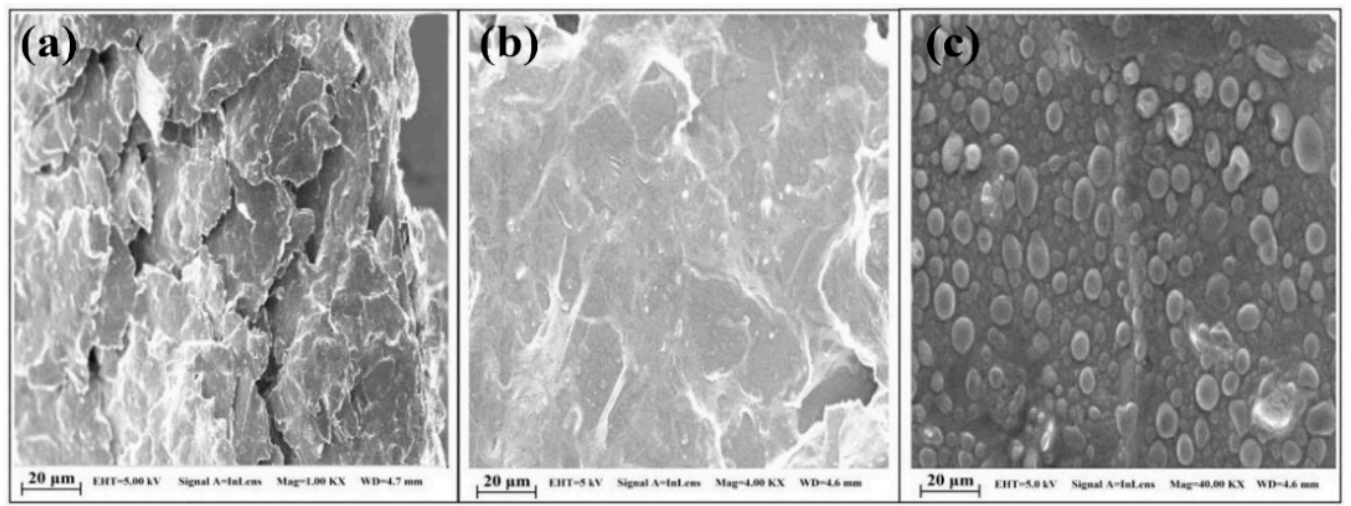

Figure 19. FE-SEM micrographs of (a) CPE, (b) PEB/CPE and (c) SDS/PEB/CPE. Reproduced with permission from [218]. Copyright 2019 Wiley-Blackwell Publishing Ltd.

\subsubsection{7- $\beta$-Estradiol (E2)}

E2 and other natural and synthetic compounds can mimic endogenous hormones [220]. They can interfere with the proper functioning of the hormonal, immune, and nervous systems of mammals [221]. Zhang et al. fabricated a polymeric/enzymatic biosensor for sensing E2 with electrodeposited poly (4,7-bis(5-(3,4-ethylenedioxythiophene)thiophen2-yl)benzothiadiazole) (Pol) and HRP onto platinum electrode [222]. The Pol/Pt surface showed uniformly distributed granular structures. The formed pores allowed the enzyme to anchor and maintain its catalytic activity. The sensor was effective in the E2 concentration range from $0.1 \mu \mathrm{M}$ to $200 \mu \mathrm{M}$ with a LOD of $105 \mathrm{nM}$. The polymer improved the reaction in two ways (i) acting as an electron mediator increasing the electron transfer between the enzyme's active center and the electrode surface, and (ii) creating an appropriate microenvironment to immobilize the protein. Poly (3,6-diamino-9-ethylcarbazole) based molecularly imprinted polymer electrode developed by Liu et al. showed to be an ultrasensitive and selective sensor for detecting $17-\beta$-estradiol even at attomolar concentrations $\left(\mathrm{aM}, 10^{-18} \mathrm{M}\right)$ [223]. The electrodeposition of the monomer (3,6-diamino-9-ethylcarbazole) was carried out by cyclic voltammetry in a mixed solvent solution of ethanol and acetate buffer containing the template (17- $\beta$-estradiol). Removal of the template was made by washing in a stirred solution of $\mathrm{H}_{2} \mathrm{SO}_{4}$ / ethanol. The surface was observed to be rough with micro islands of poly (3, 6-diamino-9-ethylcarbazole) working as active sites for the recognition of E2. A linear relationship was found between the $R_{\mathrm{ct}}$ value of the EIS response and the logarithm of E2 concentrations (see Figure 20a). The quantification of E2 showed a wide linear range from $1 \mathrm{aM}$ to $10 \mu \mathrm{M}$ (see Figure 20b) with an exceptionally low LOD of $0.36 \mathrm{aM}$. The repeatability of the MIP sensor in $100 \mathrm{aM}$ E2 for 5 times gave an RSD of $6.96 \%$.
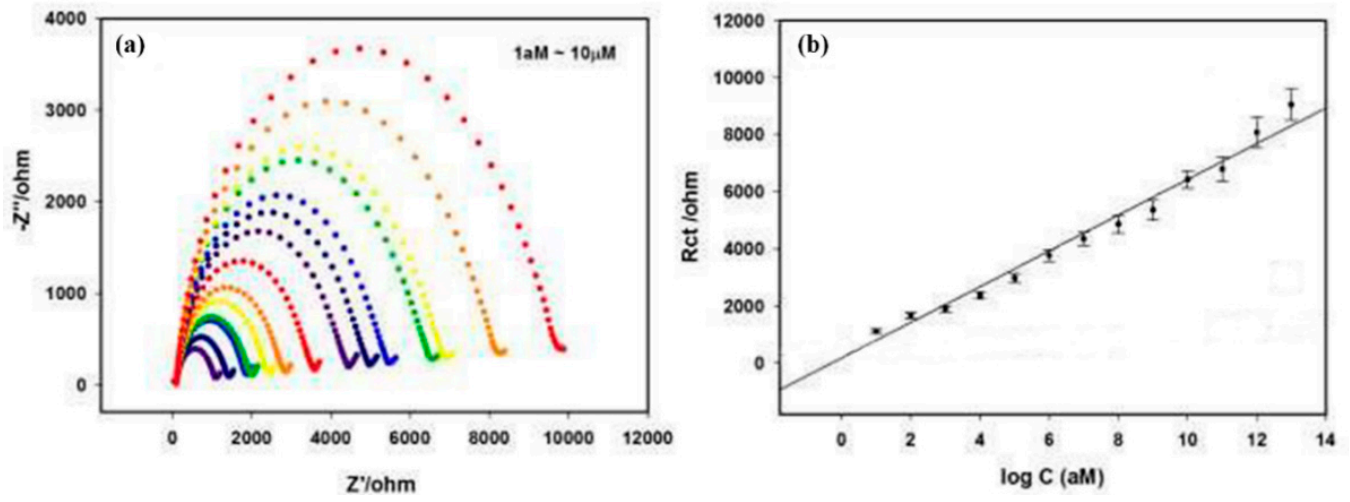

Figure 20. (a) EIS response of the MIP sensor towards 17- $\beta$-estradiol in the concentration of 1 aM to $10 \mu \mathrm{M}$. (b) Calibration curve of the $R_{c t}$ values versus the logarithm concentration of 17- $\beta$-estradiol. Modified with permission from [223]. Copyright 2018 Elsevier. 


\subsubsection{Paracetamol (PR)}

PR or acetaminophen (N-acetyl-p-aminophenol) is an effective analgesic and antipyretic agent is one of the most commonly used medications worldwide [224,225]. Normally, is a safe analgesic agent, but excessive and long-term usage may lead to the accumulation of toxic metabolites, which leads to liver and kidney damage [226]. Electrochemical methods for PR determination are selective, rapid, low cost, and easy in handling in contrast with spectrometry, chromatography, or mass methods [227]. Different dyes were electrodeposited over carbon electrode surfaces as conductive polymeric films for the fabrication of PR electrochemical sensors. A glassy carbon electrode modified with Prussian blue (PB) and a molecularly imprinted polypyrrole was developed for the sensitive determination of PR [228]. PB film was electrodeposited by cyclic voltammetry in an $\mathrm{HCl}$ solution containing $\mathrm{FeCl}_{3} \cdot 6 \mathrm{H}_{2} \mathrm{O}, \mathrm{K}_{3}\left[\mathrm{Fe}(\mathrm{CN})_{6}\right]$, and $\mathrm{KCl}$. The activation of the film was carried out in the same solution without the iron species. PB/GCE was immersed in a solution with pyrrole and PR for potentiodynamically deposition onto the surface. PR was extracted in PBS containing $\mathrm{KCl}$. PB film showed irregularly shaped crystals suited in nanoclusters. Using DPV measurements, it was found that the addition of PR not only increased the peak current of PR oxidation but also decreased the current for the PB signal due to partial blocking of the channels. A linear relation was found between the ratio of the currents and the PR concentration in the range of $1.0 \mathrm{nM}-0.1 \mathrm{mM}$ with a LOD of $0.53 \mathrm{nM}$ for PR. A voltammetric study of PR was developed using an electrogenerated poly (rhodamine B)-modified CPE [229]. The modified electrode showed a good selectivity and sensitivity with a CV linear response for PR concentration ranging from $20 \mu \mathrm{M}$ to $90 \mu \mathrm{M}$ and a LOD of $2.2 \mu \mathrm{M}$. Poly (rhodamine B) accelerates the electrochemical reaction and reduces the overpotential which improves the oxidation current signal. Kuskur et al. deposited naphthol green $B$ on the bare carbon paste electrode (CPE) surface by cyclic voltammetry [230]. When naphthol green B was electropolymerized the roughness of the surface in the graphite flakes increased which was reflected in the higher peak current response. $\mathrm{By} \mathrm{CV}$, the modified electrode displayed sensitivity, selectivity, and stability for the determination of PR with a LOD of $1.6 \mu \mathrm{M}$. Chitravathi and Munichandraiah modified a GCE with a polymeric film of Nile blue using CV [231]. The formation of PNB on the surface was confirmed with the observation of a rough surface, compared to the unmodified electrode (see Figure 21) showing an increased surface area which improved the sensitivity in voltammetric determinations. EIS revealed values of $R_{\mathrm{ct}}$ for bare GCE and PNB/GCE of $3200 \mathrm{k} \Omega$ and $980 \mathrm{k} \Omega$, respectively, implying that the polymeric film increased the conductivity of the sensor. A wide linear range was observed for PR sensing from $0.2 \mu \mathrm{M}$ to $16.2 \mu \mathrm{M}$ with a LOD of $80 \mathrm{nM}$ and an RSD of $1.4 \%$ calculated for five measurements into a mixture of $0.1 \mathrm{mM}$ of PR, tramadol, and caffeine.
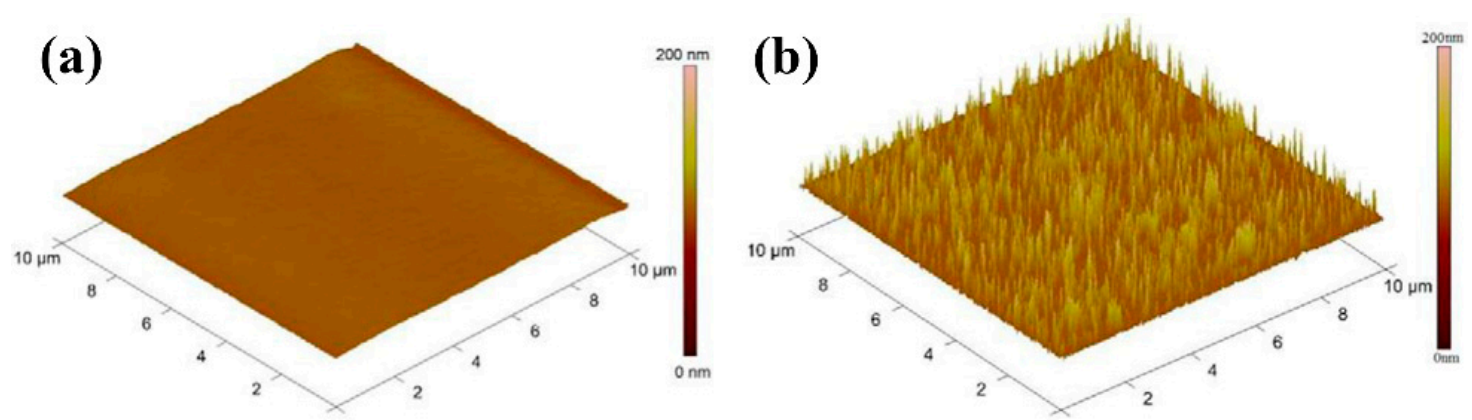

Figure 21. AFM images of the (a) unmodified glassy carbon electrode and (b) poly Nile blue modified glassy carbon electrode. Modified with permission from [231]. Copyright 2016 Elsevier.

Li et al. fabricated a electrogenerated poly (3-Methylthiophene) (P3MT)/rGO modified GCE for PR sensing [232]. P3MT/RGO/GCE sensor displayed a rough wrinkled surface indicating that (i) rGO was dispersed uniformly, and (ii) a homogeneous deposition of 
P3MT was achieved. Under optimal conditions, the anodic peak current changed linearly with PR concentration with a LOD of $25 \mathrm{nM}$. P3MT/RGO/GCE sensor not only increased reversibility of the redox reaction but also enhanced the response, which was proof of a remarkable synergistic effect between polymer and carbon material. Electrodeposited poly luminol (PLum)/f-MWCNTs modified GCE was developed as a highly sensitive PR sensor [233]. The bare GC electrode showed a non-porous uniform surface, while PLum/f-MWCNTs/GCE displayed a tube-shaped structure. Using SWASV in BR buffer solution at $\mathrm{pH} 7.0$, the electrode showed two linear responses in the range of $40 \mathrm{nM}$ to $32.2 \mu \mathrm{M}$ and $32.2 \mu \mathrm{M}$ to $172.2 \mu \mathrm{M}$ with a LOD of $25 \mathrm{nM}$. Electrodes based on PEDOT, poly (4-lithium styrenesulfonic acid) (PSSLi), and MWCNT were electrochemically fabricated for PR sensing [234]. PEDOT:PSSLi:MWCNT displayed a rough, uniform, dense, and compact structure. Carbon nanotubes formed tubular-shape structures which increased the surface area. PEDOT film acted as conductive phase and redox mediator, whereas PSSLi doped with its anion groups the oxidized form of PEDOT improving the mechanical properties of the composite. PEDOT:PSSLi:MWCNT/GCE sensor showed a linear response in the range from $1.5 \mu \mathrm{M}$ to $500 \mu \mathrm{M}$, each concentration in the calibration curve was measured five times, obtaining an RSD of $8.69 \%$. The limits of detection were $80 \mathrm{nM}$ by AdSDPV. PR was detected by a microbial biosensor based on PANI/multiwalled carbon nanotubes on gold electrodes [235]. Lyophilized Bacillus sp. cells in PBS solution at pH 7.0 were dip-coated onto the modified MWCNT/PANI/Au electrode followed by immersion in glutaraldehyde solution. The anodic peak current increased dramatically, due to the enzymatic reduction reaction to PR. Amperometric responses showed a LOD of $2.9 \mu \mathrm{M}$. The composite enhanced the sensitivity of Au electrode and $\pi-\pi$ stacking interactions between MWCNT and PANI provided good stability and conductibility. Kaur and Srivastava developed transition metal ion-exchanged polyaniline-zeolite organic-inorganic hybrid materials (PANI-Nano-ZSM-5) for simultaneous determination of EP, paracetamol, and folic acid [236]. Among all materials, $\mathrm{Cu}^{2+}$-PANI-Nano-ZSM-5 modified GCE exhibited the highest electro-catalytic activity. SEM images showed that $\mathrm{Cu}^{2+}$-PANI (see Figure 22a) displayed an irregular aggregated morphology. Spherical particles were observed in the case of $\mathrm{Cu}^{2+}$-Nano-ZSM-5 (see Figure 22b). After PANI was added, nanorods were produced on the $\mathrm{Cu}^{2+}-\mathrm{Nano}-\mathrm{ZSM}-5$ nanocomposite (see Figure 22c). $\mathrm{Cu}^{2+}$-PANI-NanoZSM-5/GCE exhibited well-defined anodic and cathodic peaks for PR, showing higher current response than the bare electrode. Under optimal conditions, a wide linear range was obtained from $15 \mathrm{nM}$ to $800 \mu \mathrm{M}$ with a detection limit of $8 \mathrm{nM}$ for PR [237].

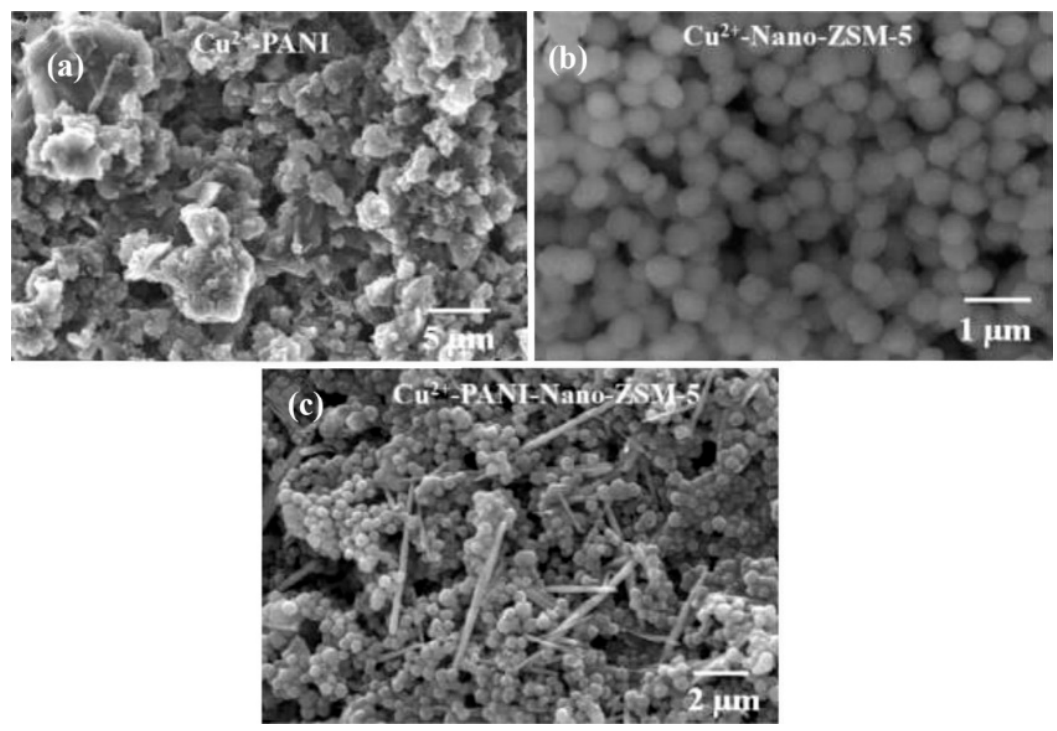

Figure 22. SEM images of (a) $\mathrm{Cu}^{2+}-\mathrm{PANI}$, (b) $\mathrm{Cu}^{2+}$-Nano-ZSM-5, and (c) $\mathrm{Cu}^{2+}$-PANI-Nano-ZSM-5 nanocomposite. Reproduced with permission from [237]. Copyright 2015 Elsevier. 


\subsubsection{Other Drugs}

Acetylsalicylic acid (ASA) is an important nonsteroidal anti-inflammatory [238], analgesic [239] and antipyretic drug [240]. However, is also known to have effects such as gastric acid secretion and dieresis if abused. A new electrochemical sensor made of manganese dioxide $\left(\mathrm{MnO}_{2}\right)$ - antimony trioxide $\left(\mathrm{Sb}_{2} \mathrm{O}_{3}\right)$ together with PANI on tin oxide (FTO) electrode $\left(\mathrm{MnO}_{2}-\mathrm{Sb}_{2} \mathrm{O}_{3} / \mathrm{PANI} / / \mathrm{FTO}\right)$ was used for sensing ASA in urine [241]. The PANI film showed large lumpy shapes and clews structures. After $\mathrm{MnO}_{2}-\mathrm{Sb}_{2} \mathrm{O}_{3}$ deposition, the composite was agglomerated into a globular structure. Improvement in electron transfer kinetics was attributed to large surface area and high electrocatalytic activity of PANI, $\mathrm{MnO}_{2}$, and $\mathrm{Sb}_{2} \mathrm{O}_{3}$. Under optimal conditions, the sensor showed a LOD of $0.20 \mathrm{nM}$ by DPV. Successive determinations of ASA at $30 \mathrm{nM}$ were performed 30 times in a row resulting in an RSD of $1.28 \%$. An electrochemical imprinted sensor based on PPy, sol-gel, and $\mathrm{SiO}_{2} @ \mathrm{Au}$ core-shell nanoparticles showed a linear response to ASA concentration using SWV [242]. The deposition onto a gold electrode was carried out by one step using CV in a solution containing phenyltriethoxysilane, tetraethoxysilane, ethanol, trifluoroacetic acid, ASA, lithium perchlorate, pyrrole, and $\mathrm{SiO}_{2} @$ AuNPs. Pyrrole increased the stability of the resultant MIP and enhanced the conductivity resulting in a sensor with a LOD of $0.2 \mathrm{nM}$ for ASA. The imprinted sensor was reused for 10 repeated analyses with an RSD of 3.0\%.

2-Aminoethanesulphonic acid (Taurine) is an organic acid present in most living organisms. It is one of the most abundant of the low-molecular weight organic compound, e.g., a $70 \mathrm{~kg}$ human contains up to $70 \mathrm{~g}$ of taurine [243]. Taurine plays an important role in numerous physiological and pharmacological processes such as membrane stabilization, intracellular $\mathrm{Ca}^{2+}$ regulation, neuro mediators, and neuromodulator [244]. MICP films have been developed for taurine determination [245]. The platform was made onto GCE, applying several scans of potential in a solution of EDOT, riboflavin-5'-phosphate (FMN), 3-thiophene acetic acid (AAT), and taurine. Taurine was extracted from MICP using a mix of methanol-water 2:5 resulting in a porous cauliflower-like structure. A linear response toward protonated taurine was observed with a slope of $53.8 \mathrm{mV}$ per decade.

(+)-(S)-(6-methoxynaphthalen-2yl)propionic acid (Naproxen or NAP) is a widely nonsteroidal anti-inflammatory agent advocated for use in rheumatoid arthritis, degenerative joint disease, and ankylosing spondylitis [246]. MICP of overoxidized PPy on quartz crystal microbalance (QCM) has been reported by Eslami and Alizadeh for NAP sensing [247]. PPy was electrodeposited from an aqueous solution of $\mathrm{NaOH}$, pyrrole, and NAP. Optimized overoxidized sensors were employed for NAP determination achieving a linear dependency in the range of $0.1 \mu \mathrm{M}$ to $150 \mu \mathrm{M}$ and a LOD of $40 \mathrm{nM}$.

3,4-Methylenedioxymethamphetamine (MDMA), commonly known as ecstasy, is a psychoactive recreational drug important whose analytical determination in a wide variety of matrices is a relevant subject in health and forensics sciences [248]. Molecular imprinted film of poly (o-phenylenediamine) (poly (o-PD)) film was electrodeposited on screenprinted carbon electrodes for MDMA determination [249]. After the modified electrode surface was incubated into MDMA solutions for $10 \mathrm{~min}$, a LOD of $0.79 \mu \mathrm{M}$ was found by SWV. Poly (o-PD) sensors were used for MDMA determination in human blood serum and urine samples with a recovery of $81-91 \%$.

\subsection{Hydrazine}

Hydrazine, $\mathrm{N}_{2} \mathrm{H}_{4}$, and its derivatives have several application fields such as rocket fuel, insecticides, herbicides emulsifiers, textile dyes, and corrosion inhibitors [250]. An inconvenient for the electrochemical sensing is that over conventional surfaces, hydrazine needs a high overpotential for oxidation [251]. For this reason, modified electrodes to reduce the oxidation overpotential is a research challenge. Lignosulfonates (LS) are amorphous aromatic biopolymers, co-produced in the paper industry, which exhibit electrocatalytic behavior towards nicotinamide adenine dinucleotide (NADH) possibly due to the formation of quinone-hydroquinone redox couple [252]. 
Rębiś et al. developed a sensor for $\mathrm{N}_{2} \mathrm{H}_{4}$ based on PPy and lignosulfonates [253]. The biocomposite was deposited onto a GCE from an acetonitrile-water solution with Py, $\mathrm{LiClO}_{4}$, and LS. Voltammograms made with GCE/PPy-LS exhibits a catalytic signal activity towards hydrazine. An amperometric method for $\mathrm{N}_{2} \mathrm{H}_{4}$ was developed in aqueous solutions obtaining a LOD of $1.6 \mu \mathrm{M}$. The electrocatalytic effect was ascribed to the quinone groups from LS acting as redox mediator and the semiconductivity of the polypyrrole. A carbon nitride, $\mathrm{gC}_{3} \mathrm{~N}_{4}$, PANI, and silver nanoparticles composite was tested for $\mathrm{N}_{2} \mathrm{H}_{4}$ sensing [254]. Bulk $\mathrm{gC}_{3} \mathrm{~N}_{4}$ was synthesized from melamine precursors, exfoliated, and co-deposited with PANI onto fluorine-doped tin oxide (FTO). FE-SEM shows a net-like structure with good distributed electrogenerated AgNPs. Voltammograms of hydrazine shows a catalytic current dependence with the concentration of hydrazine (see Figure 23). A chronoamperometric method was used for hydrazine determination achieving a LOD of $300 \mu \mathrm{M}$.
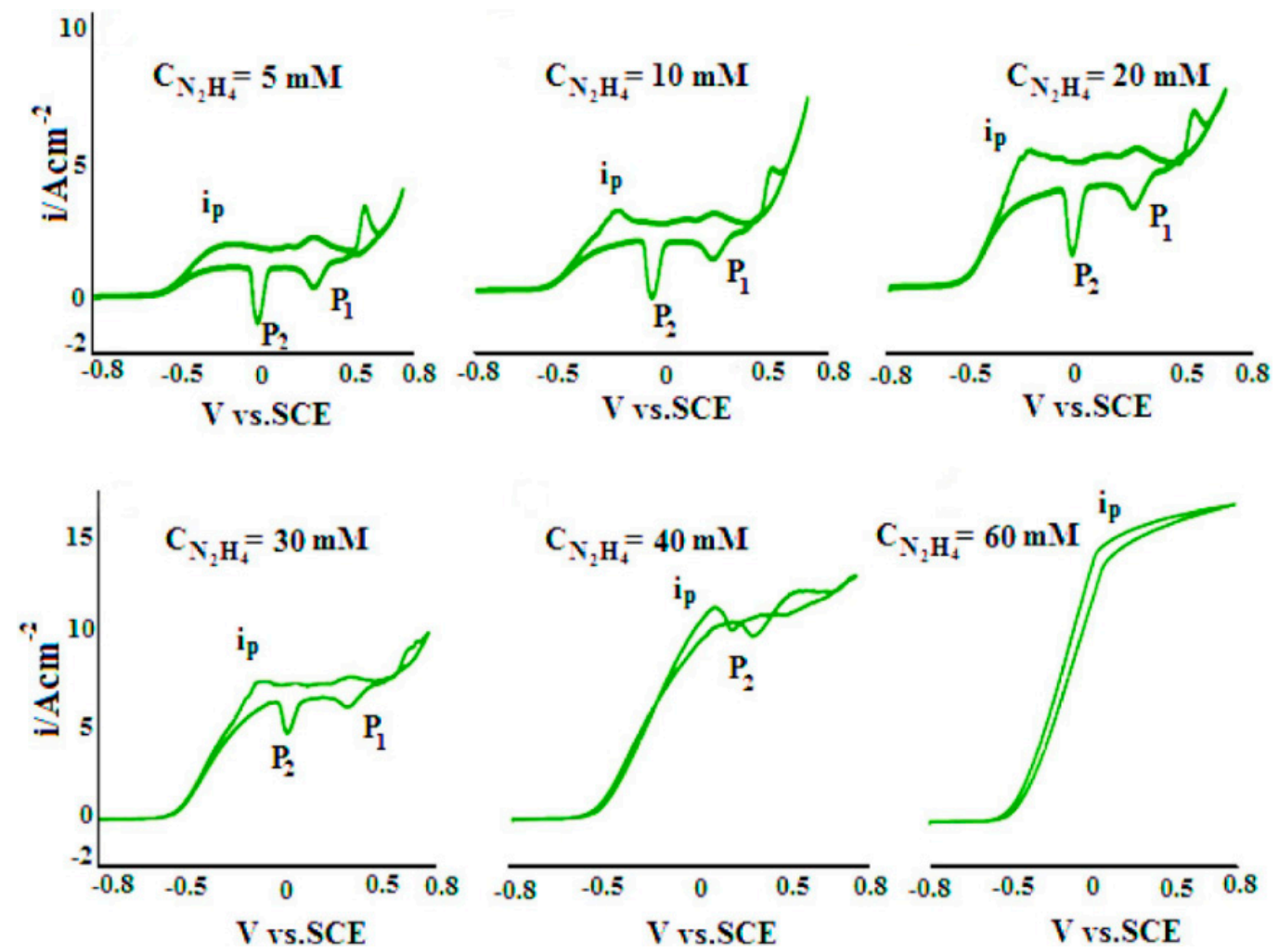

Figure 23. $\mathrm{CV}$ responses of the $\mathrm{FTO} / \mathrm{PANI}-\mathrm{gC}_{3} \mathrm{~N}_{4} / \mathrm{AgNP}$ electrode at a scan rate of $50 \mathrm{mV}$ in the presence of different hydrazine concentrations. Modified with permission from [254]. Copyright 2018 Elsevier.

Copper nanoparticles-decorated polyaniline-derived mesoporous carbon on CGE was used as a sensor for $\mathrm{N}_{2} \mathrm{H}_{4}$ [255]. Mesoporous $\mathrm{N}$-doped carbon nanoparticles (CNP) were synthesized by chemical polymerization of aniline employing silica nanoparticles as a template followed by pyrolysis at $1000^{\circ} \mathrm{C}$. $\mathrm{CNP} / \mathrm{Cu}$ material has a nanopore structure with an average pore size of $11 \mathrm{~nm}$ with homogeneously distributed copper (111) nanoparticles. Hydrazine oxidation showed electrocatalytic activity for CNP/Cu compared to CNP and bare GCE. Nickel-iron nanoparticles $\left(\mathrm{NiFe}_{2} \mathrm{O}_{4} \mathrm{NP}\right)$ were covered with poly (rhodamine) (PRd) by oxidative polymerization were prepared by Lashkenari et al. [256]. PRd@NiFe $\mathrm{O}_{4}$ micrographs showed cubic particles with an average size of $80 \mathrm{~nm}$. Voltammograms of hydrazine showed a reduction of the onset potential of ca $200 \mathrm{mV}$ and a larger current of approximately $20 \%$ in respect of non-modified surfaces. Ramaraj et al. developed a disposable $\mathrm{N}_{2} \mathrm{H}_{4}$ sensor based on copper(II) hexacyanoferrate complex nanocubes stabilized with poly (diallydimethylamonium chloride) (PDDA) [257]. Screen-printed carbon 
electrodes were modified by drop-casting the nanoparticles into ethanol. Voltammograms of hydrazine showed a ten-fold increase of current signal with respect to the bare electrode. Hydrazine determination was carried out with a chronoamperometric technique achieving a LOD of $10 \mathrm{nM}$, a linear range of $30 \mathrm{nM}$ to $570 \mu \mathrm{M}$, and recoveries of $96.0-99.1 \%$ into real water samples. Besides, $4.9 \%$ of the initial current response was lost after continuously measuring a solution of $50 \mathrm{mM}$ hydrazine for $5000 \mathrm{~s}$. A paper-based inkjet-printed sensor for hydrazine determination was developed by Beduk et al. [258]. Three layers of commercial PEDOT:PSS was printed on paper followed by two layers of $\mathrm{ZnO}$ precursor ink. After drying on a hot plate at $150^{\circ} \mathrm{C}$, one final layer of nafion was printed resulting in a hydrazine sensor with a LOD of $5 \mu \mathrm{M}$ by chronoamperometry. Following the same principle, a zinc oxide nanocomposite covered with polythiophene $(\mathrm{PTy} @ \mathrm{ZnO})$ has been prepared by sol-gel methodology then deposited on GCE for the hydrazine determination [259]. EIS experiments were made with hydrazine founding a notable decrease in electron transfer resistance, indicating a fast electron transfer, in contrast to the bare electrode. An amperometric method was developed for hydrazine determination reporting a LOD of $0.207 \mu \mathrm{M}$ with a response time below $5 \mathrm{~s}$. A three-dimensional macroporous PEDOT decorated with copper nanoparticles was electrochemically fabricated by Xu et al. [260]. GCE/3D-PEDOT/ $\mathrm{Cu}_{\mathrm{x}} \mathrm{O}$ exhibits a 3D structure with bumps and open macropores formed by nanofibers and decorated with spherical copper oxide particles of ca. $230 \mathrm{~nm}$ size. Hydrazine was detected by amperometric measurements into aqueous solutions at $\mathrm{pH}$ 8.0, obtaining a LOD of $0.2 \mu \mathrm{M}$ and recoveries ranging from $98 \%$ to $104 \%$ into tap and lake water real samples. Alizarin red S, 1,2-dihydroxy-9,10-anthraquinone-sulfonate (ALS) was potentiodynamically electropolymerized onto pencil graphite electrode obtaining flakes-like structures [261]. The GCE/PALS was employed for hydrazine determination with amperometric methods achieving a LOD of $0.28 \mu \mathrm{M}$, a linear range from 1 to $600 \mathrm{mM}$, and recoveries of $95-108 \%$ in water samples. Polydopamine (PDA)-rGO was employed for build an hydrazine sensor achieving a LOD of $10 \mathrm{nM}$ in aqueous solution at $\mathrm{pH} 7.0$ by SWV [262]. This sensor showed a reproducibility ranging from $1 \%$ to $4 \%$ expressed as RSD.

\subsection{Nitrites}

Nitrites are important in the nitrogen cycle and food preservation, as well as a fertilizing agent $[263,264]$. However, when ingested, it causes the oxidation of hemoglobin into methemoglobin in the blood, avoiding this protein to bind with oxygen molecule [265]. Nitrite can react with degradation products of meat forming nitrosamines which are carcinogen compounds [266]. The World Health Organization (WHO) reported that nitrite levels in water should stay below $3 \mathrm{mg} / \mathrm{L}(65 \mu \mathrm{M})$ [267]. Thus, a precise determination of nitrite is of high importance for the environment and human health.

PEDOT and carbon quantum dots (CQDs) has been used for nitrite sensing by modifying a glassy carbon electrode (CQDs/PEDOT/GCE) [268]. Direct electrochemical polymerization of the composite was performed by potentiostatic methods in an aqueous solution containing CQDs and EDOT. The CQD-PEDOT film was rough and lumpy with small pores throughout the film, enlarging the surface area. The nanocomposite act as a promoter to enhance the kinetics of the electrochemical oxidation process which effectively electro-catalyzes oxidation of nitrite. The CQDs/PEDOT/GCE showed a nitrite linear response with a range from $0.5 \mu \mathrm{M}$ to $1110 \mu \mathrm{M}$ and a LOD of $88 \mathrm{nM}$. A similar approach was followed by Wang et al. by modifying a CGE with PEDOT doped with nano-sized hydroxyapatite (nHAp/PEDOT/GCE) [269]. The electrodeposition was carried out under a potentiostatic regime in a solution containing nHAp and EDOT. The nHAp/PEDOT film exhibited a rough three-dimensional reticular structure. EIS showed a lower $R_{c t}$ for nHAp/PEDOT/GCE if compared to the one obtained in bare GCE, attributed to the large surface area and enhanced conductivity of the nanocomposite. Linear amperometric response for nitrite concentrations ranged from $0.25 \mu \mathrm{M}$ to $1.05 \mathrm{mM}$ with a LOD of $83 \mathrm{nM}$. A multilayered film of electrogenerated poly (3,4-ethylenedioxythiophene)/poly (thiomethyl 3,4-ethylenedioxythiophene)/gold nanoparticle (PEDOT-SH/PEDOT/Au) 
nanocomposite was fabricated by Ge et al. [270]. PEDOT film exhibited nanofiber structures that formed a porous network. PEDOT-SH thickened the nanofibers and formed block structures. AuNPs were distributed uniformly on the porous network directed by bonding interactions with thiol groups. Au/PEDOT-SH/PEDOT/GCE sensor exhibited a LOD of $51 \mathrm{nM}$ and two amperometric linear ranges from $0.15 \mathrm{mM}$ to $1 \mathrm{mM}$ and from $1 \mathrm{mM}$ to $16 \mathrm{mM}$, for nitrite concentration. Zuo et al. designed a sensitive and selective nitrite sensor based on phosphovanadomolybdates $\mathrm{H}_{6}\left[\mathrm{PMo}_{9} \mathrm{~V}_{3} \mathrm{O}_{40}\right]$, poly (ethylenimine), poly (3,4-ethylenedioxy thiophene) and gold nanoparticles on glassy carbon (AuNP/PEDOT/PMog $\mathrm{V}_{3} / \mathrm{PEI} / \mathrm{GCE}$ ) [271]. After GCE modification, a rough surface was obtained showing uniform distribution of gold nanoparticles in the polymer film. This amperometric sensor showed a linear range and LOD of $2.5 \mathrm{nM}-1.43 \mathrm{mM}$ and $1.0 \mathrm{nM}$, respectively. These outstanding results might be related to PEDOT $\pi$-conjugation and the presence of sulfur atoms, which chemically bond with the well-distributed gold nanoparticles, improving the electrical conductivity and electron transfer, while polyoxometalates act as a proton and electron reservoir in the electrocatalytic process. Poly (1,5-diaminonaphthalene) together with palladium nanoparticles and MWCNTs on glassy carbon electrode (PdNPs-poly (1,5-DAN)/MWCNTs/GCE) exhibited a high analytical performance for nitrite detection [272]. An amperometric sensor for nitrite showed a peak current proportional to its concentration in a linear range of $0.25 \mu \mathrm{M}$ to $0.1 \mathrm{mM}$, with a LOD of $80 \mathrm{nM}$. Nitrite was determined, as well, using a GCE modified with GO, PPy, and cobalt nanostructures (CoNS/GO/PPy/GCE) [273]. The GO/PPy nanocomposite showed a porous two-dimensional nanoflake structure. Cobalt NS revealed a flower-like crystal structure with open-nanoporous that significantly increase the active surface area ensuring unhindered diffusion of ions and redox substances. Under optimum conditions, nitrite concentration by amperometry showed two different linear ranges, from $1.0 \mu \mathrm{M}$ to $3.2 \mathrm{mM}$ and $6.8 \mathrm{mM}$ to $12 \mathrm{mM}$ with a LOD of $15 \mathrm{nM}$ and a response time of $1 \mathrm{~s}$.

\subsection{Phenolic Compounds}

Phenolic compounds are important chemicals used in several industries such as synthetic resins, plants, paints, textile, plastic, pharmaceutical, petroleum, and mine discharges [274-276]. However, they are considered a major class of pollutants due to their high toxicity, carcinogenicity, and low biodegradability [277]. According to Khan et al. the WHO has determined $1 \mu \mathrm{g} / \mathrm{L}$ (11 $\mathrm{nM}$ for phenol) as the maximum concentration allowed in drinking water [278]. These compounds can cause severe diseases e.g., methemoglobinemia [279], drowsiness [280], and nausea [281]. Therefore, methods for the determination of these compounds in long-term and real-time are of great significance [282,283].

Voltammetric determination of (2R,3S)-2-(3,4-dihydroxyphenyl)-3,4-dihydro-2Hchromene-3,5,7-triol (catechin) was performed using a glassy carbon electrode doped with poly (hydroxymethylated-3,4-ethylenedioxythiophene) (PEDOTM) and carboxylic group functionalized single-walled carbon nanotubes (f-SWCNTs) [284]. After potentiostatic deposition of PEDOTM on GCE, f-SWCNTs were drop-cast and dried at room temperature. The nodular and highly porous morphology of the $f$-SWCNTs/PEDOTM/GCE provided a large electroactive area which showed a linear behavior for catechin concentration, in PBS solution at $\mathrm{pH} 7.00$, ranging from $39 \mathrm{nM}$ to $40.84 \mu \mathrm{M}$ with a LOD of $13 \mathrm{nM}$. The f-SWCNTs/PEDOTM film highly increased the active surface area for the adsorption of catechin accelerating the electron transfer between electrode and solution, which boosted the current response and improved the sensitivity. Ten successive measurements allowed to determine an RSD of $1.19 \%$. One-dimensional electrogenerated PEDOT-graphene composite (PEDOT-Gr) was used for the detection of resorcinol (RC), hydroquinone (HQ), and catechol (CC) [285]. The graphene sheets showed atomic defects covering the edges and basal planes which produced high nucleation density allowing the formation of PEDOT structures with a 1D morphology in the edges of the sheets. 1D PEDOT-Gr/Ta sensor showed well-defined peaks at $12 \mathrm{mV}(\mathrm{HQ}), 120 \mathrm{mV}(\mathrm{CC})$, and $512 \mathrm{mV}(\mathrm{RC}) \mathrm{vs} . \mathrm{Ag} / \mathrm{AgCl}$ in aqueous solution with linear ranges of $5-250 \mu \mathrm{M}, 0.4-350 \mu \mathrm{M}$ and $6-2000 \mu \mathrm{M}$, and LODs of 
$60 \mathrm{nM}, 80 \mathrm{nM}$, and $0.16 \mu \mathrm{M}$, respectively. The high electron affinity and aromaticity of thiophene with the high conductivity of graphene nanosheets and the specific electron transfer properties accessible only to 1D material all together showed exceptional ability to adsorb and capture electrons of multiple analytes and discriminate between them. Sensitive and selective sensor for CC and HQ was fabricated by Kuskur et al. employing electrodeposited poly (Naphthol green B) modified carbon paste electrode (poly (NGB)/CPE) [286]. The morphology changed from irregularly shaped micrometer-sized flakes of graphite to a uniform arrangement of poly (NGB) molecules on the surface of the electrode. The bare electrode showed amalgamated and indistinguishable signals for CC and HQ, while poly (NG B)/CPE showed a separation of $125 \mathrm{mV}$. Under optimal conditions, the modified CPE can detect CC and HQ with LODs of $0.19 \mu \mathrm{M}$ and $0.20 \mu \mathrm{M}$, respectively. Improved detection for modified CPE raises due to the formation of stable redox-active layers and high electron transfer efficiency of poly (NGB) acting as mediators for electrocatalysis of biological compounds. A selective non-enzymatic sensor for CC determination was developed using copper-polypyrrole modified GC electrode (Cu-PPy/GCE) [287]. SEM images revealed globular PPy structures resulting in a microporous morphology, while $\mathrm{Cu}$ deposits showed pinecone-like morphologies on the micropores of the PPy surface. Under optimized conditions, amperometric measurements showed a linear range from $50 \mathrm{nM}$ to $1.0 \mathrm{mM}$ with a LOD of $10 \mathrm{nM}$ (see Figure 24a). The high electrocatalytic behavior and selectivity of Cu-PPy/GCE towards CC were attributed to the formation of a five-member $\mathrm{Cu}$ (II)-o-quinolate intermediate complex and the CC oxidation to o-quinone through the reduction of $\mathrm{Cu}$ (II) to $\mathrm{Cu}$ (I) that enhances the electron transference (Figure 24b). An RSD of $6.3 \%$ was obtained from the current responses of ten successive measurements.

(a)

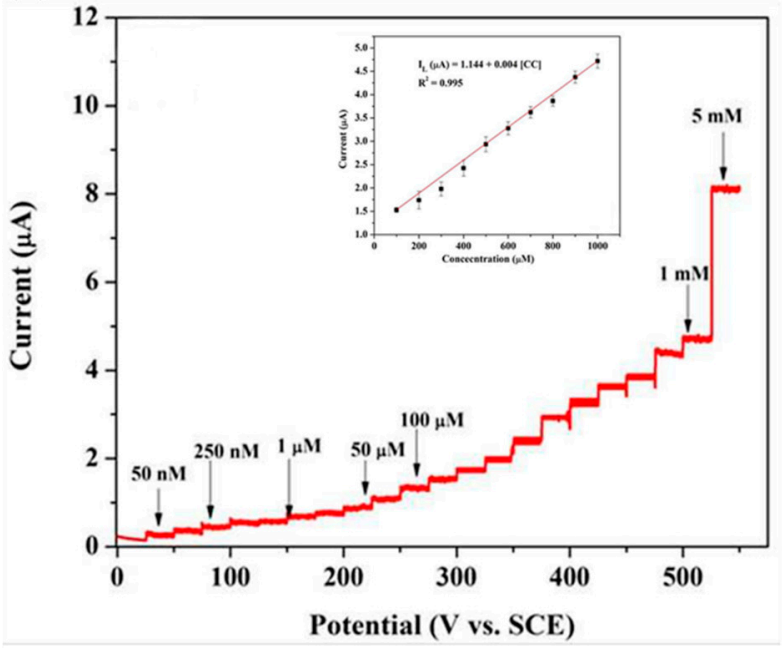

(b)
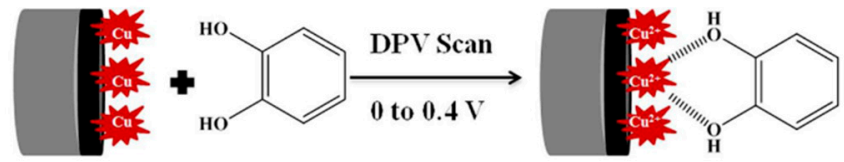

Cu - PPy/GCE
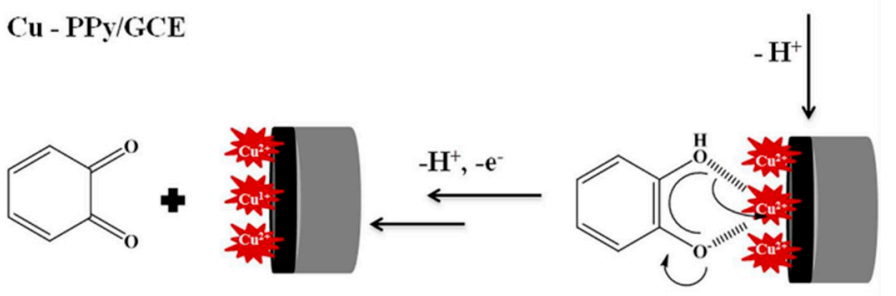

Figure 24. (a) Chronoamperogram for the sequential addition of catechol at Cu-PPy/GCE in $0.1 \mathrm{M} \mathrm{PBS}(\mathrm{pH}=7.0)$ at $0.3 \mathrm{~V}$ vs. SCE. (b) Schematic representation of the formation of a five-membered ring with $\mathrm{Cu}(\mathrm{II})$ and catechol and further oxidation of catechol at Cu-PPy/GCE. Modified with permission from [287]. Copyright 2017 Electrochemical Society.

\subsection{Nitroaromatic Compounds}

Nitroaromatic compounds are considered pollutants that commonly infiltrate soil and groundwater because of their usage in industries of rubber, dye, pharma, detergent, resin, paper, and widely in the armament industry as explosives [288,289]. On humans, the toxicological impact is high because they persist for long periods, producing several health problems such as skin damage and necrosis [290]. These kinds of compounds are chemically stable and poorly biodegradable because of their nitro-substituted aromatic structure [291]. However, one advantage for the application of electrochemical methods is the easily reducible nitro groups allowing development sensors with good sensitivity, 
selectivity, and fast response [292]. Furthermore, modifying electrodes with polymers and metallic nanoparticles had proven to result in a great increase in the recognition of analytes and stability of the electrodes [293].

Nitroaromatic explosive materials such 2,4,6-trinitrotoluene (TNT), 2,4-dinitrotoluene (DNT) and 2,4,6-trinitrophenylmethylnitramine (tetryl) were detected using glassy carbon electrode coated with electrogenerated poly (o-phenylenediamine-aniline) and gold nanoparticles (AuNp/P(o-PDA-co-ANI)/GCE) [294]. Poly (o-PDA) film was able to catalyze nitroaromatic compounds; however, the coating peeled off the surface after several measurements. In the case of PANI film, it exhibited stability through measurements, but it was non-reactive to nitroaromatic compounds. P[o-PDA-co-ANI] exhibited both stability and electroactivity, in which nitroaromatic compounds were detected through $\pi$-acceptor/donor interactions. AuNPs provided increased binding because s-/ $\pi$-donor amine/aniline groups could link gold nanoparticles interacting with the electron-poor nitroaromatic compounds. Linear responses were observed for TNT ranging from $11 \mu \mathrm{M}$ to $176 \mu \mathrm{M}$ with a LOD of $9.2 \mu \mathrm{M}$, for DNT ranging from $11 \mu \mathrm{M}$ to $220 \mu \mathrm{M}$ with a LOD of $7.0 \mu \mathrm{M}$, and for tetryl ranging from $17.4 \mu \mathrm{M}$ to $348.3 \mu \mathrm{M}$ with a LOD of $13.2 \mu \mathrm{M}$. Potentiodynamic deposition of polyalizarin red (PAR) on glassy carbon electrode (PAR/GCE) was proposed by Chen et al. for detection of nitrofurazone, nitrofurantoin, and furazolidone [295]. The reduction peak current of nitrofurazone using PAR/GCE, in HAc-NaAc buffer solution at pH 5.0, was 2.47 times higher than the bare GCE signal. DPV sensor showed a peak current proportional to the concentration in the range of $3.0-50.0 \mu \mathrm{M}$ and $50.0-200.0 \mu \mathrm{M}$, with a LOD of $0.33 \mu \mathrm{M}$ for nitrofurazone. Analysis of furantoin and furazolidone showed linear ranges of $10-40 \mu \mathrm{M}$ and $50-140 \mu \mathrm{M}$, respectively, with a corresponding LODs of $0.73 \mu \mathrm{M}$ and $1.56 \mu \mathrm{M}$. The repeatability test was performed 15 times where the peak current of the reduction was $94.73 \%$ of the initial value. Nitrophenol isomers were sensed using graphite electrodes coated with poly (p-aminobenzene sulfonic acid) (poly (p-ABSA)) film [296]. An electrochemical potentiodynamic deposition was carried out using an aqueous solution containing p-ABSA. o-NP, $\mathrm{m}-\mathrm{NP}$, and p-NP isomers were simultaneously determined at $0.119 \mathrm{~V},-0.125 \mathrm{~V}$, and $0.027 \mathrm{~V}$ vs. SCE using a semi-derivative technique which improved the resolution and enhanced the sensitivity of $\mathrm{CV}$ curves. Liner ranges for the oxidation peaks of the intermediate products of nitrophenol were 3-800 $\mathrm{mM}$ for o-NP, and 3-700 mM for both $\mathrm{m}-\mathrm{NP}$ and $\mathrm{p}-\mathrm{NP}$. Sensitivity and LODs for o-NP $(0.28 \mathrm{mM}), \mathrm{m}-\mathrm{NP}(0.5 \mathrm{mM})$, and $\mathrm{p}-\mathrm{NP}(0.3 \mathrm{mM})$ were attributed to the favorable electrocatalytic activity of poly (p-ABSA) towards the oxidation of hydroxyl aminophenol. Nitrofurantoin (NFT), nitrofurazone (NFZ), furaltadone (FTD), and furazolidone (FZD) were successfully determined using a screen-printed carbon electrode coated with overoxidized multi-walled carbon nanotubes and poly (melamine) (PME/MWCNT*/SPCE) [297]. Multifunctional melamine was electropolymerized from an $\mathrm{HCl}$ solution by cyclic voltammetry on MWCNT modified electrodes leading to the formation of microporous structures. While the bare SPCE is very hydrophobic with a water contact angle of $136^{\circ}$, the PME/MWCNT*/SPCE displayed a reduced hydrophobic nature with a value of $52.1^{\circ}$. The linear relation from peak current and concentration for NFT, FZD, and NFZ ranged for all from $50 \mathrm{nM}$ to $2.0 \mu \mathrm{M}$ with LODs of $12 \mathrm{nM}, 7 \mathrm{nM}$, and $6 \mathrm{nM}$, respectively. The linear response for FTD was higher going from $50 \mathrm{nM}$ to $5.0 \mu \mathrm{M}$ and a LOD of $14 \mathrm{nM}$. A gold electrode modified with electrogenerated 3,5-diamino-1,2,4-triazole (35DT) was used for sensing 4-nitrophenol (4NP) [298]. The anodic current of the modified electrode compared to the bare one was ca. 5 times higher (see Figure 25) in acetate buffer at $\mathrm{pH}$ 4.5. A linear response was obtained by DPV for 4NP concentration ranging from $0.24 \mu \mathrm{M}$ to $130.6 \mu \mathrm{M}$ with a detection limit of $9 \mathrm{nM}$. In the repeatability test, an RSD value of $2.56 \%$ was obtained after six measurements. 


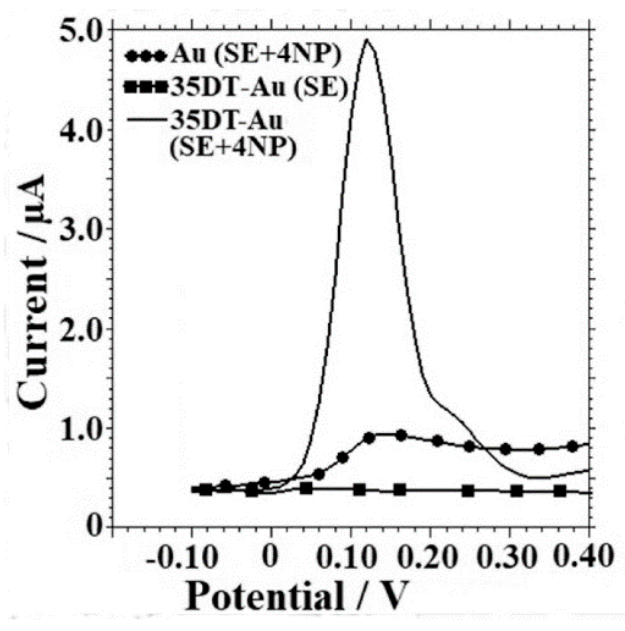

Figure 25. Differential pulse voltammetry of poly (35DT)/Au electrode without 4-nitrophenol (solid square line), a bare gold electrode with $50 \mathrm{mM}$ of 4-nitrophenol (solid circle line), and poly (35DT)/ Au electrode with $50 \mu \mathrm{M}$ of 4-nitrophenol (solid line). Modified with permission from [298]. Copyright 2019 Wiley-VCH Verlag GmbbH and Co.

Arulraj et al. fabricated an electrogenerated nano polypyrrole/sodium dodecyl sulphate (ENPPy/SDS) film for the determination of 4NP [299]. Oxidation peak current showed a linear response in the range of $0.1 \mathrm{nM}-100 \mu \mathrm{M}$ with a LOD of $0.1 \mathrm{nM}$ and sensitivity of $4.45 \mu \mathrm{A} \mu \mathrm{M}^{-1}$. The catalytic effect of ENPPy/SDS film can be explained by the electrochemical treatment in which the initial globular structure (see Figure 26a) is nano cracked and decreases the particle size of the polymer (see Figure 26b). Cracks allowed 4NP diffusion into the polymer matrix through capillary action and act as micro electrochemical cells catalyzing the reaction.
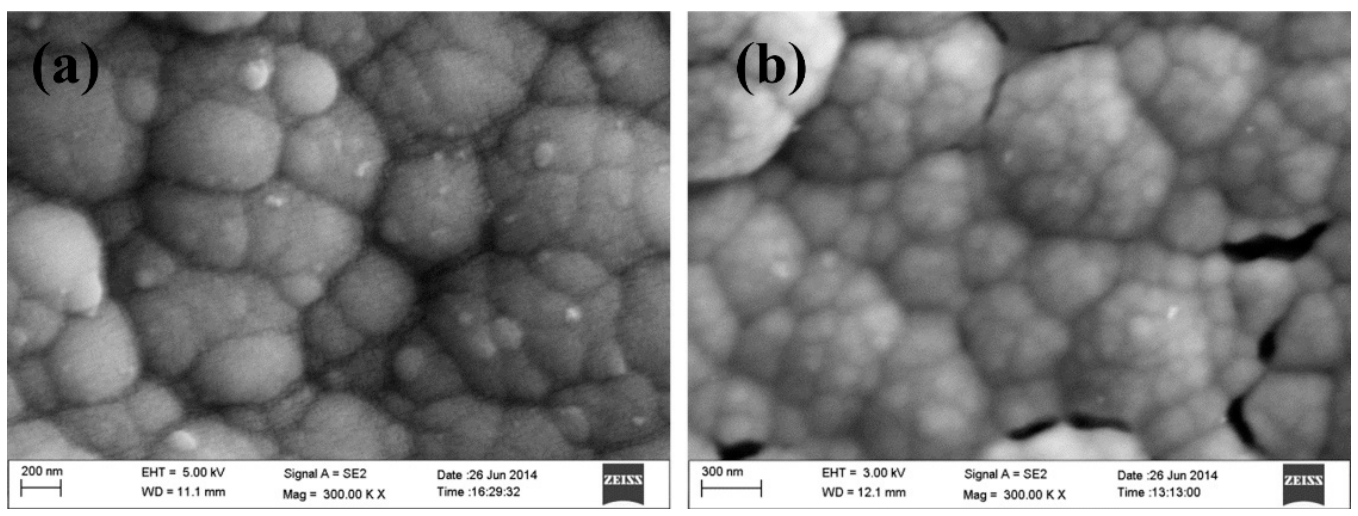

Figure 26. FESEM images of polypyrrole/sodium dodecyl sulphate film, (a) before and (b) after electrochemical treatment. Modified with permission from [299]. Copyright 2015 Elsevier.

Finally, Table 2 enlists a series of electrochemical sensors based on conducting polymers for the detection of the various emergent aqueous contaminants reviewed in the last five sections. Electrode architecture, name of the conducting polymer, synthetic methodology, analyte, detection technique, LOD, and linear range are provided as well as the reference where the information was taken. 
Table 2. Summary of the performance analysis of different electrochemical sensors based on conducting polymers for the detection of various water emergent pollutants.

\begin{tabular}{|c|c|c|c|c|c|c|c|}
\hline Electrode Architecture & Conducting Polymer & Synthesis Method & Analytes & $\begin{array}{l}\text { Detection } \\
\text { Technique }\end{array}$ & LOD $(\mu \mathrm{M})$ & Linear Range $(\mu \mathrm{M})$ & Ref. \\
\hline \multicolumn{8}{|c|}{ Diverse Pharmaceuticals } \\
\hline $\begin{array}{l}\text { Poly }[(3,6 \text {-diamino-9- } \\
\text { ethylcarbazole)]/GCE }\end{array}$ & $\begin{array}{l}\text { Poly [(3, 6-diamino-9- } \\
\text { ethylcarbazole })]\end{array}$ & $\mathrm{CV}$ & E2 & EIS & $0.36 \mathrm{aM}$ & $1 \mathrm{aM}$ to $10 \mu \mathrm{M}$ & [223] \\
\hline $\mathrm{MnO} 2-\mathrm{Sb} 2 \mathrm{O} 3 / \mathrm{PANI} / / \mathrm{FTO}$ & PANI & $\mathrm{CV}$ & ASA & DPV & 0.0002 & $0.0012-0.22868$ & [241] \\
\hline $\begin{array}{c}\text { PPy/sol-gel/SiO2@AuNPs } \\
\text { MIP/Au electrode }\end{array}$ & PPy & $\mathrm{CV}$ & ASA & SWV & 0.0002 & $0.001-0.01$ & [242] \\
\hline $\mathrm{PPy} / \mathrm{PB} / \mathrm{GCE}$ & PPy & $\mathrm{CV}$ & PR & DPV & 0.00053 & $0.001-100$ & [228] \\
\hline 3D-HPG/PTH/GCE & PTH & $\mathrm{CV}$ & MNZ & DPV & 0.001 & $0.05-70$ & [209] \\
\hline $\mathrm{rGO} / \mathrm{PPR} / \mathrm{GCE}$ & PPR & $\mathrm{CV}$ & CFX & DPV & 0.002 & $0.002-0.05$ & [219] \\
\hline $\begin{array}{c}\text { Cu2+-PANI-Nano-ZSM- } \\
\text { 5/GCE }\end{array}$ & PANI & $\mathrm{CV}$ & PR & DPV & 0.008 & $0.015-800$ & [237] \\
\hline $\begin{array}{c}\text { CS-MWCNTs+TiO2 } \\
\text { NPs/PCC/nanoporous GCE }\end{array}$ & PCC & $\mathrm{CV}$ & Acyclovir & DPASV & 0.01 & $0.03-1$ & [214] \\
\hline $\mathrm{P} 3 \mathrm{MT} / \mathrm{RGO} / \mathrm{GCE}$ & P3MT & $\mathrm{CV}$ & PR & DPV & 0.025 & $0.2-2.5$ & [232] \\
\hline PLum/f-MWCNTs/GCE & PLum & $\mathrm{CV}$ & PR & DPV & 0.025 & $0.04-32.2$ & [233] \\
\hline PEDOT:PSSLi/GCE & PEDOT & CA & PR & DPV & 0.05 & $0.14-400$ & [234] \\
\hline PEDOT:PSSLi:MWCNT/GCE & PEDOT & $\mathrm{CA}$ & PR & AdSDPV & 0.08 & $1.5-500$ & [234] \\
\hline $\mathrm{PNB} / \mathrm{GCE}$ & PNB & $\mathrm{CV}$ & PR & DPV & 0.08 & $0.2-16.2$ & [231] \\
\hline $\mathrm{DMIP} / \mathrm{CPE}$ & Poly(AMTEOS) & $\mathrm{CV}$ & MNZ & DPV & 0.091 & $0.4-200$ & [207] \\
\hline $\mathrm{HRP} / \mathrm{Pol} / \mathrm{Pt}$ & Pol & CA & E2 & DPV & 0.105 & $0.1-200$ & [222] \\
\hline MIP/AuNPs/GCE & PME & $\mathrm{CV}$ & MNZ & DPV & 0.12 & $0.5-1000$ & [208] \\
\hline SDS/PEB/CPE & PEB & $\mathrm{CV}$ & CFX & DPV & 0.183 & $50-90$ & [218] \\
\hline Poly(naphthol green B)/CPE & Poly(naphthol green B) & $\mathrm{CV}$ & PR & $\mathrm{CV}$ & 1.6 & $20-70$ & [230] \\
\hline Poly(rhodamine B)/CPE & Poly(rhodamine B) & $\mathrm{CV}$ & PR & $\mathrm{CV}$ & 2.2 & $20-90$ & [229] \\
\hline MWCNT/PANI/AuE & PANI & $\mathrm{CV}$ & PR & CA & 2.9 & $0.5-630$ & [235] \\
\hline
\end{tabular}


Table 2. Cont

\begin{tabular}{|c|c|c|c|c|c|c|c|}
\hline Electrode Architecture & Conducting Polymer & Synthesis Method & Analytes & $\begin{array}{l}\text { Detection } \\
\text { Technique }\end{array}$ & LOD $(\mu \mathrm{M})$ & Linear Range $(\mu \mathrm{M})$ & Ref. \\
\hline \multicolumn{8}{|c|}{ Hydrazine } \\
\hline GCE/PDA@GO & Poly dopmanie & $\begin{array}{l}\text { Homogeneous } \\
\text { polymerization }\end{array}$ & Hidrazine & SWV & 0.01 & 0.03 to 100 & [262] \\
\hline SPE/PDDA@[Cu(CN6)] & $\begin{array}{c}\text { Poly } \\
\text { (diallydimethylamonium } \\
\text { chloride) }\end{array}$ & Commercial polymer & Hidrazine & CA & 0.01 & 0.03 to 570 & [257] \\
\hline GCE/3D-PEDOT/CuxO & PEDOT & $\mathrm{CA}$ & Hidrazine & $\mathrm{CA}$ & 0.2 & 0.5 to 600 & [260] \\
\hline GCE/PEDOT/ZnO & PEDOT & Chemical polymerization & Hidrazine & $\mathrm{CA}$ & 0.207 & 0.5 to 48 & [259] \\
\hline GCE/PALS & Alizarin red S & $\mathrm{CV}$ & Hidrazine & CA & 0.28 & 1 to 600 & [261] \\
\hline GCE/PPy-LS & Ppy & Galvanostatic & Hidrazine & CA & 1.6 & $1-80$ & [253] \\
\hline Paper/PEDOT/ZnO/Nf & PEDOT PSS & commercial polymer & Hidrazine & CA & 5.0 & 10 to 500 & [258] \\
\hline FTO/PANI-gC3N4/AgNP & PANI & $\mathrm{CV}$ & Hidrazine & $\mathrm{CV}$ & 300.0 & $5-300 \mathrm{mM}$ & [254] \\
\hline CPE/PRA@NiFe2O4NP & Poly (rhodamine) & $\begin{array}{l}\text { Chemical oxidation with } \\
\text { KMnO4 }\end{array}$ & Hidrazine & $\mathrm{CA}, \mathrm{CV}$ & $\begin{array}{c}\text { Not } \\
\text { reported }\end{array}$ & $1-50 \mathrm{mM}$ & [256] \\
\hline $\begin{array}{l}\text { GCE/pyrolized } \\
\text { PANI/CuNP/Nf }\end{array}$ & PANI & Chemical polymerization & Hidrazine & $\mathrm{CV}$ & $\begin{array}{l}\text { Not } \\
\text { reported }\end{array}$ & 10 to $100 \mathrm{mM}$ & [255] \\
\hline \multicolumn{8}{|c|}{ Nitrites } \\
\hline $\begin{array}{c}\text { AuNP/ } \\
\text { PEDOT } / \mathrm{PMo}_{9} \mathrm{~V}_{3} / \mathrm{PEI} / \mathrm{GCE}\end{array}$ & PEDOT & $\mathrm{CV}$ & nitrite & CA & 0.001 & $0.0025-1430$ & [271] \\
\hline CoNS/GO/PPy/GCE & PPy & $\mathrm{CV}$ & nitrite & CA & 0.015 & $1.0-3200$ & [273] \\
\hline $\begin{array}{c}\text { PdNPs/poly } \\
\text { (1,5-DAN)/MWCNTs/GCE }\end{array}$ & Poly (1,5 DAN) & $\mathrm{CV}$ & nitrite & CA & 0.08 & $0.25-100$ & [272] \\
\hline nHAp/PEDOT/GCE & PEDOT & CA & nitrite & CA & 0.083 & $0.25-1050$ & [269] \\
\hline CQDs/PEDOT/GCE & PEDOT & CA & nitrite & CA & 0.088 & $0.5-1110$ & [268] \\
\hline $\begin{array}{c}\mathrm{Au} / \mathrm{PEDOT}- \\
\mathrm{SH} / \mathrm{PEDOT} / \mathrm{GCE}\end{array}$ & PEDOT-SH/PEDOT & $\mathrm{CV}$ & nitrite & CA & 51.0 & $150-1000$ & {$[270]$} \\
\hline \multicolumn{8}{|c|}{ Phenolic Compounds } \\
\hline
\end{tabular}


Table 2. Cont.

\begin{tabular}{|c|c|c|c|c|c|c|c|}
\hline Electrode Architecture & Conducting Polymer & Synthesis Method & Analytes & $\begin{array}{l}\text { Detection } \\
\text { Technique }\end{array}$ & LOD $(\mu \mathrm{M})$ & Linear Range $(\mu \mathrm{M})$ & Ref. \\
\hline$f$-SWCNTs/PEDOTM/GCE & PEDOTM & CA & catechin & $\mathrm{CV}$ & 0.013 & $0.039-40.84$ & {$[284$} \\
\hline \multirow{3}{*}{ Poly (NG B)/CPE } & \multirow{3}{*}{ Poly (NG B) } & \multirow{3}{*}{$\mathrm{CV}$} & HQ & DPV & 0.01 & $0.1-110$ & \multirow{3}{*}{286} \\
\hline & & & $\mathrm{CC}$ & $\mathrm{CV}$ & 0.19 & $0.20-90$ & \\
\hline & & & HQ & $\mathrm{CV}$ & 0.20 & $0.20-90$ & \\
\hline Cu-PPy/GCE & PPy & $\mathrm{CA}$ & $\mathrm{CC}$ & $\mathrm{CA}$ & 0.010 & $0.05-1000$ & {$[287$} \\
\hline \multirow{3}{*}{ 1D PEDOT-Gr/Ta } & \multirow{3}{*}{ PEDOT } & \multirow{3}{*}{$\mathrm{CV}$} & HQ & DPV & 0.06 & $5-250$ & \multirow{3}{*}{285} \\
\hline & & & $\mathrm{CC}$ & DPV & 0.08 & $0.4-350$ & \\
\hline & & & $\mathrm{RC}$ & DPV & 0.16 & $6-2000$ & \\
\hline \multicolumn{8}{|c|}{ Nitroaromatic Compounds } \\
\hline ENPPy/SDS/GCE & ENPPy & $\mathrm{CV}$ & $p$-NP & SWV & 0.0001 & $0.0001-100$ & {$[299$} \\
\hline Poly(35DT)/GE & Poly(35DT) & $\mathrm{CV}$ & 4-NP & DPV & 0.09 & $0.24-130.6$ & {$[298$} \\
\hline \multirow{2}{*}{ Poly (p-ABSA)/GrE } & \multirow{2}{*}{ Poly (p-ABSA) } & \multirow[t]{2}{*}{$\mathrm{CV}$} & $\mathrm{p}-\mathrm{NP}$ & SDV & 0.3 & $0.3-700$ & \multirow{2}{*}{296} \\
\hline & & & $\mathrm{m}-\mathrm{NP}$ & SDV & 0.5 & $0.3-700$ & \\
\hline \multirow{3}{*}{$\mathrm{PAR} / \mathrm{GCE}$} & \multirow{3}{*}{ PAR } & \multirow{3}{*}{$\mathrm{CV}$} & NF & DPV & 0.33 & $3.0-50$ & \multirow{3}{*}{295} \\
\hline & & & NIT & DPV & 0.73 & $10.0-40$ & \\
\hline & & & FL & DPV & 1.56 & $50-140$ & \\
\hline \multirow{4}{*}{$\mathrm{PME} / \mathrm{MWCNT}^{*} / \mathrm{SPCE}$} & \multirow{4}{*}{ PME } & \multirow{4}{*}{$\mathrm{CV}$} & NFZ & DPV & 0.006 & $0.05-2.0$ & \multirow{4}{*}[297]{} \\
\hline & & & FZD & DPV & 0.007 & $0.05-2.0$ & \\
\hline & & & NFT & DPV & 0.012 & $0.05-2.0$ & \\
\hline & & & FTD & DPV & 0.014 & $0.05-5.0$ & \\
\hline \multirow{3}{*}{$\begin{array}{c}\text { AuNp/P(o-PDA-co- } \\
\text { ANI)/GCE) }\end{array}$} & \multirow{3}{*}{ P(o-PDA-co-ANI) } & \multirow{3}{*}{$\mathrm{CV}$} & DNT & $\mathrm{CV}$ & 7.03 & $11-220$ & \multirow{3}{*}{294} \\
\hline & & & TNT & $\mathrm{CV}$ & 9.25 & $11-176$ & \\
\hline & & & Tetryl & $\mathrm{CV}$ & 13.23 & $14-348$ & \\
\hline
\end{tabular}




\section{Conclusions}

Electrochemical CP sensors have been developed for versatile and selective detection of different organic and inorganic biologically relevant compounds. The most-used monomers are derivatives of pyrroles, anilines, ethylenedioxythiophenes, and conjugated organic dyes because of their capacity to produce conducting polymers with high conductivity, large surface area, and improvement in electron transfer kinetics, which enhances the electrocatalytic activity of the sensor. Moreover, these conducting polymers can be coupled with many other materials such as graphenes, carbon nanotubes, enzymes, and metal nanoparticles for increasing adsorption of analytes which rises sensitivity and allows biocompatibility. These composites show excellent performance due to the synergetic effects of the conducting polymers with the other components improving the sensitivity, selectivity, and stability of the sensors. Electrochemical polymerization is the most used synthetic methodology for generating the polymeric film and their composites allowing for a precise thickness and morphology modulation. Molecular imprinted polymerization appears as an interesting methodology to obtain high-performance sensors. During the polymerization, the analyte molecule acts as a template that artificially synthesizes receptor structures with specific recognition, highly increasing the sensitivity and selectivity of the sensor. These electrochemical sensors based on conducting polymers display limits of detection that can even reach attomolar concentrations, which satisfy the detection requirements for traces monitoring. The design and fabrication of modified electrodes with highly ordered multilayers remain quite an unexplored research area as well as the development of non-invasive sensors like skin patches or needle-less devices.

\section{Perspectives}

There are still challenges as well as opportunities for the development of novel electrochemical polymeric sensors. Most of the thin polymeric films are generated from bifunctional monomers which leads to the formation of linear or branched polymer structures. By using the right methodology, thin films with high roughness and large surface areas are synthesized showing meso- and macroporosity. Nevertheless, recent efforts in the development of tridimensional rigid polymeric networks with high microporosity have been made resulting in semiconducting thin films that show improved sensitivity and selectivity. In recent years, a series of microporous polymer networks (MPNs) based on multifunctional carbazole monomers on GCE were tested for the analysis of 1,3,5trinitrobenzene (TNB) [300]. The monomers, which deferred mostly in the number of electroactive carbazole units, were electrodeposited by potentiostatic methods. As the monomers possess multiple carbazole functions around a rigid core unit, the resultant thin film is a three-dimensional network with permanent microporosity. Direct measurement of the specific surface area was determined for the MPNs using krypton gas sorption measurements followed by data analysis with the Brunauer-Emmett-Teller (BET) equation reaching values up to $1297 \mathrm{~m}^{2} \mathrm{~g}^{-1}$. The electron-rich MPN surface interacts with electron-poor nitroaromatic analytes via $\pi-\pi$ interactions boosting the sensitivity of the electrode, which is closely related to the specific area, showing a current increase of up to 182 between modified and nonmodified GCE. Similar works have also been published where it was demonstrated the importance of producing high microporosity films, starting from multifunctional monomers, for the sensitivity boosting of modified electrodes in the detection of various analytes [301-305].

Author Contributions: Á.T.-A., F.B.-P., and C.C.-M. wrote the draft manuscript. C.C.-M. and A.P.-C. revised the manuscript. A.P.-C. supervised the writing process and edited the manuscript. All authors have read and agreed to the published version of the manuscript.

Funding: This research received no external funding.

Institutional Review Board Statement: Not applicable.

Informed Consent Statement: Not applicable. 
Data Availability Statement: No new data were created or analyzed in this study. Data sharing is not applicable to this article.

Acknowledgments: A.P.-C. thanks to the University Yachay Tech for the internal grants No. Chem1908 and Chem19-17.

Conflicts of Interest: The authors declare no conflict of interest.

\section{Abbreviations}

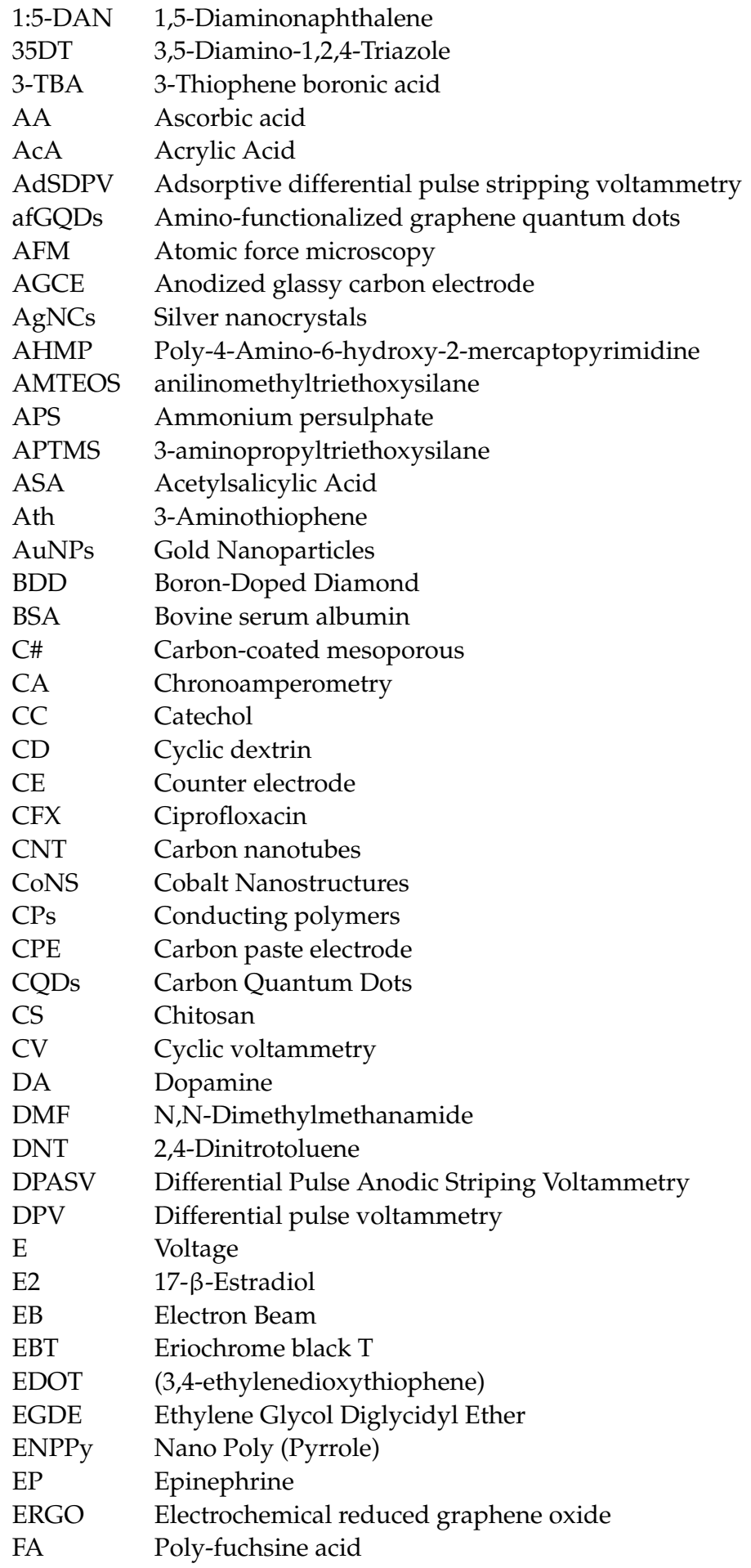




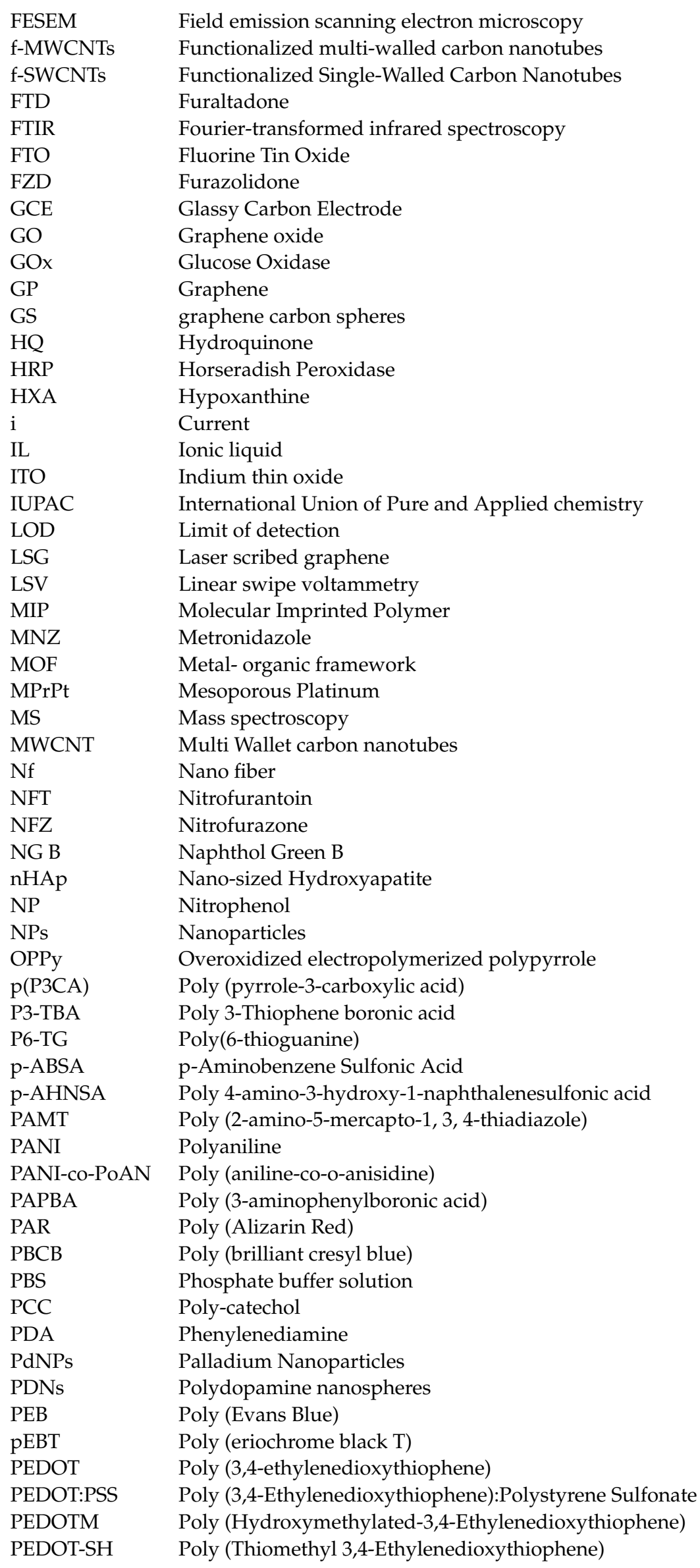




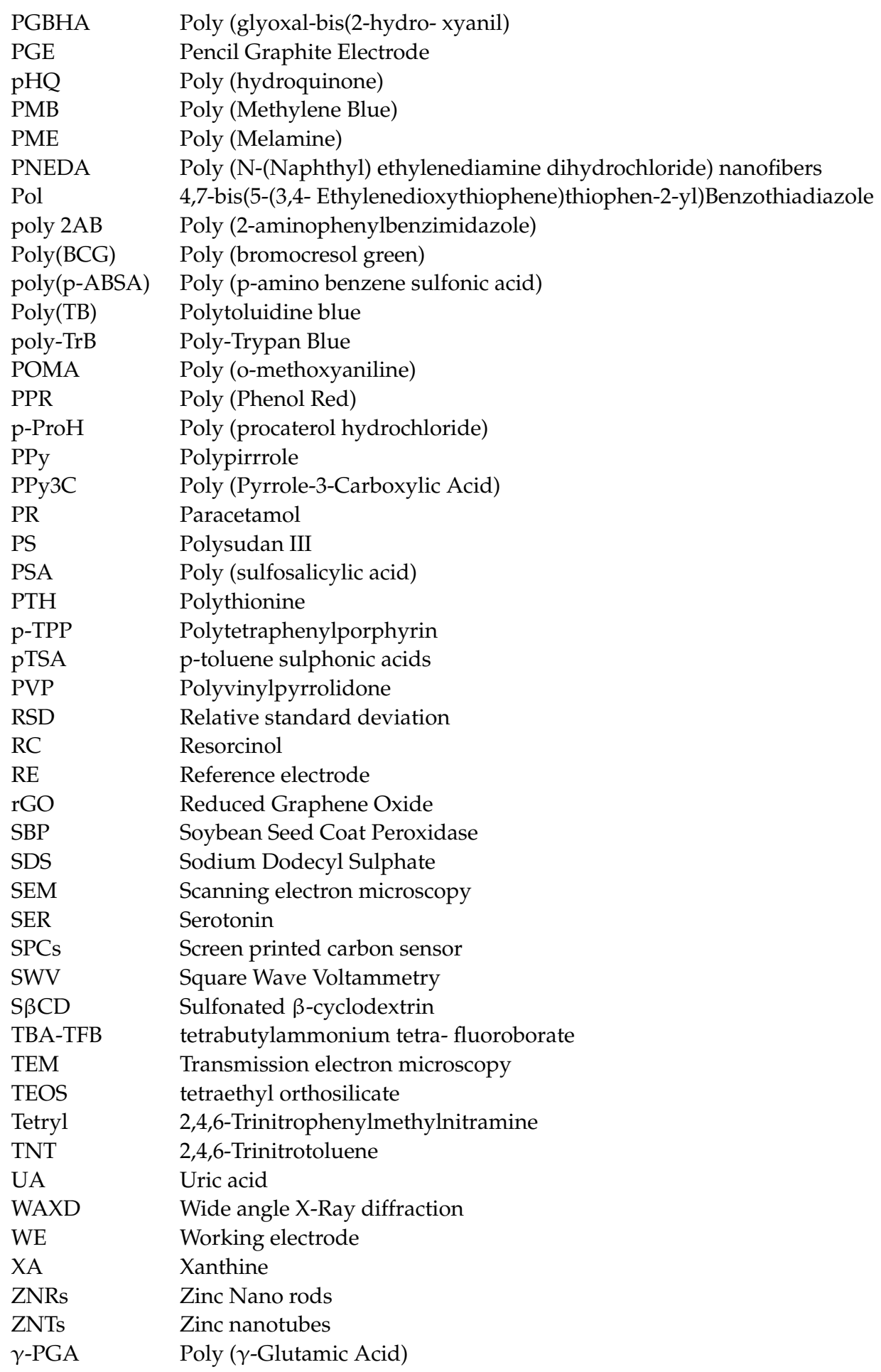

\section{References}

1. Sinha, K.; Das Mukhopadhyay, C. Quantitative detection of neurotransmitter using aptamer: From diagnosis to therapeutics. J. Biosci. 2020, 45, 1-12. [CrossRef]

2. Si, B.; Song, E. Recent Advances in the Detection of Neurotransmitters. Chemosensors 2018, 6, 1. [CrossRef]

3. Si, B.; Song, E. Molecularly imprinted polymers for the selective detection of multi-analyte neurotransmitters. Microelectron. Eng. 2018, 187-188, 58-65. [CrossRef]

4. Komoto, Y.; Ohshiro, T.; Yoshida, T.; Tarusawa, E.; Yagi, T.; Washio, T.; Taniguchi, M. Time-resolved neurotransmitter detection in mouse brain tissue using an artificial intelligence-nanogap. Sci. Rep. 2020, 10, 1-7. [CrossRef] 
5. Dai, X.; Fang, X.; Zhang, C.; Xu, R.; Xu, B. Determination of serum uric acid using high-performance liquid chromatography (HPLC)/isotope dilution mass spectrometry (ID-MS) as a candidate reference method. J. Chromatogr. B 2007, 857, 287-295. [CrossRef]

6. Wang, J.; Chang, Y.; Wu, W.B.; Zhang, P.; Lie, S.Q.; Huang, C. Label-free and selective sensing of uric acid with gold nanoclusters as optical probe. Talanta 2016, 152, 314-320. [CrossRef]

7. Badihi-Mossberg, M.; Buchner, V.; Rishpon, J. Electrochemical Biosensors for Pollutants in the Environment. Electroanalysis 2007, 19, 2015-2028. [CrossRef]

8. Xie, Z.; Ebinghaus, R. Analytical methods for the determination of emerging organic contaminants in the atmosphere. Anal. Chim. Acta 2008, 610, 156-178. [CrossRef]

9. Honeychurch, K.C.; Hart, J.P. Screen-printed electrochemical sensors for monitoring metal pollutants. TrAC Trends Anal. Chem. 2003, 22, 456-469. [CrossRef]

10. Dirtu, A.C.; Eede, N.V.D.; Malarvannan, G.; Ionas, A.C.; Covaci, A. Analytical methods for selected emerging contaminants in human matrices-A review. Anal. Bioanal. Chem. 2012, 404, 2555-2581. [CrossRef]

11. Lin, C.-Y.; Balamurugan, A.; Lai, Y.-H.; Ho, K.-C. A novel poly(3,4-ethylenedioxythiophene)/iron phthalocyanine/multiwall carbon nanotubes nanocomposite with high electrocatalytic activity for nitrite oxidation. Talanta 2010, 82, $1905-1911$. [CrossRef] [PubMed]

12. Endo, T.; Yanagida, Y.; Hatsuzawa, T. Quantitative determination of hydrogen peroxide using polymer coated Ag nanoparticles. Measurement 2008, 41, 1045-1053. [CrossRef]

13. Tohidinia, M.; Farsadrooh, M.; Bahmanzadeh, S.; Sabbaghi, N.; Noroozifar, M. Poly(quercetin)-bismuth nanowires as a new modifier for simultaneous voltammetric determination of dihydroxybenzene isomers and nitrite. RSC Adv. 2018, 8, 1237-1245. [CrossRef]

14. Kou, L.-J.; Liang, R.-N.; Wang, X.; Chen, Y.; Qin, W. Potentiometric sensor for determination of neutral bisphenol A using a molecularly imprinted polymer as a receptor. Anal. Bioanal. Chem. 2013, 405, 4931-4936. [CrossRef]

15. Goodson, K.L.; Pitt, R.; Subramaniam, S.; Clark, S. The Effect of Increased Flows on the Treatability of Emerging Contaminants at a Wastewater Treatment Plant during Rain Events. Proc. Water Environ. Fed. 2012, 2012, 7224-7237. [CrossRef]

16. Arciuli, M.; Palazzo, G.; Gallone, A.; Mallardi, A. Bioactive paper platform for colorimetric phenols detection. Sens. Actuators B Chem. 2013, 186, 557-562. [CrossRef]

17. Baek, S.; Lee, Y.; Son, Y. Amperometric Phenol Sensors Employing Conducting Polymer Microtubule Structure. Mol. Cryst. Liq. Cryst. 2010, 519, 69-76. [CrossRef]

18. Prehn, R.; Gonzalo-Ruiz, J.; Cortina-Puig, M. Electrochemical Detection of Polyphenolic Compounds in Foods and Beverages. Curr. Anal. Chem. 2012, 8, 472-484. [CrossRef]

19. El-Kosasy, A.M.; Riad, S.M.; El-Fattah, L.E.A.; Ahmad, S.A.E.-K. Novel poly (vinyl chloride) matrix membrane electrodes for the determination of phenolic pollutants in waste water. Water Res. 2003, 37, 1769-1775. [CrossRef]

20. Yang, C.; Xu, J.; Hu, S. Development of a novel nitrite amperometric sensor based on poly (toluidine blue) film electrode. J. Solid State Electrochem. 2006, 11, 514-520. [CrossRef]

21. Qu, J.; Dong, Y.; Wang, Y.; Lou, T.; Du, X.; Qu, J. Novel Nanofilm Sensor Based on Poly-(Alizarin Red)/Fe3O4 Magnetic Nanoparticles-Multiwalled Carbon Nanotubes Composite Material for Determination of Nitrite. J. Nanosci. Nanotechnol. 2016, 16, 2731-2736. [CrossRef] [PubMed]

22. Wang, H.; Yang, P.-H.; Cai, H.-H.; Cai, J. Constructions of polyaniline nanofiber-based electrochemical sensor for specific detection of nitrite and sensitive monitoring of ascorbic acid scavenging nitrite. Synth. Met. 2012, 162, 326-331. [CrossRef]

23. Dong, X.M.; Cui, Y.Z.; Li, T.D. Synthesis of Carbazole Modified Glass Plate for Detecting Nitroaromatic Compounds. Adv. Mater. Res. 2012, 557, 1074-1077. [CrossRef]

24. Green, L.; Wagner, D.A.; Glogowski, J.; Skipper, P.L.; Wishnok, J.S.; Tannenbaum, S.R. Analysis of nitrate, nitrite, and [15N]nitrate in biological fluids. Anal. Biochem. 1982, 126, 131-138. [CrossRef]

25. Bernal, J.; Del Nozal, M.J.; Martin, M.; Jiménez, J. Possibilities of gas chromatography-atomic emission detection in pesticide multiresidue analysis Application to herbicide analysis in soils. J. Chromatogr. A 1996, 754, 245-256. [CrossRef]

26. Jenkins, A.L.; Yin, R.; Jensen, J.L. Molecularly imprinted polymer sensors for pesticide and insecticide detection in water. Anal. Camb. UK 2001, 126, 798-802. [CrossRef]

27. Badea, M.; Amine, A.; Palleschi, G.; Moscone, D.; Volpe, G.; Curulli, A. New electrochemical sensors for detection of nitrites and nitrates. J. Electroanal. Chem. 2001, 509, 66-72. [CrossRef]

28. Toal, S.J.; Trogler, W.C. Polymer sensors for nitroaromatic explosives detection. J. Mater. Chem. 2006, 16, 2871-2883. [CrossRef]

29. Ronkainen, N.J.; Halsall, H.B.; Heineman, W.R. Electrochemical biosensors. Chem. Soc. Rev. 2010, 39, 1747-1763. [CrossRef]

30. Bonetto, M.C.; Muñoz, F.F.; Diz, V.E.; Sacco, N.J.; Cortón, E. Fused and unzipped carbon nanotubes, electrochemically treated, for selective determination of dopamine and serotonin. Electrochim. Acta 2018, 283, 338-348. [CrossRef]

31. Yang, Y.; Li, M.; Zhu, Z. A novel electrochemical sensor based on carbon nanotubes array for selective detection of dopamine or uric acid. Talanta 2019, 201, 295-300. [CrossRef] [PubMed]

32. Naseri, M.; Dorrajia, P.S.; Ehsani, A. Recent Progress in the Development of Conducting Polymer-Based Nanocomposites for Electrochemical Biosensors Applications: A Mini-Review. Chem. Rec. 2018, 18, 599-618. [CrossRef] [PubMed] 
33. Song, N.-N.; Wang, Y.-Z.; Yang, X.-Y.; Zong, H.-L.; Chen, Y.-X.; Ma, Z.; Chen, C.-X. A novel electrochemical biosensor for the determination of dopamine and ascorbic acid based on graphene oxide / poly(aniline-co-thionine) nanocomposite. J. Electroanal. Chem. 2020, 873, 114352. [CrossRef]

34. Yamaguchi, I.; Fujii, N.; Wang, A. $\pi$-Conjugated polymer with Alloxazine-6,9-diyl unit in the Main chain: Synthesis, chemical properties, and sensing ability for metal ions and nucleosides. React. Funct. Polym. 2020, 155, 104691. [CrossRef]

35. Samanta, S.; Roy, P.; Kar, P. Sensing of ethanol and other alcohol contaminated ethanol by conducting functional poly(ophenylenediamine). Mater. Sci. Eng. B 2020, 256, 114541. [CrossRef]

36. Moon, J.-M.; Thapliyal, N.; Hussain, K.K.; Goyal, R.N.; Shim, Y.-B. Conducting polymer-based electrochemical biosensors for neurotransmitters: A review. Biosens. Bioelectron. 2018, 102, 540-552. [CrossRef]

37. Guinovart, T.; Parrilla, M.; Crespo, G.A.; Rius, F.X.; Andrade, F.J. Potentiometric sensors using cotton yarns, carbon nanotubes and polymeric membranes. Analyst 2013, 138, 5208-5215. [CrossRef]

38. Coyle, S.; Curto, V.F.; Benito-Lopez, F.; Florea, L.; Diamond, D. Wearable Bio and Chemical Sensors; Elsevier BV: Amsterdam, The Netherlands, 2014; pp. 65-83.

39. Ghosh, S.K.; Calizo, I.; Teweldebrhan, D.; Pokatilov, E.P.; Nika, D.L.; Balandin, A.A.; Bao, W.; Miao, F.; Lau, C.N. Extremely high thermal conductivity of graphene: Prospects for thermal management applications in nanoelectronic circuits. Appl. Phys. Lett. 2008, 92, 151911. [CrossRef]

40. Shao, Y.; Wang, J.; Wu, H.; Liu, J.; Aksay, I.A.; Lin, Y. Graphene Based Electrochemical Sensors and Biosensors: A Review. Electroanalysis 2010, 22, 1027-1036. [CrossRef]

41. Stetter, J.R.; Penrose, W.R.; Yao, S. Sensors, Chemical Sensors, Electrochemical Sensors, and ECS. J. Electrochem. Soc. 2003, 150, S11-S16. [CrossRef]

42. Stradiotto, N.R.; Yamanaka, H.; Zanoni, M.V.B. Electrochemical sensors: A powerful tool in analytical chemistry. J. Braz. Chem. Soc. 2003, 14, 159-173. [CrossRef]

43. Wang, Y.; Liu, A.; Han, Y.; Li, T. Sensors based on conductive polymers and their composites: A review. Polym. Int. 2020, 69, 7-17. [CrossRef]

44. Domínguez-Renedo, O.; Alonso-Lomillo, M.A.; Arcos-Martínez, M.J. Determination of Metals Based on Electrochemical Biosensors. Crit. Rev. Environ. Sci. Technol. 2013, 43, 1042-1073. [CrossRef]

45. Skotheim, T.A.; Reynolds, J.R. Handbook of Conducting Polymers: Conjugated Polymers Processing and Applications; CRC Press: Boca Raton, FL, USA, 2007; ISBN 9781420043587.

46. Rattan, S.; Singhal, P.; Verma, A. Synthesis of PEDOT: PSS (poly(3,4-ethylenedioxythiophene))/poly(4-styrene sulfonate))/ngps (nanographitic platelets) nanocomposites as chemiresistive sensors for detection of nitroaromatics. Polym. Eng. Sci. 2013, 53, 2045-2052. [CrossRef]

47. Wang, G.; Morrin, A.; Li, M.; Liu, N.; Luo, X. Nanomaterial-doped conducting polymers for electrochemical sensors and biosensors. J. Mater. Chem. B 2018, 6, 4173-4190. [CrossRef]

48. Ibanez, J.G.; Rincón, M.E.; Gutierrez-Granados, S.; Chahma, M.; Jaramillo-Quintero, O.A.; Frontana-Uribe, B.A. Conducting Polymers in the Fields of Energy, Environmental Remediation, and Chemical-Chiral Sensors. Chem. Rev. 2018, 118, 4731-4816. [CrossRef]

49. Park, C.S.; Lee, C.-S.; Kwon, O.S. Conducting Polymer Based Nanobiosensors. Polym. Basel 2016, 8, 249. [CrossRef]

50. Naveen, M.H.; Gurudatt, N.G.; Shim, Y.-B. Applications of conducting polymer composites to electrochemical sensors: A review. Appl. Mater. Today 2017, 9, 419-433. [CrossRef]

51. Thévenot, D.R.; Toth, K.; Durst, R.A.; Wilson, G.S. Electrochemical biosensors: Recommended definitions and classification. Biosens. Bioelectron. 2001, 16, 121-131. [CrossRef]

52. Lobnik, A.; Turel, M.; Korent, P. Optical Chemical Sensors: Design and Applications. In Advances in Chemical Sensors; IntechOpen: London, UK, 2012.

53. Scheller, F.; Hintsche, R.; Pfeiffer, D.; Schubert, F.; Riedel, K.; Kindervater, R. Biosensors: Fundamentals, applications and trends. Sens. Actuators B Chem. 1991, 4, 197-206. [CrossRef]

54. Kreysa, G.; Ota, K.; Savinell, R.F. (Eds.) Encyclopedia of Applied Electrochemistry; Springer: New York, NY, USA, 2014; ISBN 978-1-4419-6995-8.

55. Wang, J. Analytical Electrochemistry; John Wiley \& Sons, Inc.: Hoboken, NJ, USA, 2006; ISBN 9780471790303.

56. Bard, A.J. Electrochemical Methods: Fundamentals and Applications, 2nd ed.; Bard, A.J., Faulkner, L.R., Eds.; John Wiley: New York, NY, USA, 2001; ISBN 0471043729.

57. Elgrishi, N.; Rountree, K.J.; McCarthy, B.D.; Rountree, E.S.; Eisenhart, T.T.; Dempsey, J.L. A Practical Beginner's Guide to Cyclic Voltammetry. J. Chem. Educ. 2018, 95, 197-206. [CrossRef]

58. Evans, D.H. Review of Voltammetric Methods for the Study of Electrode Reactions. In Microelectrodes: Theory and Applications; Springer Science and Business Media LLC: Berlin, Germany, 1991; pp. 17-32.

59. Lenik, J. Cyclodextrins Based Electrochemical Sensors for Biomedical and Pharmaceutical Analysis. Curr. Med. Chem. 2017, 24, 2359-2391. [CrossRef] [PubMed]

60. Kissinger, P.T.; Heineman, W.R. Cyclic voltammetry. J. Chem. Educ. 1983, 60, 702. [CrossRef]

61. Mabbott, G.A. An introduction to cyclic voltammetry. J. Chem. Educ. 1983, 60, 697. [CrossRef] 
62. Kawagoe, K.T.; Zimmerman, J.B.; Wightman, R. Principles of voltammetry and microelectrode surface states. J. Neurosci. Methods 1993, 48, 225-240. [CrossRef]

63. Henstridge, M.C.; Laborda, E.; Rees, N.V.; Compton, R.G. Marcus-Hush-Chidsey theory of electron transfer applied to voltammetry: A review. Electrochim. Acta 2012, 84, 12-20. [CrossRef]

64. Bard, A.J.; Faulkner, L.R. Electrochemical Methods_Fundamentals and Applications; Wiley: New York, NY, USA, $1980 ;$ p. 718.

65. Keteklahijani, Y.Z. Development of Electrochemical Sensors Based on Polymer Nanocomposites for Sensing of Neurotransmitter Dopamine. Ph.D. Dissertation, University of Calgary, Calgary, AB, Canada, 2020.

66. Rifkin, S.C.; Evans, D.H. General equation for voltammetry with step-functional potential changes applied to differential pulse voltammetry. Anal. Chem. 1976, 48, 1616-1618. [CrossRef]

67. Simões, F.R.; Xavier, M. Electrochemical Sensors. In Nanoscience and its Applications; Elsevier BV: Amsterdam, The Netherlands, 2017; pp. 155-178. ISBN 9780323497800.

68. Dias, L.G.; Meirinho, S.G.; Veloso, A.C.; Rodrigues, L.R.; Peres, A.M. Electronic Tongues and Aptasensors; Elsevier BV: Amsterdam, The Netherlands, 2017; pp. 371-402. ISBN 9780081007464.

69. Franklin, R.; Martin, S.; Strong, T.; Brown, R. Chemical and Biological Systems: Chemical Sensing Systems for Liquids; Elsevier BV: Amsterdam, The Netherlands, 2016; ISBN 9780128035818.

70. Scott, K. Electrochemical principles and characterization of bioelectrochemical systems. In Microbial Electrochemical and Fuel Cells; Elsevier BV: Amsterdam, The Netherlands, 2016; pp. 29-66. ISBN 9781782423966.

71. Marx, Í.M.G.; Veloso, A.C.; Dias, L.G.; Casal, S.; Pereira, J.A.; Peres, A.M. Electrochemical Sensor-Based Devices for Assessing Bioactive Compounds in Olive Oils: A Brief Review. Electronics 2018, 7, 387. [CrossRef]

72. Adeloju, S. Amperometry. In Encyclopedia of Analytical Science; Elsevier BV: Amsterdam, The Netherlands, 2004; pp. 70-79. ISBN 9780123693976.

73. Gaudin, V. Chapter 11: Receptor-based electrochemical biosensors for the detection of contaminants in food products. In Electrochemical Biosensors; Ensafi, A.A., Ed.; Elsevier: Amsterdam, The Netherlands, 2019; pp. 307-365. [CrossRef]

74. Delahay, P.; Mamantov, G. Voltammetry at Constant Current: Review of Theoretical Principles. Anal. Chem. 1955, 27, 478-483. [CrossRef]

75. Westbroek, P. Electrochemical methods. In Analytical Electrochemistry in Textiles; Elsevier BV: Amsterdam, The Netherlands, 2005; pp. 37-69. ISBN 9781855739192.

76. Amine, A.; Mohammadi, H. Amperometry. In Reference Module in Chemistry, Molecular Sciences and Chemical Engineering; Elsevier BV: Amsterdam, The Netherlands, 2018; ISBN 9780081019832.

77. Roy, N.; Yasmin, S.; Jeon, S. Effective electrochemical detection of dopamine with highly active molybdenum oxide nanoparticles decorated on 2, 6 diaminopyridine/reduced graphene oxide. Microchem. J. 2020, 153, 104501. [CrossRef]

78. Ramachandran, R.; Leng, X.; Zhao, C.; Xu, Z.-X.; Wang, F. 2D siloxene sheets: A novel electrochemical sensor for selective dopamine detection. Appl. Mater. Today 2020, 18, 100477. [CrossRef]

79. Lu, Z.; Li, Y.; Liu, T.; Wang, G.; Sun, M.; Jiang, Y.; He, H.; Wang, Y.; Zou, P.; Wang, X.; et al. A dual-template imprinted polymer electrochemical sensor based on AuNPs and nitrogen-doped graphene oxide quantum dots coated on NiS2/biomass carbon for simultaneous determination of dopamine and chlorpromazine. Chem. Eng. J. 2020, 389, 124417. [CrossRef]

80. Wang, Y.; Wang, S.; Tao, L.; Min, Q.; Xiang, J.; Wang, Q.; Xie, J.; Yue, Y.; Wu, S.; Li, X.; et al. A disposable electrochemical sensor for simultaneous determination of norepinephrine and serotonin in rat cerebrospinal fluid based on MWNTs-ZnO/chitosan composites modified screen-printed electrode. Biosens. Bioelectron. 2015, 65, 31-38. [CrossRef] [PubMed]

81. Poh, E.Z.; Hahne, D.; Moretti, J.; Harvey, A.R.; Clarke, M.; Rodger, J. Simultaneous quantification of dopamine, serotonin, their metabolites and amino acids by LC-MS/MS in mouse brain following repetitive transcranial magnetic stimulation. Neurochem. Int. 2019, 131, 104546. [CrossRef]

82. Kemp, S.F.; Lockey, R.F.; Simons, F.E.R. On behalf of the World Allergy Organization ad hoc Committee on Epinephrine in Anaphylaxis Epinephrine: The drug of choice for anaphylaxis-A statement of the World Allergy Organization. Allergy 2008, 63, 1061-1070. [CrossRef]

83. Zhou, K.; Shen, D.; Li, X.; Chen, Y.; Hou, L.; Zhang, Y.; Sha, J. Molybdenum oxide-based metal-organic framework/polypyrrole nanocomposites for enhancing electrochemical detection of dopamine. Talanta 2020, 209, 120507. [CrossRef]

84. Jain, R.; Jadon, N.; Pawaiya, A. Polypyrrole based next generation electrochemical sensors and biosensors: A review. TrAC Trends Anal. Chem. 2017, 97, 363-373. [CrossRef]

85. Qian, T.; Yu, C.; Zhou, X.; Wu, S.; Shen, J. Au nanoparticles decorated polypyrrole/reduced graphene oxide hybrid sheets for ultrasensitive dopamine detection. Sens. Actuators B Chem. 2014, 193, 759-763. [CrossRef]

86. Adhikari, A.; De, S.; Halder, A.; Pattanayak, S.; Dutta, K.; Mondal, D.; Rana, D.; Ghosh, R.; Bera, N.K.; Chattopadhyay, S.; et al. Biosurfactant tailored synthesis of porous polypyrrole nanostructures: A facile approach towards $\mathrm{CO} 2$ adsorption and dopamine sensing. Synth. Met. 2018, 245, 209-222. [CrossRef]

87. Harley, C.C.; Annibaldi, V.; Yu, T.; Breslin, C.B. The selective electrochemical sensing of dopamine at a polypyrrole film doped with an anionic $\beta$-cyclodextrin. J. Electroanal. Chem. 2019, 855, 113614. [CrossRef]

88. Chen, X.; Li, D.; Ma, W.; Yang, T.; Zhang, Y.; Zhang, D. Preparation of a glassy carbon electrode modified with reduced graphene oxide and overoxidized electropolymerized polypyrrole, and its application to the determination of dopamine in the presence of ascorbic acid and uric acid. Microchim. Acta 2019, 186, 407. [CrossRef] [PubMed] 
89. Demirkan, B.; Bozkurt, S.; Cellat, K.; Arıkan, K.; Yılmaz, M.; Şavk, A.; Çalımlı, M.H.; Nas, M.S.; Atalar, M.N.; Alma, M.H.; et al. Palladium supported on polypyrrole/reduced graphene oxide nanoparticles for simultaneous biosensing application of ascorbic acid, dopamine, and uric acid. Sci. Rep. 2020, 10, 1-10. [CrossRef]

90. Wang, H.-H.; Chen, X.-J.; Li, W.-T.; Zhou, Z.; Guo, X.-C.; Kang, W.-Y.; Kou, D.-X.; Zhou, Z.-J.; Meng, Y.-N.; Tian, Q.; et al. ZnO nanotubes supported molecularly imprinted polymers arrays as sensing materials for electrochemical detection of dopamine. Talanta 2018, 176, 573-581. [CrossRef] [PubMed]

91. Liu, Y.-C.; Hsu, W.-F.; Wu, T.-M. Electrochemical determination of dopamine using a conductive polypyrrole/carbon-coated mesoporous silica composite electrode. J. Appl. Electrochem. 2020, 50, 311-319. [CrossRef]

92. Eom, G.; Oh, C.; Moon, J.; Kim, H.; Kim, M.K.; Kim, K.; Seo, J.-W.; Kang, T.; Lee, H.J. Highly sensitive and selective detection of dopamine using overoxidized polypyrrole/sodium dodecyl sulfate-modified carbon nanotube electrodes. J. Electroanal. Chem. 2019, 848, 113295. [CrossRef]

93. Adhikari, A.; De, S.; Rana, D.; Nath, J.; Ghosh, D.; Dutta, K.; Chakraborty, S.; Chattopadhyay, S.; Chakraborty, M.; Chattopadhyay, D. Selective sensing of dopamine by sodium cholate tailored polypyrrole-silver nanocomposite. Synth. Met. 2020, 260, 116296. [CrossRef]

94. Li, Z.; Zhou, X.; Shi, J.; Zou, X.; Huang, X.; Tahir, H.E.; ZhiHua, L.; Xucheng, Z.; Jiyong, S.; Xiaobo, Z.; et al. Preparation of conducting polyaniline/protoporphyrin composites and their application for sensing VOCs. Food Chem. 2019, 276, 291-297. [CrossRef] [PubMed]

95. Ebrahim, S.; Shokry, A.; Khalil, M.M.A.; Ibrahim, H.; Soliman, M. Polyaniline/Ag nanoparticles/graphene oxide nanocomposite fluorescent sensor for recognition of chromium (VI) ions. Sci. Rep. 2020, 10, 1-11. [CrossRef]

96. Alfano, B.; Massera, E.; De Maria, A.; De Girolamo, A.; Di Francia, G.; Veneri, P.D.; Napolitano, T.; Borriello, A. Polyaniline proton doping for sensor application. In Proceedings of the 2015 XVIII AISEM Annual Conference, Trento, Italy, 3-5 February 2015; pp. 1-4.

97. Ashraf, P.M.; Lalitha, K.; Edwin, L. Synthesis of polyaniline hybrid composite: A new and efficient sensor for the detection of total volatile basic nitrogen molecules. Sens. Actuators B Chem. 2015, 208, 369-378. [CrossRef]

98. Mahalakshmi, S.; Sridevi, V. Conducting, crystalline and electroactive polyaniline-Au nanocomposites through combined acid and oxidative doping pathways for biosensing applications: Detection of dopamine. Mater. Chem. Phys. 2019, 235, 121728. [CrossRef]

99. Chang, Y.H.; Abdullah, J.; Alias, Y.B. The selective electrochemical detection of dopamine in the presence of ascorbic acid and uric acid using electro-polymerised- $\beta$-cyclodextrin incorporated f-MWCNTs/polyaniline modified glassy carbon electrode. Microchem. J. 2019, 148, 322-330. [CrossRef]

100. Sangamithirai, D.; Munusamy, S.; Narayanan, V.; Stephen, A. A voltammetric biosensor based on poly(o-methoxyaniline)-gold nanocomposite modified electrode for the simultaneous determination of dopamine and folic acid. Mater. Sci. Eng. C 2018, 91, 512-523. [CrossRef] [PubMed]

101. Ganash, A.A.; AlQarni, S.A.; Hussein, M.A. Poly(aniline-co-o-anisidine)/graphene oxide Au nanocomposites for dopamine electrochemical sensing application. J. Appl. Electrochem. 2018, 49, 179-194. [CrossRef]

102. Rahman, M.; Ahmed, A.; Lee, J.-J. A Conducting Poly(N-(1-Naphthyl)ethylenediamine dihydrochloride) Nanofibers for the Sensitive and Interference-Free Detection of Dopamine. J. Electrochem. Soc. 2018, 165, B89-B95. [CrossRef]

103. Dükar, N.; Tunç, S.; Öztürk, K.; Demirci, S.; Dumangöz, M.; Çelebi, M.S.; Kuralay, F. Highly sensitive and selective dopamine sensing in biological fluids with one-pot prepared graphene/poly(o-phenylenediamine) modified electrodes. Mater. Chem. Phys. 2019, 228, 357-362. [CrossRef]

104. Kannan, A.; Sevvel, R. A highly selective and simultaneous determination of paracetamol and dopamine using poly-4amino-6-hydroxy-2-mercaptopyrimidine (Poly-AHMP) film modified glassy carbon electrode. J. Electroanal. Chem. 2017, 791, 8-16. [CrossRef]

105. Ramya, R.; Sangaranarayanan, M.V. Electrochemical Sensing of Anesthetics using Polythiophene Coated Glassy Carbon Electrodes. ChemistrySelect 2019, 4, 9776-9783. [CrossRef]

106. Dervisevic, M.; Senel, M.; Cevik, E. Novel impedimetric dopamine biosensor based on boronic acid functional polythiophene modified electrodes. Mater. Sci. Eng. C 2017, 72, 641-649. [CrossRef]

107. Gueye, M.N.; Carella, A.; Faure-Vincent, J.; Demadrille, R.; Simonato, J.-P. Progress in understanding structure and transport properties of PEDOT-based materials: A critical review. Prog. Mater. Sci. 2020, 108, 100616. [CrossRef]

108. Hui, Y.; Bian, C.; Xia, S.; Tong, J.; Wang, J. Synthesis and electrochemical sensing application of poly(3,4-ethylenedioxythiophene)based materials: A review. Anal. Chim. Acta 2018, 1022, 1-19. [CrossRef]

109. Meng, L.; Turner, A.P.; Mak, W.C. Tunable 3D nanofibrous and bio-functionalised PEDOT network explored as a conducting polymer-based biosensor. Biosens. Bioelectron. 2020, 159, 112181. [CrossRef] [PubMed]

110. Soares, A.L.; Zamora, M.L.; Marchesi, L.F.; Vidotti, M. Adsorption of catechol onto PEDOT films doped with gold nanoparticles: Electrochemical and spectroscopic studies. Electrochim. Acta 2019, 322, 134773. [CrossRef]

111. Donahue, M.J.; Sanchez-Sanchez, A.; Inal, S.; Qu, J.; Owens, R.M.; Mecerreyes, D.; Malliaras, G.G.; Martin, D.C. Tailoring PEDOT properties for applications in bioelectronics. Mater. Sci. Eng. R Rep. 2020, 140, 100546. [CrossRef]

112. Xu, G.; Jarjes, Z.A.; Desprez, V.; Kilmartin, P.A.; Travas-Sejdic, J. Sensitive, selective, disposable electrochemical dopamine sensor based on PEDOT-modified laser scribed graphene. Biosens. Bioelectron. 2018, 107, 184-191. [CrossRef] [PubMed] 
113. Sandoval-Rojas, A.P.; Cortés, M.T.; Hurtado, J. Electrochemical synthesis of poly(3,4-ethylenedioxythiophene) doped with a new bis(pyrazolyl)methane disulfonate and its behavior towards dopamine detection. J. Electroanal. Chem. 2019, 837, 200-207. [CrossRef]

114. Ali, A.; Jamal, R.; Abdiryim, T.; Huang, X. Synthesis of monodispersed PEDOT/Au hollow nanospheres and its application for electrochemical determination of dopamine and uric acid. J. Electroanal. Chem. 2017, 787, 110-117. [CrossRef]

115. Üğe, A.; Zeybek, D.K.; Zeybek, B. An electrochemical sensor for sensitive detection of dopamine based on MWCNTs/CeO 2 -PEDOT composite. J. Electroanal. Chem. 2018, 813, 134-142. [CrossRef]

116. Tukimin, N.; Abdullah, J.; Sulaiman, Y. Electrodeposition of poly(3,4-ethylenedioxythiophene)/reduced graphene oxide/manganese dioxide for simultaneous detection of uric acid, dopamine and ascorbic acid. J. Electroanal. Chem. 2018, 820, 74-81. [CrossRef]

117. Song, Z.; Sheng, G.; Cui, Y.; Li, M.; Song, Z.; Ding, C.; Luo, X. Low fouling electrochemical sensing in complex biological media by using the ionic liquid-doped conducting polymer PEDOT: Application to voltammetric determination of dopamine. Microchim. Acta 2019, 186, 220. [CrossRef]

118. Qian, Y.; Ma, C.; Song, H.; Gao, J.; Liu, M.; Xie, K.; Wang, S.; Sun, K.; Song, H. High performance electrochemical electrode based on polymeric composite film for sensing of dopamine and catechol. Sens. Actuators B Chem. 2018, 255, 1655-1662. [CrossRef]

119. Pananon, P.; Sriprachuabwong, C.; Wisitsoraat, A.; Chuysinuan, P.; Tuantranont, A.; Saparpakorn, P.; Dechtrirat, D. A facile one-pot green synthesis of gold nanoparticle-graphene-PEDOT:PSS nanocomposite for selective electrochemical detection of dopamine. RSC Adv. 2018, 8, 12724-12732. [CrossRef]

120. Inagaki, C.S.; Oliveira, M.M.; Bergamini, M.F.; Marcolino-Junior, L.H.; Zarbin, A.J.G. Facile synthesis and dopamine sensing application of three component nanocomposite thin films based on polythiophene, gold nanoparticles and carbon nanotubes. $J$. Electroanal. Chem. 2019, 840, 208-217. [CrossRef]

121. Naik, T.S.K.; Mwaurah, M.M.; Swamy, B.K. Fabrication of poly (sudan III) modified carbon paste electrode sensor for dopamine: A voltammetric study. J. Electroanal. Chem. 2019, 834, 71-78. [CrossRef]

122. Hsieh, M.-T.; Whang, T.-J. Mechanistic investigation on the electropolymerization of phenol red by cyclic voltammetry and the catalytic reactions toward acetaminophen and dopamine using poly(phenol red)-modified GCE. J. Electroanal. Chem. 2017, 795, 130-140. [CrossRef]

123. Kong, D.; Zhuang, Q.; Han, Y.; Xu, L.; Wang, Z.; Jiang, L.; Su, J.; Lu, C.; Chi, Y. Simultaneous voltammetry detection of dopamine and uric acid in human serum and urine with a poly(procaterol hydrochloride) modified glassy carbon electrode. Talanta 2018, 185, 203-212. [CrossRef] [PubMed]

124. Lu, J.; Kou, Y.; Jiang, X.; Wang, M.; Xue, Y.; Tian, B.; Tan, L. One-step preparation of poly(glyoxal-bis(2-hydroxyanil))-aminofunctionalized graphene quantum dots-MnO2 composite on electrode surface for simultaneous determination of vitamin B2 and dopamine. Colloids Surf. A Physicochem. Eng. Asp. 2019, 580, 123652. [CrossRef]

125. Li, X.; Lu, X.; Kan, X. 3D electrochemical sensor based on poly(hydroquinone)/gold nanoparticles/nickel foam for dopamine sensitive detection. J. Electroanal. Chem. 2017, 799, 451-458. [CrossRef]

126. Edris, N.M.M.A.; Abdullah, J.; Kamaruzaman, S.; Saiman, M.I.; Sulaiman, Y. Electrochemical reduced graphene oxidepoly(eriochrome black T)/gold nanoparticles modified glassy carbon electrode for simultaneous determination of ascorbic acid, dopamine and uric acid. Arab. J. Chem. 2018, 11, 1301-1312. [CrossRef]

127. Palakollu, V.N.; Karpoormath, R. Enhanced electrochemical sensing of dopamine based on carboxylic acid functionalized multi-walled carbon nanotubes/poly(toluidine blue) composite. Synth. Met. 2018, 245, 87-95. [CrossRef]

128. Arroquia, A.; Acosta, I.; Armada, M.P.G. Self-assembled gold decorated polydopamine nanospheres as electrochemical sensor for simultaneous determination of ascorbic acid, dopamine, uric acid and tryptophan. Mater. Sci. Eng. C 2020, 109, 110602. [CrossRef]

129. Ramya, R.; Muthukumaran, P.; Wilson, J. Electron beam-irradiated polypyrrole decorated with Bovine serum albumin pores: Simultaneous determination of epinephrine and L-tyrosine. Biosens. Bioelectron. 2018, 108, 53-61. [CrossRef] [PubMed]

130. Ghanbari, K.; Hajian, A. Electrochemical characterization of Au/ZnO/PPy/RGO nanocomposite and its application for simultaneous determination of ascorbic acid, epinephrine, and uric acid. J. Electroanal. Chem. 2017, 801, 466-479. [CrossRef]

131. Bonyadi, S.; Ghanbari, K.; Ghiasi, M. All-electrochemical synthesis of a three-dimensional mesoporous polymeric gC3N4/PANI/CdO nanocomposite and its application as a novel sensor for the simultaneous determination of epinephrine, paracetamol, mefenamic acid, and ciprofloxacin. New J. Chem. 2020, 44, 3412-3424. [CrossRef]

132. Tsele, T.P.; Adekunle, A.S.; Fayemi, O.E.; Ebenso, E.E. Electrochemical detection of Epinephrine using Polyaniline nanocomposite films doped with $\mathrm{TiO}_{2}$ and $\mathrm{RuO}_{2}$ Nanoparticles on Multi-walled Carbon Nanotube. Electrochim. Acta 2017, 243, 331-348. [CrossRef]

133. Zhang, J.; Guo, X.-T.; Zhou, J.-P.; Liu, G.-Z.; Zhang, S.-Y. Electrochemical preparation of surface molecularly imprinted poly(3aminophenylboronic acid)/MWCNTs nanocomposite for sensitive sensing of epinephrine. Mater. Sci. Eng. C 2018, 91, 696-704. [CrossRef] [PubMed]

134. Liu, F.; Kan, X. Conductive imprinted electrochemical sensor for epinephrine sensitive detection and double recognition. J. Electroanal. Chem. 2019, 836, 182-189. [CrossRef]

135. Taei, M.; Hasanpour, F.; Tavakkoli, N.; Bahrameian, M. Electrochemical characterization of poly(fuchsine acid) modified glassy carbon electrode and its application for simultaneous determination of ascorbic acid, epinephrine and uric acid. J. Mol. Liq. 2015, 211, 353-362. [CrossRef] 
136. Ding, M.; Zhou, Y.; Liang, X.; Zou, H.; Wang, Z.; Wang, M.; Ma, J. An electrochemical sensor based on graphene/poly(brilliant cresyl blue) nanocomposite for determination of epinephrine. J. Electroanal. Chem. 2016, 763, 25-31. [CrossRef]

137. Özcan, A.; Ilkbaş, S. Poly(pyrrole-3-carboxylic acid)-modified pencil graphite electrode for the determination of serotonin in biological samples by adsorptive stripping voltammetry. Sens. Actuators B Chem. 2015, 215, 518-524. [CrossRef]

138. Ran, G.; Chen, C.; Gu, C. Serotonin sensor based on a glassy carbon electrode modified with multiwalled carbon nanotubes, chitosan and poly(p-aminobenzenesulfonate). Microchim. Acta 2015, 182, 1323-1328. [CrossRef]

139. Raj, M.; Gupta, P.; Goyal, R.N.; Shim, Y.-B. Graphene/conducting polymer nano-composite loaded screen printed carbon sensor for simultaneous determination of dopamine and 5-hydroxytryptamine. Sens. Actuators B Chem. 2017, 239, 993-1002. [CrossRef]

140. Ran, G.; Chen, X.; Xia, Y. Electrochemical detection of serotonin based on a poly(bromocresol green) film and $\mathrm{Fe}_{3} \mathrm{O}_{4}$ nanoparticles in a chitosan matrix. RSC Adv. 2017, 7, 1847-1851. [CrossRef]

141. Al-Graiti, W.; Foroughi, J.; Liu, Y.; Chen, J. Hybrid Graphene/Conducting Polymer Strip Sensors for Sensitive and Selective Electrochemical Detection of Serotonin. ACS Omega 2019, 4, 22169-22177. [CrossRef] [PubMed]

142. Chung, S.; Akhtar, M.H.; Benboudiaf, A.; Park, D.; Shim, Y.-B. A Sensor for Serotonin and Dopamine Detection in Cancer Cells Line Based on the Conducting Polymer-Pd Complex Composite. Electroanalysis 2020, 32, 520-527. [CrossRef]

143. Soltani, Z.; Rasheed, K.; Kapusta, D.R.; Reisin, E. Potential role of uric acid in metabolic syndrome, hypertension, kidney injury, and cardiovascular diseases: Is it time for reappraisal? Curr. Hypertens. Rep. 2013, 15, 175-181. [CrossRef] [PubMed]

144. Dai, H.; Wang, N.; Wang, D.; Zhang, X.; Ma, H.; Lin, M. Voltammetric uric acid sensor based on a glassy carbon electrode modified with a nanocomposite consisting of polytetraphenylporphyrin, polypyrrole, and graphene oxide. Microchim. Acta 2016, 183, 3053-3059. [CrossRef]

145. Mahmoudian, M.; Basirun, W.; Sookhakian, M.; Abdullah, J.; Zalnezhad, E.; Hazarkhani, H.; Alias, Y. Synthesis and characterization of $\alpha-\mathrm{Fe} 2 \mathrm{O} 3 /$ polyaniline nanotube composite as electrochemical sensor for uric acid detection. Adv. Powder Technol. 2019, 30, 384-392. [CrossRef]

146. Rajabi, H.; Noroozifar, M. New synthesis of poly ortho-methoxyaniline nanostructures and its application to construct modified multi-wall carbon nanotube/graphite paste electrode for simultaneous determination of uric acid and folic acid. Mater. Sci. Eng. C 2017, 75, 791-797. [CrossRef]

147. Özcan, A.; Ilkbaş, S. Preparation of poly(3,4-ethylenedioxythiophene) nanofibers modified pencil graphite electrode and investigation of over-oxidation conditions for the selective and sensitive determination of uric acid in body fluids. Anal. Chim. Acta 2015, 891, 312-320. [CrossRef]

148. Huang, X.; Shi, W.; Li, J.; Bao, N.; Yu, C.; Gu, H. Determination of salivary uric acid by using poly(3,4-ethylenedioxythipohene) and graphene oxide in a disposable paper-based analytical device. Anal. Chim. Acta 2020, 1103, 75-83. [CrossRef]

149. Zheng, W.; Zhao, M.; Liu, W.; Yu, S.; Niu, L.; Li, G.; Li, H.; Liu, W. Electrochemical sensor based on molecularly imprinted polymer/reduced graphene oxide composite for simultaneous determination of uric acid and tyrosine. J. Electroanal. Chem. 2018, 813, 75-82. [CrossRef]

150. Yan, H.; Xiao, H.; Xie, Q.; Liu, J.; Sun, L.; Zhou, Y.; Zhang, Y.; Chao, L.; Chen, C.; Yao, S. Simultaneous electroanalysis of isoniazid and uric acid at poly(sulfosalicylic acid)/electroreduced carboxylated graphene modified glassy carbon electrode. Sens. Actuators B Chem. 2015, 207, 167-176. [CrossRef]

151. Taei, M.; Hasanpour, F.; Habibollahi, S.; Shahidi, L.; Habibolahi, S. Simultaneous electrochemical sensing of cysteine, uric acid and tyrosine using a novel Au-nanoparticles/poly-Trypan Blue modified glassy carbon electrode. J. Electroanal. Chem. 2017, 789, 140-147. [CrossRef]

152. Lan, D.; Zhang, L. Electrochemical synthesis of a novel purine-based polymer and its use for the simultaneous determination of dopamine, uric acid, xanthine and hypoxanthine. J. Electroanal. Chem. 2015, 757, 107-115. [CrossRef]

153. Shalini, A.; Paulraj, P.; Pandian, K.; Anbalagan, G.; Jaisankar, V. Single pot synthesis, characterization of PPy@C composites modified electrode for the electrocatalytic determination of ascorbic acid in commercial fruit samples. Surf. Interfaces 2019, 17, 100386. [CrossRef]

154. Fang, Y.; Qi, J.; Deng, M.; Tian, Y.; Wen, Q.; Wang, M. Preparation in-situ of carbon nanotubes/polyaniline modified electrode and application for ascorbic acid detection. J. Electroanal. Chem. 2015, 755, 39-46. [CrossRef]

155. Ji, W.-F.; Chu, C.-M.; Hsu, S.-C.; Lu, Y.-D.; Yu, Y.-C.; Santiago, K.S.; Yeh, J.-M. Synthesis and characterization of organo-soluble aniline oligomer-based electroactive doped with gold nanoparticles, and application to electrochemical sensing of ascorbic acid. Polym. Guildf 2017, 128, 218-228. [CrossRef]

156. Devi, C.L.; Narayanan, S.S. Poly(amido amine) dendrimer and silver nanoparticle-multi-walled carbon nanotubes composite with poly(neutral red)-modified electrode for the determination of ascorbic acid. Bull. Mater. Sci. 2019, 42, 73. [CrossRef]

157. Motshakeri, M.; Travas-Sejdic, J.; Phillips, A.R.; Kilmartin, P.A. Rapid electroanalysis of uric acid and ascorbic acid using a poly(3,4-ethylenedioxythiophene)-modified sensor with application to milk. Electrochim. Acta 2018, 265, 184-193. [CrossRef]

158. Du, X.; Zhang, Z.; Zhang, C.; Zhang, Y.; Chen, Q. One-step electrodeposition of poly (3,4-ethylenedioxythiophene) on carboxylated multi-wall carbon nanotubes and its application in ascorbic acid sensing. J. Electroanal. Chem. 2016, 782, 84-90. [CrossRef]

159. Ergün, E.; Kart, Ş.; Zeybek, D.K.; Zeybek, B. Simultaneous electrochemical determination of ascorbic acid and uric acid using poly(glyoxal-bis(2-hydroxyanil)) modified glassy carbon electrode. Sens. Actuators B Chem. 2016, 224, 55-64. [CrossRef]

160. Lee, H.; Hong, Y.S.; Baik, S.; Hyeon, T.; Kim, D.-H. Enzyme-Based Glucose Sensor: From Invasive to Wearable Device. Adv. Healthc. Mater. 2018, 7, e1701150. [CrossRef] 
161. Clark, L.C., Jr.; Lyons, C. Electrode systems for continuous monitoring in cardiovascular surgery. Ann. N. Y. Acad. Sci. 1962, 102, 29-45. [CrossRef]

162. Sabu, C.; Henna, T.; Raphey, V.; Nivitha, K.; Pramod, K. Advanced biosensors for glucose and insulin. Biosens. Bioelectron. 2019, 141, 111201. [CrossRef]

163. Thunyakontirakun, W.; Sriwichai, S.; Phanichphant, S.; Janmanee, R. Fabrication of poly(pyrrole-3-carboxylic acid)/graphene oxide composite thin film for glucose biosensor. Mater. Today Proc. 2019, 17, 2070-2077. [CrossRef]

164. Fang, L.; Liang, B.; Yang, G.; Hu, Y.; Zhu, Q.; Ye, X. A needle-type glucose biosensor based on PANI nanofibers and PU/E-PU membrane for long-term invasive continuous monitoring. Biosens. Bioelectron. 2017, 97, 196-202. [CrossRef] [PubMed]

165. Miao, Z.; Wang, P.; Zhong, A.; Yang, M.; Xu, Q.; Hao, S.; Hu, X. Development of a glucose biosensor based on electrodeposited gold nanoparticles-polyvinylpyrrolidone-polyaniline nanocomposites. J. Electroanal. Chem. 2015, 756, 153-160. [CrossRef]

166. Feng, X.; Cheng, H.; Pan, Y.; Zheng, H. Development of glucose biosensors based on nanostructured graphene-conducting polyaniline composite. Biosens. Bioelectron. 2015, 70, 411-417. [CrossRef]

167. Zheng, H.; Liu, M.; Yan, Z.; Chen, J. Highly selective and stable glucose biosensor based on incorporation of platinum nanoparticles into polyaniline-montmorillonite hybrid composites. Microchem. J. 2020, 152, 104266. [CrossRef]

168. Sun, L.; Ma, Y.; Zhang, P.; Chao, L.; Huang, T.; Xie, Q.; Chen, C.; Yao, S. An amperometric enzyme electrode and its biofuel cell based on a glucose oxidase-poly(3-anilineboronic acid)-Pd nanoparticles bionanocomposite for glucose biosensing. Talanta 2015, 138, 100-107. [CrossRef]

169. Li, J.; Bi, X.; Tamulevičius, S.; Erts, D.; Chang, C.-F.; Gu, Y. Fabrication of a biocompatible and continuous glucose biosensor with the poly(3,4-ethylenedioxythiophene) modified electrode. J. Taiwan Inst. Chem. Eng. 2019, 104, 1-7. [CrossRef]

170. Tekbaşoğlu, T.Y.; Soganci, T.; Ak, M.; Koca, A.; Şener, M.K. Enhancing biosensor properties of conducting polymers via copolymerization: Synthesis of EDOT-substituted bis(2-pyridylimino)isoindolato-palladium complex and electrochemical sensing of glucose by its copolymerized film. Biosens. Bioelectron. 2017, 87, 81-88. [CrossRef] [PubMed]

171. Krzyczmonik, P.; Socha, E.; Skrzypek, S. Electrochemical Detection of Glucose in Beverage Samples Using Poly(3,4ethylenedioxythiophene)-Modified Electrodes with Immobilized Glucose Oxidase. Electrocatalysis 2017, 9, 380-387. [CrossRef]

172. Krzyczmonik, P.; Socha, E.; Skrzypek, S. Immobilization of glucose oxidase on modified electrodes with composite layers based on poly(3,4-ethylenedioxythiophene). Bioelectrochemistry 2015, 101, 8-13. [CrossRef] [PubMed]

173. Dilgin, D.G.; Ertek, B.; Dilgin, Y. A low-cost, fast, disposable and sensitive biosensor study: Flow injection analysis of glucose at poly-methylene blue-modified pencil graphite electrode. J. Iran. Chem. Soc. 2018, 15, 1355-1363. [CrossRef]

174. Papi, M.A.P.; Caetano, F.R.; Bergamini, M.F.; Marcolino-Junior, L.H. Facile synthesis of a silver nanoparticles/polypyrrole nanocomposite for non-enzymatic glucose determination. Mater. Sci. Eng. C 2017, 75, 88-94. [CrossRef] [PubMed]

175. Yang, J.; Cho, M.; Pang, C.; Lee, Y. Highly sensitive non-enzymatic glucose sensor based on over-oxidized polypyrrole nanowires modified with $\mathrm{Ni}(\mathrm{OH})_{2}$ nanoflakes. Sens. Actuators B Chem. 2015, 211, 93-101. [CrossRef]

176. Ahammad, A.J.S.; Al Mamun, A.; Akter, T.; Mamun, M.A.; Faraezi, S.; Monira, F.Z. Enzyme-free impedimetric glucose sensor based on gold nanoparticles / polyaniline composite film. J. Solid State Electrochem. 2016, 20, 1933-1939. [CrossRef]

177. Sedghi, R.; Pezeshkian, Z. Fabrication of non-enzymatic glucose sensor based on nanocomposite of MWCNTs-COOH-Poly(2aminothiophenol)-Au NPs. Sens. Actuators B Chem. 2015, 219, 119-124. [CrossRef]

178. Ansari, S.A.; Ahmed, A.; Ferdousi, F.K.; Salam, A.; Shaikh, A.; Barai, H.R.; Lopa, N.S.; Rahman, M. Conducting poly(aniline blue)-gold nanoparticles composite modified fluorine-doped tin oxide electrode for sensitive and non-enzymatic electrochemical detection of glucose. J. Electroanal. Chem. 2019, 850, 113394. [CrossRef]

179. Azharudeen, A.M.; Karthiga, R.; Rajarajan, M.; Suganthi, A. Fabrication, characterization of polyaniline intercalated NiO nanocomposites and application in the development of non-enzymatic glucose biosensor. Arab. J. Chem. 2020, 13, 4053-4064. [CrossRef]

180. Hocevar, M.A.; Fabregat, G.; Armelin, E.; Ferreira, C.; Alemán, C. Nanometric polythiophene films with electrocatalytic activity for non-enzymatic detection of glucose. Eur. Polym. J. 2016, 79, 132-139. [CrossRef]

181. Amirzadeh, Z.; Javadpour, S.; Shariat, M.H.; Knibbe, R. Non-enzymatic glucose sensor based on copper oxide and multi-wall carbon nanotubes using PEDOT:PSS matrix. Synth. Met. 2018, 245, 160-166. [CrossRef]

182. Huang, P.-C.; Shen, M.-Y.; Yu, H.-H.; Wei, S.-C.; Luo, S.-C. Surface Engineering of Phenylboronic Acid-Functionalized Poly(3,4ethylenedioxythiophene) for Fast Responsive and Sensitive Glucose Monitoring. ACS Appl. Bio Mater. 2018, 1, 160-167. [CrossRef]

183. Hui, N.; Wang, S.; Xie, H.; Xu, S.; Niu, S.; Luo, X. Nickel nanoparticles modified conducting polymer composite of reduced graphene oxide doped poly(3,4-ethylenedioxythiophene) for enhanced nonenzymatic glucose sensing. Sens. Actuators B Chem. 2015, 221, 606-613. [CrossRef]

184. Mazloum-Ardakani, M.; Amin-Sadrabadi, E.; Khoshroo, A. Enhanced activity for non-enzymatic glucose oxidation on nickel nanostructure supported on PEDOT:PSS. J. Electroanal. Chem. 2016, 775, 116-120. [CrossRef]

185. Kim, D.-M.; Moon, J.-M.; Lee, W.-C.; Yoon, J.-H.; Choi, C.S.; Shim, Y.-B. A potentiometric non-enzymatic glucose sensor using a molecularly imprinted layer bonded on a conducting polymer. Biosens. Bioelectron. 2017, 91, 276-283. [CrossRef]

186. Hui, N.; Wang, W.; Xu, G.; Luo, X. Graphene oxide doped poly(3,4-ethylenedioxythiophene) modified with copper nanoparticles for high performance nonenzymatic sensing of glucose. J. Mater. Chem. B 2014, 3, 556-561. [CrossRef]

187. Wu, L.-N.; Zhong, J.-P.; Waqas, M.; Jiang, Z.; Fan, Y.; Sun, Y.; Li, J.; Chen, W. Controllable synthesis of six corner star-like Cu2O/PEDOT-MWCNT composites and their performance toward electrochemical glucose sensing. Electrochim. Acta 2019, 318, 837-846. [CrossRef] 
188. Wang, J.; Wang, M.; Guan, J.; Wang, C.; Wang, G. Construction of a non-enzymatic sensor based on the poly(ophenylenediamine)/Ag-NPs composites for detecting glucose in blood. Mater. Sci. Eng. C 2017, 71, 844-851. [CrossRef]

189. Liu, L.; Chen, Y.; Lv, H.; Wang, G.; Hu, X.; Wang, C. Construction of a non-enzymatic glucose sensor based on copper nanoparticles/poly(o-phenylenediamine) nanocomposites. J. Solid State Electrochem. 2015, 19, 731-738. [CrossRef]

190. Vilela, E.T.; Carvalho, R.D.C.S.; Neto, S.Y.; Luz, R.D.C.S.; Damos, F.S. Exploiting charge/ions compensating processes in PANI/SPANI/reduced graphene oxide composite for development of a high sensitive $\mathrm{H}_{2} \mathrm{O}_{2}$ sensor. J. Electroanal. Chem. 2015, 752, 75-81. [CrossRef]

191. Luo, M.; Wang, W.; Zhao, Q.; Li, M.; Chen, Y.; Lu, Z.; Liu, K.; Wang, N. Chemiluminescence biosensor for hydrogen peroxide determination by immobilizing horseradish peroxidase onto PVA- co -PE nanofiber membrane. Eur. Polym. J. 2017, 91, 307-314. [CrossRef]

192. Ojani, R.; Hamidi, P.; Raoof, J.B. Efficient nonenzymatic hydrogen peroxide sensor in acidic media based on Prussian blue nanoparticles-modified poly(o-phenylenediamine)/glassy carbon electrode. Chin. Chem. Lett. 2016, 27, 481-486. [CrossRef]

193. Zhou, B.; Liang, L.-M.; Yao, J. Nanoflakes of an aminoacid-based chiral coordination polymer: Synthesis, optical and electrochemical properties, and application in electrochemical sensing of H2O2. J. Solid State Chem. 2015, 223, 152-155. [CrossRef]

194. Vilian, A.T.E.; Chen, S.-M.; Kwak, C.H.; Hwang, S.-K.; Huh, Y.S.; Huh, Y.S. Immobilization of hemoglobin on functionalized multi-walled carbon nanotubes-poly-l-histidine-zinc oxide nanocomposites toward the detection of bromate and $\mathrm{H}_{2} \mathrm{O}_{2}$. Sens. Actuators B Chem. 2016, 224, 607-617. [CrossRef]

195. Saidu, F.K.; Joseph, A.; Varghese, E.V.; Thomas, G.V. Silver nanoparticles-embedded poly(1-naphthylamine) nanospheres for low-cost non-enzymatic electrochemical $\mathrm{H}_{2} \mathrm{O}_{2}$ sensor. Polym. Bull. 2019, 77, 5825-5846. [CrossRef]

196. Mercante, L.A.; Facure, M.H.; Sanfelice, R.C.; Migliorini, F.; Mattoso, L.H.; Correa, D.S. One-pot preparation of PEDOT:PSSreduced graphene decorated with Au nanoparticles for enzymatic electrochemical sensing of $\mathrm{H}_{2} \mathrm{O}_{2}$. Appl. Surf. Sci. 2017, 407, 162-170. [CrossRef]

197. Zhang, R.; Jiang, C.; Fan, X.; Yang, R.; Sun, Y.; Zhang, C. A gold electrode modified with a nanoparticulate film composed of a conducting copolymer for ultrasensitive voltammetric sensing of hydrogen peroxide. Microchim. Acta 2018, 185, 58. [CrossRef]

198. Chen, C.; Hong, X.; Xu, T.; Chen, A.; Lu, L.; Gao, Y. Hydrogen peroxide biosensor based on the immobilization of horseradish peroxidase onto a poly(aniline-co-N-methylthionine) film. Synth. Met. 2016, 212, 123-130. [CrossRef]

199. Torres, D.I.; Miranda, M.V.; Orto, V.C.D. One-pot preparation of SBP-PANI-PAA-ethylene glycol diglycidyl ether sensor for electrochemical detection of $\mathrm{H}_{2} \mathrm{O}_{2}$. Sens. Actuators B Chem. 2017, 239, 1016-1025. [CrossRef]

200. Yusoff, F.; Muhamad, N.B. Synthesis and characterization of reduced graphene oxide/PEDOT composite as cathode materials for oxygen reduction reaction. Mater. Today Proc. 2019, 16, 2023-2029. [CrossRef]

201. Wang, J.; Wang, Y.; Cui, M.; Xu, S.; Luo, X. Enzymeless voltammetric hydrogen peroxide sensor based on the use of PEDOT doped with Prussian Blue nanoparticles. Microchim. Acta 2016, 184, 483-489. [CrossRef]

202. Lete, C.; Marin, M.; Anghel, E.M.; Preda, L.; Matei, C.; Lupu, S. Sinusoidal voltage electrodeposition of PEDOT-Prussian blue nanoparticles composite and its application to amperometric sensing of $\mathrm{H}_{2} \mathrm{O}_{2}$ in human blood. Mater. Sci. Eng. C 2019, 102, 661-669. [CrossRef] [PubMed]

203. Teker, M.Ş.; Karaca, E.; Pekmez, N.Ö.; Tamer, U.; Pekmez, K. Şen; Karaca, E.; Pekmez, N. Özçiçek; Tamer, U.; Pekmez, K. An Enzyme-free $\mathrm{H}_{2} \mathrm{O}_{2}$ Sensor Based on Poly(2-Aminophenylbenzimidazole)/Gold Nanoparticles Coated Pencil Graphite Electrode. Electroanalysis 2018, 31, 75-82. [CrossRef]

204. Lu, B.; Yuan, X.; Ren, Y.; Shi, Q.; Wang, S.; Dong, J.; Nan, Z.-D. Cost-effective three dimensional Ag/polymer dyes/graphenecarbon spheres hybrids for high performance nonenzymatic sensor and its application in living cell $\mathrm{H} 2 \mathrm{O} 2$ detection. Bioelectrochemistry 2018, 123, 103-111. [CrossRef] [PubMed]

205. Cui, H.-F.; Bai, Y.-F.; Wu, W.-W.; He, X.; Luong, J.H.T. Modification with mesoporous platinum and poly(pyrrole-3-carboxylic acid)-based copolymer on boron-doped diamond for nonenzymatic sensing of hydrogen peroxide. J. Electroanal. Chem. 2016, 766, 52-59. [CrossRef]

206. Gu, Y.; Yan, X.; Liu, W.; Li, C.; Chen, R.; Tang, L.; Lu, N.; Yang, M. Biomimetic sensor based on copper-poly(cysteine) film for the determination of metronidazole. Electrochim. Acta 2015, 152, 108-116. [CrossRef]

207. Xiao, N.; Deng, J.; Cheng, J.; Ju, S.; Zhao, H.; Xie, J.; Qian, D.; He, J. Carbon paste electrode modified with duplex molecularly imprinted polymer hybrid film for metronidazole detection. Biosens. Bioelectron. 2016, 81, 54-60. [CrossRef]

208. Gu, Y.; Yan, X.; Li, C.; Zheng, B.; Li, Y.; Liu, W.; Lu, N.; Yang, M. Biomimetic sensor based on molecularly imprinted polymer with nitroreductase-like activity for metronidazole detection. Biosens. Bioelectron. 2016, 77, 393-399. [CrossRef]

209. Yang, M.; Guo, M.; Feng, Y.; Lei, Y.; Cao, Y.; Zhu, D.; Yu, Y.; Ding, L. Sensitive Voltammetric Detection of Metronidazole Based on Three-Dimensional Graphene-Like Carbon Architecture/Polythionine Modified Glassy Carbon Electrode. J. Electrochem. Soc. 2018, 165, B530-B535. [CrossRef]

210. Wang, P.; Gan, T.; Zhang, J.; Luo, J.; Zhang, S. Polyvinylpyrrolidone-enhanced electrochemical oxidation and detection of acyclovir. J. Mol. Liq. 2013, 177, 129-132. [CrossRef]

211. Hamtaka, M.; Dorrajia, P.S.; Hosseinib, M.; Dorrajia, P.S. Improved Performance for Acyclovir Sensing in the Presence of Deep Eutectic Solvent and Nanostructures and Polymer. IEEE Sens. J. 2020, 20, 623-630. [CrossRef]

212. Heli, H.; Zarghan, M.; Jabbari, A.; Parsaei, A.; Moosavi-Movahedi, A.A. Electrocatalytic oxidation of the antiviral drug acyclovir on a copper nanoparticles-modified carbon paste electrode. J. Solid State Electrochem. 2009, 14, 787-795. [CrossRef] 
213. Dorraji, P.S.; Jalali, F. Differential pulse voltammetric determination of nanomolar concentrations of antiviral drug acyclovir at polymer film modified glassy carbon electrode. Mater. Sci. Eng. C 2016, 61, 858-864. [CrossRef]

214. Hamtak, M.; Dorrajia, P.S.; Hosseini, M.; Dorraji, P.S. Sensitive Determination of Acyclovir in Biological and Pharmaceutical Samples Based on Polymeric Film Decorated with Nanomaterials on Nanoporous Glassy Carbon Electrode. J. Electrochem. Soc. 2018, 165, B632-B637. [CrossRef]

215. Shahrokhianab, S.; Azimzadeh, M.; Amini, M.K. Modification of glassy carbon electrode with a bilayer of multiwalled carbon nanotube/tiron-doped polypyrrole: Application to sensitive voltammetric determination of acyclovir. Mater. Sci. Eng. C 2015, 53, 134-141. [CrossRef]

216. Ahmed, A.M.K.; Hanoon, I.T.; Ahmed, S.H. Determination of the Ciprofloxacin Hydrochloride Drug in Some Pharmaceuticals using Manufactured Membrane Selective Electrodes. Syst. Rev. Pharm. 2020, 11, 622-626. [CrossRef]

217. Hatamluyi, B.; Zahed, F.M.; Es'Haghi, Z.; Darroudi, M. Carbon Quantum Dots Co-catalyzed with ZnO Nanoflowers and Poly (CTAB) Nanosensor for Simultaneous Sensitive Detection of Paracetamol and Ciprofloxacin in Biological Samples. Electroanal. 2020, 32, 1818-1827. [CrossRef]

218. Pushpanjali, P.A.; Manjunatha, J.G.; Shreenivas, M.T. The Electrochemical Resolution of Ciprofloxacin, Riboflavin and Estriol Using Anionic Surfactant and Polymer-Modified Carbon Paste Electrode. ChemistrySelect 2019, 4, 13427-13433. [CrossRef]

219. Chauhan, R.; Gill, A.A.; Nate, Z.; Karpoormath, R. Highly selective electrochemical detection of ciprofloxacin using reduced graphene oxide/poly(phenol red) modified glassy carbon electrode. J. Electroanal. Chem. 2020, 871, 114254. [CrossRef]

220. Zhang, N.; Zhang, W.; Ye, J.; Zhan, S.; Xia, B.; Lv, J.; Xu, H.; Du, G.; Wang, L. A Label-Free Colorimetric Biosensor for $17 \beta$-Estradiol Detection Using Nanoparticles Assembled by Aptamer and Cationic Polymer. Aust. J. Chem. 2016, 69, 12-19. [CrossRef]

221. Wang, A.; Ding, Y.; Li, L.; Duan, D.; Mei, Q.; Zhuang, Q.; Cui, S.; He, X. A novel electrochemical enzyme biosensor for detection of $17 \beta$-estradiol by mediated electron-transfer system. Talanta 2019, 192, 478-485. [CrossRef] [PubMed]

222. Spychalska, K.; Zajac, D.; Cabaj, J. Electrochemical biosensor for detection of $17 \beta$-estradiol using semi-conducting polymer and horseradish peroxidase. RSC Adv. 2020, 10, 9079-9087. [CrossRef]

223. Liu, W.; Li, H.; Yu, S.; Zhang, J.; Zheng, W.; Niu, L.; Li, G. Poly(3,6-diamino-9-ethylcarbazole) based molecularly imprinted polymer sensor for ultra-sensitive and selective detection of 17- $\beta$-estradiol in biological fluids. Biosens. Bioelectron. 2018, 104, 79-86. [CrossRef]

224. Chiam, E.; Weinberg, L.; Bellomo, R. Paracetamol: A review with specific focus on the haemodynamic effects of intravenous administration. Hear. lung Vessel. 2015, 7, 121-132.

225. Li, M.; Wang, W.; Chen, Z.; Song, Z.; Luo, X. Electrochemical determination of paracetamol based on Au@graphene core-shell nanoparticles doped conducting polymer PEDOT nanocomposite. Sens. Actuators B Chem. 2018, 260, 778-785. [CrossRef]

226. Wei, Y.; Zeng, Q.; Bai, S.; Wang, M.; Wang, L. Nanosized Difunctional Photo Responsive Magnetic Imprinting Polymer for Electrochemically Monitored Light-Driven Paracetamol Extraction. ACS Appl. Mater. Interfaces 2017, 9, 44114-44123. [CrossRef]

227. Palakollu, V.N.; Chiwunze, T.E.; Liu, C.; Karpoormath, R. Electrochemical sensitive determination of acetaminophen in pharmaceutical formulations at iron oxide/graphene composite modified electrode. Arab. J. Chem. 2020, 13, 4350-4357. [CrossRef]

228. Dai, Y.; Li, X.; Lu, X.; Kan, X. Voltammetric determination of paracetamol using a glassy carbon electrode modified with Prussian Blue and a molecularly imprinted polymer, and ratiometric read-out of two signals. Microchim. Acta 2016, 183, 2771-2778. [CrossRef]

229. Kuskur, C.M.; Swamy, B.K.; Jayadevappa, H.; Ganesh, P.S. Poly (rhodamine B) sensor for norepinephrine and paracetamol: A voltammetric study. Ionics 2018, 24, 3631-3640. [CrossRef]

230. Kuskur, C.M.; Swamy, B.K.; Jayadevappa, H. Poly (naphthol green B) modified carbon paste electrode for the analysis of paracetamol and norepinephrine. Ionics 2018, 25, 1845-1855. [CrossRef]

231. Chitravathi, S.; Munichandraiah, N. Voltammetric determination of paracetamol, tramadol and caffeine using poly(Nile blue) modified glassy carbon electrode. J. Electroanal. Chem. 2016, 764, 93-103. [CrossRef]

232. Li, C.; Si, W.; Lei, B.; Zhang, C.; Lei, W.; Hao, Q. Electrochemical Determination of Paracetamol at Poly(3-Methylthiophene)/Reduced Graphene Oxide Modified Glassy Carbon Electrode. Nano 2018, 13, 13. [CrossRef]

233. Gholivand, M.-B.; Ahmadi, E. Square Wave Anodic Stripping Voltammetric Determination of Paracetamol at Poly Luminol/Functionalized Multi-Walled Carbon Nanotubes Modified Glassy Carbon Electrode. Russ. J. Electrochem. 2019, 55, 1151-1161. [CrossRef]

234. Sipa, K.; Socha, E.; Skrzypek, S.; Krzyczmonik, P. Electrodes Modified with Composite Layers Based on Poly(3,4ethylenedioxythiophene) as Sensors for Paracetamol. Anal. Sci. 2017, 33, 287-292. [CrossRef]

235. Bayram, E.; Akyilmaz, E. Development of a new microbial biosensor based on conductive polymer/multiwalled carbon nanotube and its application to paracetamol determination. Sens. Actuators B Chem. 2016, 233, 409-418. [CrossRef]

236. Kaur, B.; Prathap, M.U.A.; Srivastava, R. Synthesis of Transition-Metal Exchanged Nanocrystalline ZSM-5 and Their Application in Electrochemical Oxidation of Glucose and Methanol. ChemPlusChem 2012, 77, 1119-1127. [CrossRef]

237. Kaur, B.; Srivastava, R. Simultaneous determination of epinephrine, paracetamol, and folic acid using transition metal ionexchanged polyaniline-zeolite organic-inorganic hybrid materials. Sens. Actuators B Chem. 2015, 211, 476-488. [CrossRef]

238. Ghadimi, H.; Tehrani, R.M.A.; Basirun, W.J.; Ab Aziz, N.J.; Mohamed, N.; Ab Ghani, S. Electrochemical determination of aspirin and caffeine at MWCNTs-poly-4-vinylpyridine composite modified electrode. J. Taiwan Inst. Chem. Eng. 2016, 65, 101-109. [CrossRef] 
239. Feng, Q.; Zhao, Y.; Li, H.; Zhang, Y.; Xia, X.; Yan, Q. Frontal polymerization and characterization of interpenetrating polymer networks composed of poly(N-isopropylacrylamide) and polyvinylpyrrolidone. Colloid Polym. Sci. 2018, 296, 165-172. [CrossRef]

240. Suriyanarayanan, S.; Mandal, S.; Ramanujam, K.; Nicholls, I.A. Electrochemically synthesized molecularly imprinted polythiophene nanostructures as recognition elements for an aspirin-chemosensor. Sens. Actuators B Chem. 2017, 253, 428-436. [CrossRef]

241. Puangjan, A.; Chaiyasith, S.; Wichitpanya, S.; Daengduang, S.; Puttota, S. Electrochemical sensor based on $\mathrm{PANI} \mathrm{MnO}_{2}-\mathrm{Sb}_{2} \mathrm{O}_{3}$ nanocomposite for selective simultaneous voltammetric determination of ascorbic acid and acetylsalicylic acid. J. Electroanal. Chem. 2016, 782, 192-201. [CrossRef]

242. Deiminiat, B.; Razavipanah, I.; Rounaghi, G.H.; Arbab-Zavar, M.H. A novel electrochemical imprinted sensor for acetylsalicylic acid based on polypyrrole, sol-gel and $\mathrm{SiO}_{2} @$ Au core-shell nanoparticles. Sens. Actuators B Chem. 2017, 244, 785-795. [CrossRef]

243. Huxtable, R.J. Physiological actions of taurine. Physiol. Rev. 1992, 72, 101-163. [CrossRef] [PubMed]

244. Huxtable, R.J.; Sebring, L.A. Towards a unifying theory for the actions of taurine. Trends Pharmacol. Sci. 1986, 7, 481-485. [CrossRef]

245. Kupis-Rozmysłowicz, J.; Wagner, M.; Bobacka, J.; Lewenstam, A.; Migdalski, J. Biomimetic membranes based on molecularly imprinted conducting polymers as a sensing element for determination of taurine. Electrochim. Acta 2016, 188, 537-544. [CrossRef]

246. Brogden, R.N.; Pinder, R.M.; Sawyer, P.R.; Speight, T.M.; Avery, G.S. Naproxen. Drugs 1975, 9, 326-363. [CrossRef]

247. Eslami, M.R.; Alizadeh, N. Nanostructured conducting molecularly imprinted polypyrrole based quartz crystal microbalance sensor for naproxen determination and its electrochemical impedance study. RSC Adv. 2016, 6, 9387-9395. [CrossRef]

248. Green, A.R.; Cross, A.J.; Goodwin, G.M. Review of the pharmacology and clinical pharmacology of 3,4-methylenedioxymetham phetamine (MDMA or "Ecstasy"). Psychopharmacology 1995, 119, 247-260. [CrossRef]

249. Couto, R.A.; Costa, S.S.; Mounssef, B.; Pacheco, J.G.; Fernandes, E.; Carvalho, F.; Rodrigues, C.M.; Delerue-Matos, C.; Braga, A.A.C.; Gonçalves, L.M.; et al. Electrochemical sensing of ecstasy with electropolymerized molecularly imprinted poly(ophenylenediamine) polymer on the surface of disposable screen-printed carbon electrodes. Sens. Actuators B Chem. 2019, 290, 378-386. [CrossRef]

250. Rothgery, E.F. Hydrazine and Its Derivatives. In Kirk-Othmer Encyclopedia of Chemical Technology; Wiley: Hoboken, NJ, USA, 2004; ISBN 9780471238966.

251. Abbaspour, A.; Kamyabi, M.A. Electrocatalytic oxidation of hydrazine on a carbon paste electrode modified by hybrid hexacyanoferrates of copper and cobalt films. J. Electroanal. Chem. 2005, 576, 73-83. [CrossRef]

252. Blaza, J.N.; Bridges, H.R.; Aragão, D.; Dunn, E.A.; Heikal, A.; Cook, G.M.; Nakatani, Y.; Hirst, J. The mechanism of catalysis by type-II NADH:quinone oxidoreductases. Sci. Rep. 2017, 7, 40165. [CrossRef] [PubMed]

253. Rębiś, T.; Sobkowiak, M.; Milczarek, G. Electrocatalytic oxidation and detection of hydrazine at conducting polymer/lignosulfonate composite modified electrodes. J. Electroanal. Chem. 2016, 780, 257-263. [CrossRef]

254. Afshari, M.; Dinari, M.; Momeni, M.M. The graphitic carbon nitride/polyaniline/silver nanocomposites as a potential electrocatalyst for hydrazine detection. J. Electroanal. Chem. 2019, 833, 9-16. [CrossRef]

255. Zhang, T.; Asefa, T. Copper nanoparticles/polyaniline-derived mesoporous carbon electrocatalysts for hydrazine oxidation. Front. Chem. Sci. Eng. 2018, 12, 329-338. [CrossRef]

256. Lashkenari, M.S.; Shahrokhi, B.; Ghorbani, M.; Falah, J.; Rostami, H. Polyrhodanine/NiFe $2 \mathrm{O}_{4}$ nanocomposite: A novel electrocatalyst for hydrazine oxidation reaction. Int. J. Hydrog. Energy 2018, 43, 11244-11252. [CrossRef]

257. Ramaraj, S. A novel and Disposable Amperometric Hydrazine Sensor based on Polydimethyldiallylamine Stabilized Copper(II)hexacyanoferrate Nanocubes modified Screen- printed Carbon Electrode. Int. J. Electrochem. Sci. 2017, 12, 5567-5580. [CrossRef]

258. Beduk, T.; Bihar, E.; Surya, S.G.; Castillo, A.N.; Inal, S.; Salama, K.N. A paper-based inkjet-printed PEDOT:PSS/ZnO sol-gel hydrazine sensor. Sens. Actuators B Chem. 2020, 306, 127539. [CrossRef]

259. Faisal, M.; Harraz, F.A.; Al-Salami, A.; Al-Sayari, S.; Al-Hajry, A.; Al-Assiri, M. Polythiophene/ZnO nanocomposite-modified glassy carbon electrode as efficient electrochemical hydrazine sensor. Mater. Chem. Phys. 2018, 214, 126-134. [CrossRef]

260. Xu, F.; Xie, S.; Liu, Y.; Wang, L. Electrochemical preparation of a three dimensional PEDOT-Cu x O hybrid for enhanced oxidation and sensitive detection of hydrazine. Anal. Methods 2016, 8, 316-325. [CrossRef]

261. Karakaya, S. Development of an amperometric hydrazine sensor at a disposable poly(alizarin red S) modified pencil graphite electrode. Mon. Chem. Chem. Mon. 2019, 150, 1911-1920. [CrossRef]

262. Peng, H.; Liang, C. Electrochemical determination of hydrazine based on polydopamine-reduced graphene oxide nanocomposite. Full Nanotub. Carbon Nanostruct. 2016, 25, 29-33. [CrossRef]

263. Dai, J.; Deng, D.; Yuan, Y.; Zhang, J.; Deng, F.; He, S. Amperometric nitrite sensor based on a glassy carbon electrode modified with multi-walled carbon nanotubes and poly(toluidine blue). Microchim. Acta 2016, 183, 1553-1561. [CrossRef]

264. Hui, N.; Chai, F.; Lin, P.; Song, Z.; Sun, X.; Li, Y.; Niu, S.; Luo, X. Electrodeposited Conducting Polyaniline Nanowire Arrays Aligned on Carbon Nanotubes Network for High Performance Supercapacitors and Sensors. Electrochim. Acta 2016, 199, 234-241. [CrossRef]

265. Kannan, A.; Sivanesan, A.; Kalaivani, G.; Manivel, A.; Sevvel, R. A highly selective and simultaneous determination of ascorbic acid, uric acid and nitrite based on a novel poly-N-acetyl-1-methionine (poly-NALM) thin film. RSC Adv. 2016, 6, 96898-96907. [CrossRef] 
266. Dağcı, K.; Alanyalıŏlu, M. Preparation of Free-Standing and Flexible Graphene/Ag Nanoparticles/Poly(pyronin Y) Hybrid Paper Electrode for Amperometric Determination of Nitrite. ACS Appl. Mater. Interfaces 2016, 8, 2713-2722. [CrossRef]

267. Liu, W.; Gu, Y.; Sun, G.; Na, K.; Li, C.; Tang, L.; Zhang, Z.; Yang, M. Poly(diallydimethylammonium chloride) Functionalized Graphene/Double-walled Carbon Nanotube Composite for Amperometric Determination of Nitrite. Electroanalysis 2016, 28, 484-492. [CrossRef]

268. Jiao, M.; Li, Z.; Li, Y.; Cui, M.; Luo, X. Poly(3,4-ethylenedioxythiophene) doped with engineered carbon quantum dots for enhanced amperometric detection of nitrite. Microchim. Acta 2018, 185, 249. [CrossRef]

269. Wang, G.; Han, R.; Feng, X.; Li, Y.; Lin, J.; Luo, X. A glassy carbon electrode modified with poly(3,4-ethylenedioxythiophene) doped with nano-sized hydroxyapatite for amperometric determination of nitrite. Microchim. Acta 2017, 1, 1721-1727. [CrossRef]

270. Ge, Y.; Jamal, R.; Zhang, R.; Zhang, W.; Yu, Z.; Yan, Y.; Liu, Y.; Abdiryim, T. Electrochemical synthesis of multilayered PEDOT/PEDOT-SH/Au nanocomposites for electrochemical sensing of nitrite. Microchim. Acta 2020, 187, 1-10. [CrossRef] [PubMed]

271. Zuo, J.; Zhang, Z.; Jiao, J.; Ma, H.; Zhang, D.; Ma, H. Sensitive and selective nitrite sensor based on phosphovanadomolybdates H6[PMo9V3O40], poly(3,4-ethylenedioxythiophene) and Au nanoparticles. Sens. Actuators B Chem. 2016, 236, 418-424. [CrossRef]

272. Shi, S. Electrochemically Co-Deposition of Palladium Nanoparticles and Poly(1, 5-diaminonaphthalene) onto Multiwalled Carbon Nanotubes (MWCNTs) Modified Electrode and its Application for Amperometric Determination of Nitrite. Int. J. Electrochem. Sci. 2019, 14, 7983-7994. [CrossRef]

273. Wang, J.; Hui, N. A nanocomposite consisting of flower-like cobalt nanostructures, graphene oxide and polypyrrole for amperometric sensing of nitrite. Microchim. Acta 2017, 184, 2411-2418. [CrossRef]

274. Bazrafshan, E.; Amirian, P.; Mahvi, A.H.; Ansari-Moghaddam, A. Application of adsorption process for phenolic compounds removal from aqueous environments: A systematic review. Glob. Nest J. 2016, 18, 146-163.

275. Abay, I.; Denizli, A.; Bişkin, E.; Salih, B. Removal and pre-concentration of phenolic species onto $\beta$-cyclodextrin modified poly(hydroxyethylmethacrylate-ethyleneglycoldimethacrylate) microbeads. Chemosphere 2005, 61, 1263-1272. [CrossRef]

276. Bi, W.; Wang, M.; Yang, X.; Row, K.H. Facile synthesis of poly(ionic liquid)-bonded magnetic nanospheres as a highperformance sorbent for the pretreatment and determination of phenolic compounds in water samples. J. Sep. Sci. 2014, 37, 1632-1639. [CrossRef]

277. Goswami, B.; Mahanta, D. Polyaniline coated nickel oxide nanoparticles for the removal of phenolic compounds: Equilibrium, kinetics and thermodynamic studies. Colloids Surf. A Physicochem. Eng. Asp. 2019, 582, 123843. [CrossRef]

278. Khan, N.; Anwer, A.H.; Ahmad, A.; Sabir, S.; Sevda, S.; Khan, M.D. Investigation of CNT/PPy-Modified Carbon Paper Electrodes under Anaerobic and Aerobic Conditions for Phenol Bioremediation in Microbial Fuel Cells. ACS Omega 2019, 5, 471-480. [CrossRef]

279. Ozoner, S.K.; Yilmaz, F.; Celik, A.; Keskinler, B.; Erhan, E. A novel poly(glycine methacrylate-co-3-thienylmethyl methacrylate)polypyrrole-carbon nanotube-horseradish peroxidase composite film electrode for the detection of phenolic compounds. Curr. Appl. Phys. 2011, 11, 402-408. [CrossRef]

280. Khor, S.; Lee, Y.; Ahmad, M.; Karuppiah, N.; Sidek, H.; Abdullah, J. Poly(hydroxyl ethyl methacrylate) hydrogel matrix for phenol biosensor. In Proceedings of the Asian Conference on Sensors, Kebangsann, Malaysia, 18 July 2003; pp. $207-211$.

281. Wei, T.; Huang, X.; Zeng, Q.; Wang, L. Simultaneous electrochemical determination of nitrophenol isomers with the polyfurfural film modified glassy carbon electrode. J. Electroanal. Chem. 2015, 743, 105-111. [CrossRef]

282. Zheng, H.; Yan, Z.; Wang, M.; Chen, J.; Zhang, X. Biosensor based on polyaniline-polyacrylonitrile-graphene hybrid assemblies for the determination of phenolic compounds in water samples. J. Hazard. Mater. 2019, 378, 120714. [CrossRef] [PubMed]

283. Xiao, Z.; Qin, W.; Shi, L. A Electrochemical Sensor based on Poly (Sulfosalicylic Acid) Film Modified Electrode and Application to Phenol Detection in Oilfield Wastewater. Int. J. Smart Home 2016, 10, 299-308. [CrossRef]

284. Yao, Y.; Zhang, L.; Wen, Y.; Wang, Z.; Zhang, H.; Hu, D.; Xu, J.; Duan, X. Voltammetric determination of catechin using singlewalled carbon nanotubes/poly(hydroxymethylated-3,4-ethylenedioxythiophene) composite modified electrode. Ionics 2015, 21, 2927-2936. [CrossRef]

285. Tian, F.; Li, M.; Li, M.; Li, C.; Lei, Y.; Yang, B. Synthesis of one-dimensional poly(3,4-ethylenedioxythiophene)-graphene composites for the simultaneous detection of hydroquinone, catechol, resorcinol, and nitrite. Synth. Met. 2017, 226, 148-156. [CrossRef]

286. Kuskur, C.M.; Swamy, B.K.; Jayadevappa, H. Poly (naphthol green B) modified carbon paste electrode sensor for catechol and hydroquinone. J. Electroanal. Chem. 2017, 804, 99-106. [CrossRef]

287. Aravindan, N.; Preethi, S.; Sangaranarayanan, M.V. Non-Enzymatic Selective Determination of Catechol Using Copper Microparticles Modified Polypyrrole Coated Glassy Carbon Electrodes. J. Electrochem. Soc. 2017, 164, B274-B284. [CrossRef]

288. Guo, Z.; Florea, A.; Cristea, C.; Bessueille, F.; Vocanson, F.; Goutaland, F.; Zhang, A.; Săndulescu, R.; Lagarde, F.; JaffrezicRenault, N. 1,3,5-Trinitrotoluene detection by a molecularly imprinted polymer sensor based on electropolymerization of a microporous-metal-organic framework. Sens. Actuators B Chem. 2015, 207, 960-966. [CrossRef]

289. Giribabu, K.; Haldorai, Y.; Rethinasabapathy, M.; Jang, S.-C.; Suresh, R.; Cho, W.-S.; Huh, Y.S.; Roh, C.; Huh, Y.S.; Narayanan, V. Glassy carbon electrode modified with poly(methyl orange) as an electrochemical platform for the determination of 4-nitrophenol at nanomolar levels. Curr. Appl. Phys. 2017, 17, 1114-1119. [CrossRef] 
290. Marinovic, S.; Mudrinić, T.; Jović-Jovičić, N.; Ajduković, M.; Milutinović-Nikolić, A.; Bankovic, P.; Mojovic, Z. Non-toxic poly(vinyl alcohol)/clay composites as electrode material for detection of 4-chlorophenol and 4-nitrophenol. J. Electroanal. Chem. 2019, 848, 113280. [CrossRef]

291. Sobkowiak, M.; Rebis, T.; Milczarek, G. Electrocatalytic sensing of poly-nitroaromatic compounds on multiwalled carbon nanotubes modified with alkoxysulfonated derivative of PEDOT. Mater. Chem. Phys. 2017, 186, 108-114. [CrossRef]

292. Sağlam, Ş.; Üzer, A.; Erçağ, E.; Apak, M.R. Electrochemical Determination of TNT, DNT, RDX, and HMX with Gold Nanoparticles/Poly(Carbazole-Aniline) Film-Modified Glassy Carbon Sensor Electrodes Imprinted for Molecular Recognition of Nitroaromatics and Nitramines. Anal. Chem. 2018, 90, 7364-7370. [CrossRef] [PubMed]

293. Dechtrirat, D.; Yingyuad, P.; Prajongtat, P.; Chuenchom, L.; Sriprachuabwong, C.; Tuantranont, A.; Tang, I.-M. A screen-printed carbon electrode modified with gold nanoparticles, poly(3,4-ethylenedioxythiophene), poly(styrene sulfonate) and a molecular imprint for voltammetric determination of nitrofurantoin. Microchim. Acta 2018, 185, 261. [CrossRef] [PubMed]

294. Sağlam, Ş.; Üzer, A.; Tekdemir, Y.; Erçă̆, E.; Apak, M.R. Electrochemical sensor for nitroaromatic type energetic materials using gold nanoparticles/poly(o-phenylenediamine-aniline) film modified glassy carbon electrode. Talanta 2015, 139, 181-188 [CrossRef] [PubMed]

295. Chen, C.; Chen, W.; Jiang, J.; Qian, L.; Zhang, X. Nitrofuran Determination in Aquaculture Water by Using Poly-Alizarin Red-Modified Electrode. J. Electrochem. Soc. 2019, 166, H425-H432. [CrossRef]

296. Yao, C.; Sun, H.; Fu, H.-F.; Tan, Z.-C. Sensitive simultaneous determination of nitrophenol isomers at poly(p-aminobenzene sulfonic acid) film modified graphite electrode. Electrochim. Acta 2015, 156, 163-170. [CrossRef]

297. Chiu, S.-H.; Su, Y.-L.; Le, A.V.T.; Cheng, S.-H. Nanocarbon material-supported conducting poly(melamine) nanoparticle-modified screen-printed carbon electrodes for highly sensitive determination of nitrofuran drugs by adsorptive stripping voltammetry. Anal. Bioanal. Chem. 2018, 410, 6573-6583. [CrossRef]

298. Calam, T.T. Electrochemical Oxidative Determination and Electrochemical Behavior of 4-Nitrophenol Based on an Au Electrode Modified with Electro-polymerized 3,5-Diamino-1,2,4-triazole Film. Electroanalysis 2020, 32, 149-158. [CrossRef]

299. Arulraj, A.D.; Vijayan, M.; Vasantha, V.S. Highly selective and sensitive simple sensor based on electrochemically treated nano polypyrrole-sodium dodecyl sulphate film for the detection of para-nitrophenol. Anal. Chim. Acta 2015, 899, 66-74. [CrossRef]

300. Palma-Cando, A.; Scherf, U. Electrogenerated Thin Films of Microporous Polymer Networks with Remarkably Increased Electrochemical Response to Nitroaromatic Analytes. ACS Appl. Mater. Interfaces 2015, 7, 11127-11133. [CrossRef]

301. Palma-Cando, A.; Preis, E.; Scherf, U. Silicon- or Carbon-Cored Multifunctional Carbazolyl Monomers for the Electrochemical Generation of Microporous Polymer Films. Macromolecules 2016, 49, 8041-8047. [CrossRef]

302. Palma-Cando, A.; Brunklaus, G.; Scherf, U. Thiophene-Based Microporous Polymer Networks via Chemical or Electrochemical Oxidative Coupling. Macromolecules 2015, 48, 6816-6824. [CrossRef]

303. Palma-Cando, A.; Rendón-Enríquez, I.; Tausch, M.W.; Scherf, U. Thin Functional Polymer Films by Electropolymerization. Nanomaterials 2019, 9, 1125. [CrossRef] [PubMed]

304. Bai, S.; Hu, Q.; Zeng, Q.; Wang, M.; Wang, L. Variations in Surface Morphologies, Properties, and Electrochemical Responses to Nitro-Analyte by Controlled Electropolymerization of Thiophene Derivatives. ACS Appl. Mater. Interfaces 2018, 10, 11319-11327. [CrossRef]

305. Ponnappa, S.P.; MacLeod, J.; Umer, M.; Soda, N.; Pannu, A.S.; Shiddiky, M.J.; Ayoko, G.A.; O’Mullane, A.P.; Sonar, P. Electropolymerized Porous Polymer Films on Flexible Indium Tin Oxide Using Trifunctional Furan Substituted Benzene Conjugated Monomer for Biosensing. ACS Appl. Polym. Mater. 2020, 2, 351-359. [CrossRef] 